Florida International University

FIU Digital Commons

FIU Electronic Theses and Dissertations

University Graduate School

$11-8-2012$

\title{
A Longitudinal Exploration of the Relationship Between Oral Reading Fluency and Reading Comprehension Achievement Among a Sample of Diverse Young Learners
}

Teri L. Acquavita

Florida International University, tacqu001@fiu.edu

DOI: $10.25148 /$ etd.FI12112704

Follow this and additional works at: https://digitalcommons.fiu.edu/etd

\section{Recommended Citation}

Acquavita, Teri L., "A Longitudinal Exploration of the Relationship Between Oral Reading Fluency and Reading Comprehension Achievement Among a Sample of Diverse Young Learners" (2012). FIU Electronic Theses and Dissertations. 742.

https://digitalcommons.fiu.edu/etd/742 


\section{FLORIDA INTERNATIONAL UNIVERSITY \\ Miami, Florida}

\section{A LONGITUDINAL EXPLORATION OF THE RELATIONSHIP BETWEEN \\ ORAL READING FLUENCY AND READING COMPREHENSION ACHIEVEMENT \\ AMONG A SAMPLE OF DIVERSE YOUNG LEARNERS}

A dissertation submitted in partial fulfillment of the

requirements for the degree of

DOCTOR OF EDUCATION

in

CURRICULUM AND INSTRUCTION

by

Teri L. Acquavita

2012 
To: Dean Delia C. Garcia

College of Education

This dissertation, written by Teri L. Acquavita, and entitled A Longitudinal Exploration of the Relationship between Oral Reading Fluency and Reading Comprehension Achievement Among a Sample of Diverse Young Learners, having been approved in respect to style and intellectual content, is referred to you for judgment.

We have read this dissertation and recommend that it be approved.

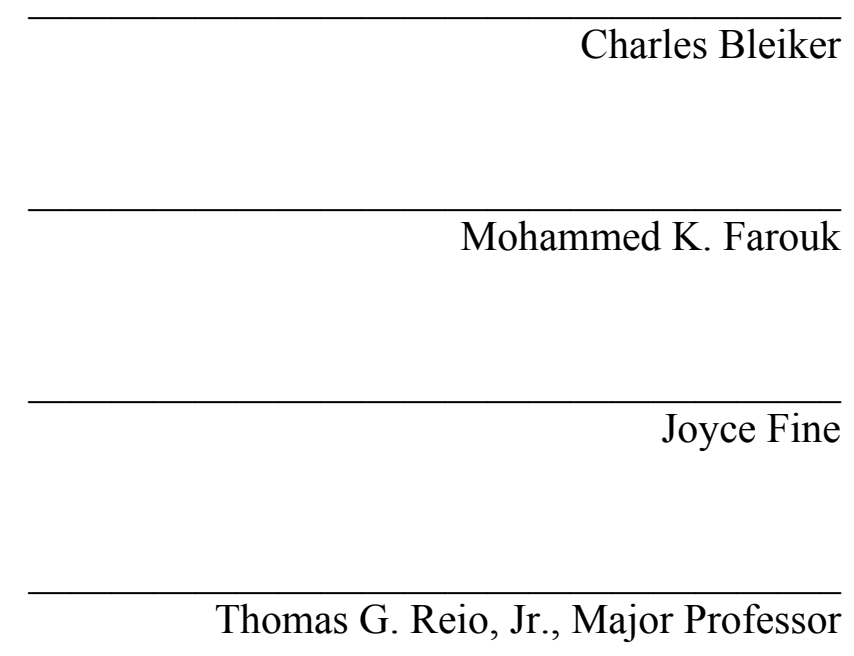

Date of Defense: November 8, 2012

The dissertation of Teri L. Acquavita is approved.

Dean Delia C. Garcia

College of Education

Dean Lakshmi N. Reddi

University Graduate School

Florida International University, 2012 
(C) Copyright 2012 by Teri L. Acquavita All rights reserved. 


\section{DEDICATION}

I dedicate this work to my patient and loving close circle of family and friends who encouraged me to persevere despite some very difficult moments when the task appeared much too grand to endure.

A very special dedication is extended to my best friend, Bella, who rested at my

feet for endless hours while I studied and sadly left this world before I finished. I endured because of you and I miss you dearly! 


\section{ACKNOWLEDGMENTS}

For imparting upon me their extensive knowledge in teaching and learning and providing continued mentorship throughout my studies, I thank my dissertation committee members Dr. Charles Bleiker, Dr. Joyce Fine, and Dr. Mohammed Farouk. Additionally, I appreciate the invaluable constructive feedback provided by Dr. Linda Bliss and Dr. Isadore Newman whose expertise in research and technical writing are remarkable.

A special thank you goes to Dr. Thomas Reio, my committee chairperson, who eagerly assumed this very difficult role following the loss of two previous committee chairs. Dr. Reio always provided just the right advice while challenging me to the extent he knew I could handle.

Finally, I thank my family for their patience and understanding in supporting me through to the end of this long journey, especially as the years rolled on and it appeared as though this project would not be brought to fruition. 


\begin{abstract}
OF THE DISSERTATION
A LONGITUDINAL EXPLORATION OF THE RELATIONSHIP BETWEEN

ORAL READING FLUENCY AND READING COMPREHENSION ACHIEVEMENT

AMONG A SAMPLE OF DIVERSE YOUNG LEARNERS

by
\end{abstract}

Teri L. Acquavita

Florida International University, 2012

Miami, Florida

Professor Thomas G. Reio, Jr., Major Professor

Exploring the relationship between early oral reading fluency ability and reading comprehension achievement among an ethnically and racially diverse sample of young learners from low-income families, attending elementary school within a large public school district in southeast Florida is the purpose of this longitudinal study. Although many studies have been conducted to address the relationship between oral reading fluency ability and reading comprehension achievement, most of the existing research failed either to disaggregate the data by demographic subgroups or secure a large enough sample of students to adequately represent the diverse subgroups.

The research questions that guided this study were: (a) To what extent does early oral reading fluency ability measured in first, second, or third grade correlate with reading comprehension achievement in third grade? (b) To what extent does the relationship of early oral reading fluency ability and reading comprehension achievement vary by demographic subgroup membership (i.e., gender, race/ethnicity, socioeconomic status) among a diverse sample of students? 
A predictive research design using archived secondary data was employed in this nonexperimental quantitative methods study of 1,663 third grade students who attended a cohort of 25 Reading First funded schools. The data analyzed derived from the Dynamic Indicators of Basic Early Literacy Skills Oral Reading Fluency (DIBELS ORF) measure administered in first, second, and third grades and the Florida Comprehensive Assessment Test of the Sunshine State Standards (FCAT-SSS) Reading administered in third grade.

Linear regression analyses between each of the oral reading fluency and reading comprehension measures produced significant positive correlations. Hierarchical regression analyses supported the predictive potential of all three oral reading fluency ability measures toward reading comprehension achievement, with the first grade oral reading fluency ability measure explaining the most significant variance in third grade reading comprehension achievement.

Male students produced significant overall differences in variance when compared to female students as did the Other student subgroup (i.e., Asian, Multiracial, and Native American) when compared to Black, White, and Hispanic students. No significant differences in variance were produced between students from low and moderate socioeconomic families. These findings are vital toward adding to the literature of diverse young learners. 


\section{TABLE OF CONTENTS}

CHAPTER

PAGE

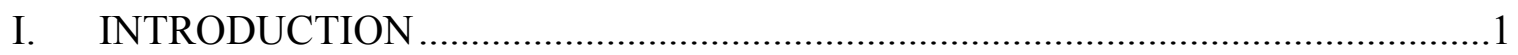

Rationale for the Study ..................................................................................

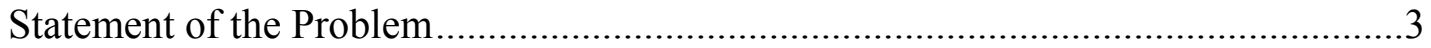

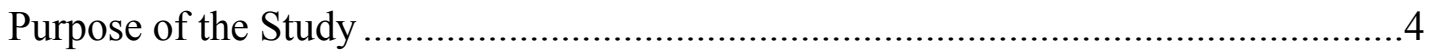

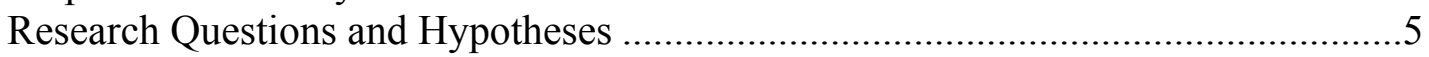

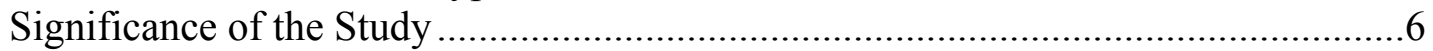

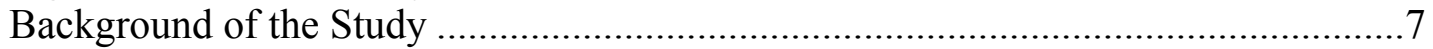

Proficient Reading Ability is Essential Knowledge...................................................

Impact of Federal Legislation on the Reading Education of Young Learners .............8

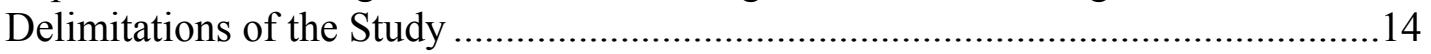

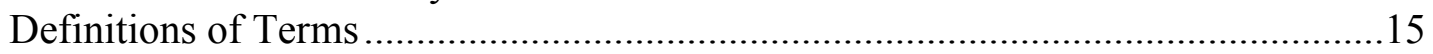

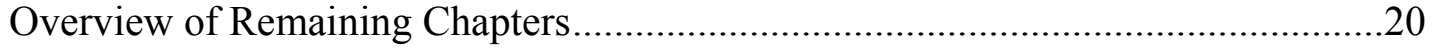

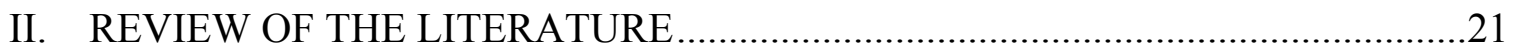

Curriculum, Instruction, and Assessment in Early Reading ....................................21

The Achievement Gap in Reading Development ……….......................................25

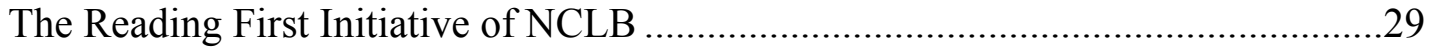

Reading Fluency Development in Young Learners...................................................31

Federal Accountability Targeting Early Reading Achievement..................................36

Early Predictors of Reading Achievement..............................................................4

ORF and Reading Achievement Assessments in Florida .........................................43

ORF and Reading Achievement Assessments in Delaware .....................................50

ORF and Reading Achievement Assessments in Pennsylvania ................................53

ORF and Reading Achievement Assessments in Tennessee ....................................56

Impact of the Federal Reading First Initiative .......................................................60

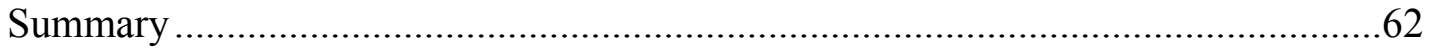

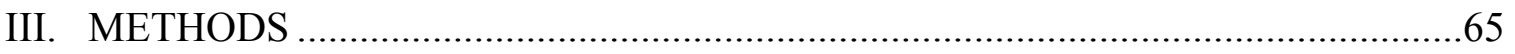

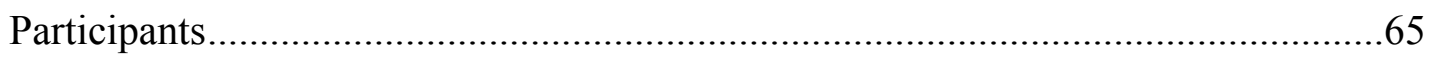

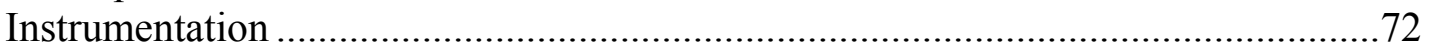

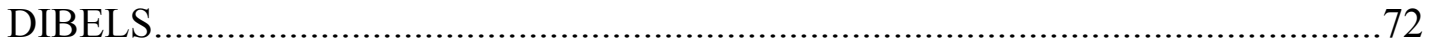

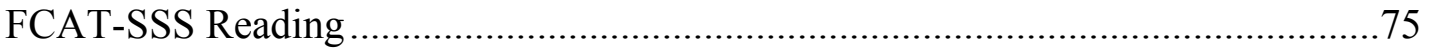

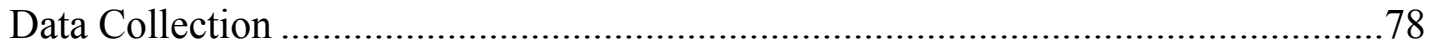

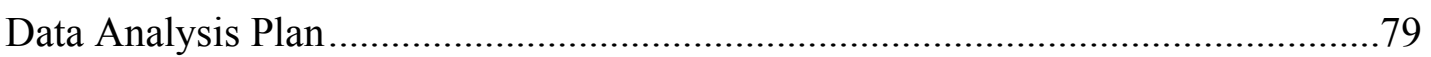

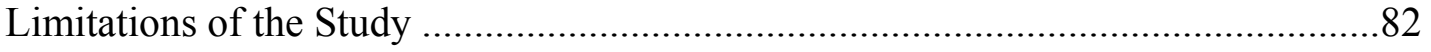

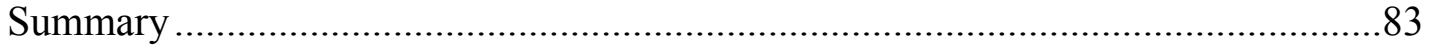

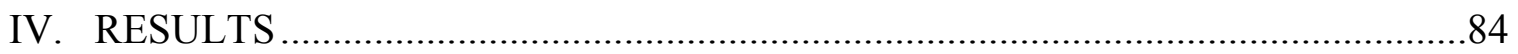

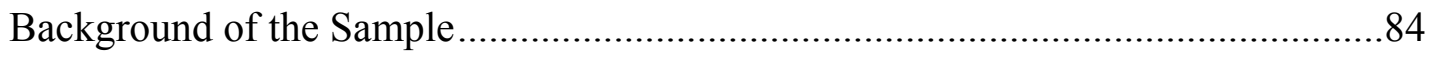

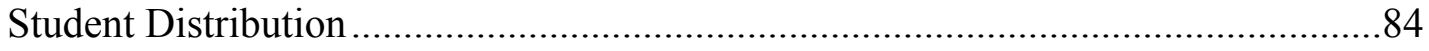

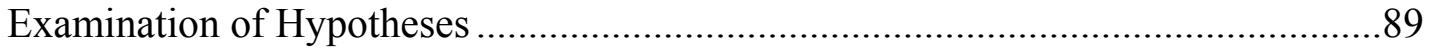




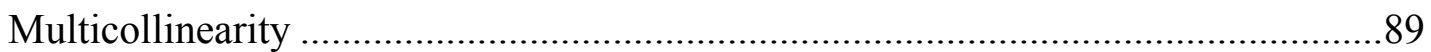

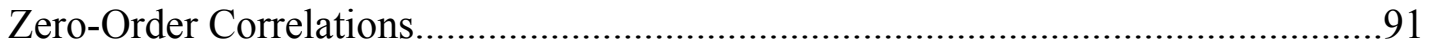

Linear Regression Analyses.........................................................................92

Hierarchical Multiple Regression Analyses............................................................95

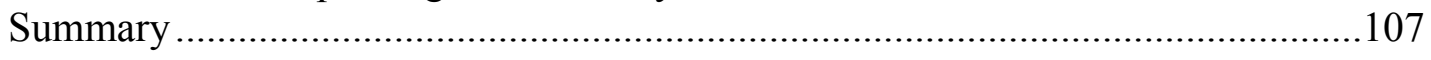

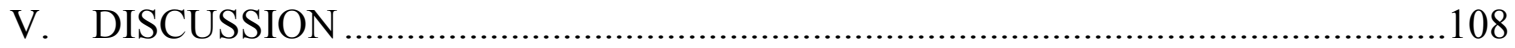

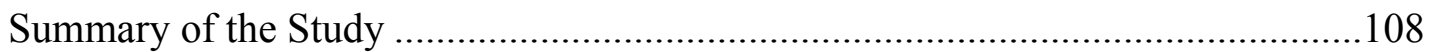

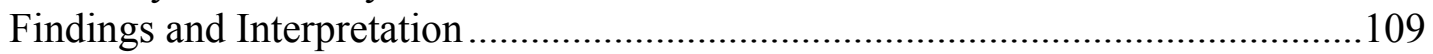

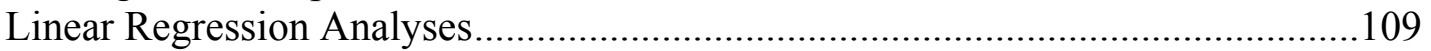

Hierarchical Regression Analyses ..................................................................... 110

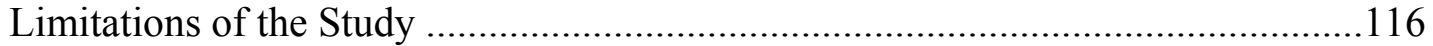

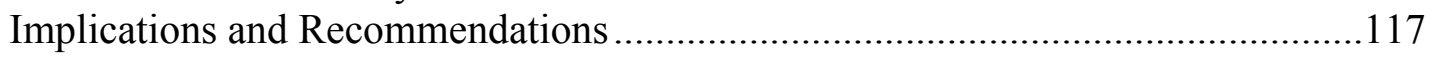

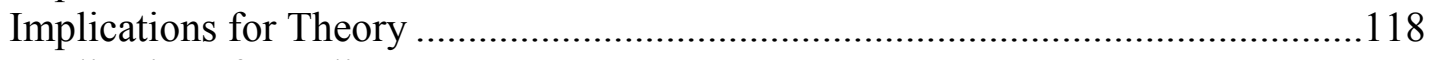

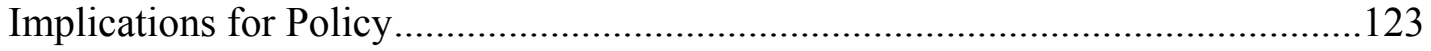

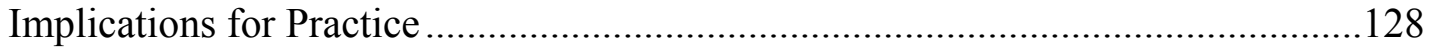

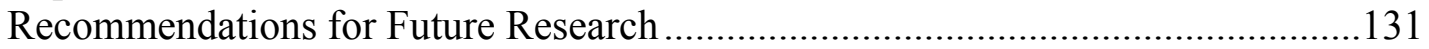

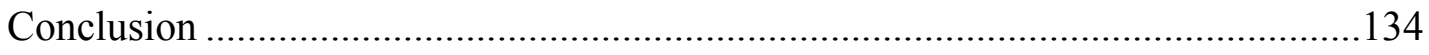

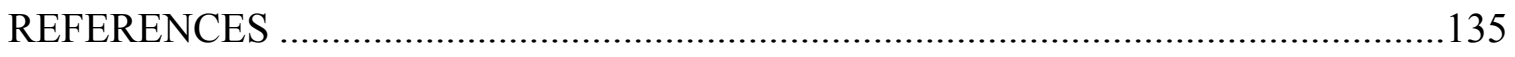

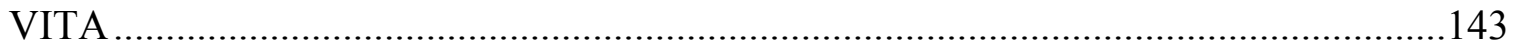




\section{LIST OF TABLES}

TABLE

PAGE

1. Population of Third Grade Students Attending Cohort One Schools During the 2008-09 School Year

2. Comparison of State and District Demographics of Student Population In Attendance During the 2008-09 School Year...

3. Demographics of School-wide Student Population Attending Cohort One Schools During the 2008-09 School Year..... .71

4. Spring Benchmark Goals and Indicators of Risk For DIBELS ORF at Grades 1, 2, and 3

5. Frequency Table of Student Population Distribution .85

6. Frequency Table of Gender and Socioeconomic Status By Race/Ethnicity.....

7. Frequency Table of Socioeconomic Status By Gender

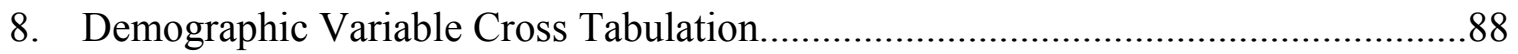

9. Correlation Coefficients Between the Three DIBELS ORF Assessments ................90

10. Zero-Order Correlation Coefficients For DIBELS ORF Ability and FCAT Reading Comprehension Achievement

11. Linear Regression Analysis of Relationship Between Third Grade Reading Comprehension Achievement and First Grade Oral Reading Fluency Ability

12. Linear Regression Analysis of Relationship Between Third Grade Reading Comprehension Achievement and Second Grade Oral Reading Fluency Ability......94

13. Linear Regression Analysis of Relationship Between Third Grade Reading Comprehension Achievement and Third Grade Oral Reading Fluency Ability

14. Hierarchical Multiple Regression Analyses Predicting Third Grade Reading Comprehension Achievement From First, Second, and Third Grade Oral Reading Fluency Ability

15. Hierarchical Multiple Regression Analyses Predicting Third Grade Reading Comprehension Achievement From First, Second, and Third Grade Oral Reading Fluency Ability By Gender Subgroups 
16. Hierarchical Multiple Regression Analyses Predicting Third Grade Reading Comprehension Achievement From First, Second, and Third Grade Oral Reading Fluency Ability By Racial/Ethnic Subgroups

17. Hierarchical Multiple Regression Analyses Predicting Third Grade Reading Comprehension Achievement From First, Second, and Third Grade Oral Reading Fluency Ability By Socioeconomic Status Subgroups. 


\section{LIST OF ABBREVIATIONS AND ACRONYMS}

AYP

CBM

CCSS Common Core State Standards

CCSSO Council of Chief State School Officers

DIBELS Dynamic Indicators of Basic Early Literacy Skills

DSTP Delaware Student Testing Program

ELL English Language Learner

ESEA Elementary and Secondary Education Act

ETS Education Technology Services

FCAT Florida Comprehensive Assessment Test

FCRR Florida Center for Reading Research

FDOE Florida Department of Education

FDOS Florida Department of State

GRA+DE Group Reading Assessment and Diagnostic Evaluation

IRB Institutional Review Board

LD Learning Disabled

LNF Letter Naming Fluency

MCA Minnesota Comprehensive Assessment

NCEE National Commission on Excellence in Education

NCES National Center for Education Statistics

NCLB No Child Left Behind

NGACBP National Governors Association Center for Best Practices 


\begin{tabular}{|c|c|}
\hline NICHD & National Institute of Child Health and Human Development \\
\hline NRP & National Reading Panel \\
\hline NRT & Norm Referenced Test \\
\hline NWF & Nonsense Word Fluency \\
\hline ORF & Oral Reading Fluency \\
\hline PARCC & Partnership for Assessment of Readiness for College and Careers \\
\hline PSF & Phoneme Segmentation Fluency \\
\hline PSSA & Pennsylvania System of School Assessment \\
\hline REA & Reading Excellence Act \\
\hline RF & Retell Fluency \\
\hline $\mathrm{ROC}$ & Receiver Operating Characteristic \\
\hline SAT & Stanford Achievement Test \\
\hline SES & Socioeconomic Status \\
\hline SFPE & Schott Foundation for Public Education \\
\hline SRP & Standard Reading Passages \\
\hline SSS & Sunshine State Standards \\
\hline USDA & United States Department of Agriculture \\
\hline USDOE & United States Department of Education \\
\hline VIF & Variance Inflation Factor \\
\hline WCPM & Words Correct Per Minute \\
\hline
\end{tabular}




\section{CHAPTER I}

\section{INTRODUCTION}

This current study explored the relationship between early oral reading fluency ability and reading comprehension achievement among an ethnically and racially diverse sample of young learners attending elementary school within a large public school district in southeast Florida. This study is vital toward adding to the literature about learners of diverse demographic backgrounds, as it included large numbers of racial and ethnic minority students and students from low-income families, for whom the available research remains limited.

In Chapter 1, the rationale for the study, statement of the problem, purpose of the study, and research questions are discussed. Further presented in Chapter 1 are significance and background of the study, delimitations, definitions of terms, and an overview of the remaining chapters.

\section{Rationale for the Study}

The ultimate goal of reading is to understand and comprehend the meaning of written text (Allington, 2001; Hudson, Lane, \& Pullen, 2005; Snow, Burns, \& Griffin, 1998; Torgesen, 2002). It is comprehension, or the intentional thinking that takes place between the text and the reader that leads to the construction of meaning, of which Durkin (1993) so eloquently referred to as the "very essence of reading" (p. 12). Although reading the words on the page and constructing meaning from the content happens effortlessly for proficient readers; for non-proficient readers, struggling to read the words and understand what is written presents frustration and is often the result of varied skill deficiencies in reading (Snow et al., 1998). Diagnosing reading deficiencies 
and supporting struggling learners in remediating their reading deficiencies are key to scaffolding them toward becoming independent proficient readers (Allington, 2001). No matter what reading deficiencies young learners may exhibit, comprehension is generally impaired, and is often accompanied by the inability to read text fluently.

As guiding research for the federal legislation of the No Child Left Behind (NCLB) Act of 2001, the Report of the National Reading Panel: Teaching Children to Read (National Institute of Child Health and Human Development [NICHD], 2000) recognized reading fluency as one of five essential components of reading instruction, in addition to phonemic awareness, phonics, vocabulary, and comprehension. Long before the National Reading Panel Report (NICHD), Allington (1983) stressed the importance of reading fluency as a foundational skill necessary for effective literacy development. For decades, reading fluency has been considered an important foundational literacy skill, yet it failed to receive the emphasized attention until recently brought to the national forefront through policy reforms of the federal NCLB legislation (Rasinski, 2005).

With a renewed national interest in reading fluency development, standardized assessment of fluency has become common practice toward measuring and promoting accountability for the early reading progress of young learners (Torgesen, 2003). Held accountable for their students' fluency progress, increasing numbers of teachers are compelled to focus on isolated instruction in fluency.

In school districts throughout the state of Florida and across the nation, oral reading fluency assessments continue to be administered periodically throughout the year to monitor the reading progress of young learners (Florida Center for Reading Research [FCRR], 2009; Torgesen, 2003). This has led to increased attention to current isolated 
instruction in oral reading fluency. Although Florida public school districts are mandated through state legislation (State Board Rule 6A-6.053 in Florida Statute Section 1011.62) to implement a comprehensive core reading program that incorporates all essential components of reading instruction (Florida Department of State [FDOS], 2011), teachers often find it difficult to deliver a comprehensive, balanced reading instructional model when heavy emphasis has been placed on the accountability of achievement in isolated skills.

As current teaching methods encourage focus on one or two isolated components of reading, Wolf (2007) has reminded us that one of the best predictors of reading success is exposure to connected text during early childhood. Young children, immersed within environments of rich oral and written opportunities, are far more likely to become successful readers than their linguistically impoverished peers (Wolf, 2007). Yet isolated skill instruction focusing heavily on one or two reading components has become predominant educational practice, leading to less emphasis in the remaining essential components of reading. Effectively supporting the reader's understanding of text, as demonstrated through comprehension achievement, has become a critical issue concerning our young, developing learners.

\section{Statement of the Problem}

The problem examined in this current study focused on whether reading fluency development, used for monitoring the progress of young learners, serves as an early predictor of reading proficiency (Good \& Kaminski, 2005) as measured by comprehension achievement on the Florida Comprehensive Assessment Test of the Sunshine State Standards in Reading (FCAT-SSS Reading; Florida Department of 
Education [FDOE], 2005), across multiple demographic subgroups of students. If oral reading fluency ability correlates with reading comprehension achievement in young learners, then determining the predictive power between these two variables could be used to guide educators in targeting learners' differentiated instructional needs by determining the most effective scaffolded support necessary for developing proficient readers. If no significant correlation or predictive power exists between these two variables, then less emphasis on the oral reading fluency ability of young learners may be warranted and further research may be necessary to determine what constitutes as sufficient early predictors of reading proficiency.

\section{Purpose of the Study}

The primary purpose of this study was to conduct a longitudinal exploration of the relationship between early oral reading fluency ability and reading comprehension achievement among an ethnically and racially diverse sample of young learners from low-income families, attending elementary school within a large public school district in southeast Florida. Although many studies have been conducted to address the relationship between oral reading fluency ability and reading comprehension achievement, most of the existing research failed either to disaggregate the data according to student demographic subgroups or secure a large enough sample of students to adequately represent the diverse subgroups. Several analyses were performed to determine this relationship and answer the research questions below.

Archived, secondary data collected annually over 3 years (2007 through 2009) were analyzed to determine if a correlation exists between students' performance as measured on an oral reading fluency assessment (administered at the end of first, second, 
and third grades) and reading comprehension achievement as measured on an outcome assessment (administered at the end of third grade), among a cohort of students.

Demographic student data were further examined to determine if the relationship between oral reading fluency ability and reading comprehension achievement varies across gender and racial/ethnic subgroups of students from low-income families.

\section{Research Questions and Hypotheses}

This current study addressed two main research questions.

\section{Research Question 1}

To what extent does early oral reading fluency ability measured in first, second, or third grade correlate with reading comprehension achievement in third grade?

Hypothesis 1. The early oral reading fluency ability measured in first grade will significantly correlate positively with reading comprehension achievement in third grade, as measured by the FCAT-SSS Reading (FDOE, 2005).

Hypothesis 2. The early oral reading fluency ability measured in second grade will significantly correlate positively with reading comprehension achievement in third grade, as measured by the FCAT-SSS Reading (FDOE, 2005).

Hypothesis 3. The early oral reading fluency ability measured in third grade will significantly correlate positively with reading comprehension achievement in third grade, as measured by the FCAT-SSS Reading (FDOE, 2005).

\section{Research Question 2}

To what extent does the relationship of early oral reading fluency ability and reading comprehension achievement vary by demographic subgroup membership (i.e., gender, race/ethnicity, socioeconomic status) among a diverse sample of students? 
Hypothesis 4. The relationship of early oral reading fluency ability and reading comprehension achievement, as measured by the FCAT-SSS Reading (FDOE, 2005), significantly varies by gender (i.e., male, female).

Hypothesis 5. The relationship of early oral reading fluency ability and reading comprehension achievement, as measured by the FCAT-SSS Reading (FDOE, 2005), significantly varies by race/ethnicity (i.e., Black, White, Hispanic, Other).

\section{Significance of the Study}

Several recent research studies have confirmed some predictive ability of oral reading fluency assessment measures toward achievement on standardized state reading comprehension assessments (Buck \& Torgesen, 2002; Hintze \& Silberglitt, 2005; Kloo, 2006; Riedel, 2007; Roehrig, Petscher, Nettles, Hudson, \& Torgesen, 2008; Uribe-Zarain, 2006). Although some of these studies targeted large populations of students attending higher achieving schools (Buck \& Torgesen, 2002; Hintze \& Silberglitt, 2005), other studies included smaller populations of students with more diverse demographic backgrounds attending both lower and higher achieving schools and produced significant differences in findings when the data were disaggregated by racial and ethnic diversity (Kloo, 2006; Roehrig et al., 2008; Uribe-Zarain, 2006).

Little research however has examined the relationship between oral reading fluency development and achievement in reading comprehension for large populations of racially/ethnically and socioeconomically diverse students attending lower performing schools, and neither has this relationship been examined longitudinally. Although several of these studies provided significant evidence of correlation between the two early reading assessments, most have failed either to disaggregate the data according to student 
demographic subgroups or secure a large enough sample of students to adequately represent the diverse subgroups.

The scope of this current study focused on the effectiveness of early oral reading fluency progress-monitoring assessments for predicting reading comprehension achievement, when analyzed among a large sample of diverse students attending historically lower performing schools in South Florida. The findings of this study are vital toward adding to the literature about learners with varied demographic backgrounds, as it included large numbers of racial and ethnic minority students and students from lowincome families, for whom the available research remains limited. The purpose of this current study is to provide policy makers, educators, researchers, and other stakeholders, evidence regarding the extent relationships exist between early oral reading fluency ability and reading comprehension achievement to more adequately support the implementation of effective instructional practice that will lead to increased student achievement among diverse populations of young learners.

\section{Background of the Study}

\section{Proficient Reading Ability is Essential Knowledge}

"What knowledge is most worthwhile?" a question raised long ago by Herbert Spencer in the 1800 s, remains just as popular of an inquiry today for which educators struggle to seek a definitive answer (Schubert, 1986, p. 1). Although many conflicting theories about what is worth knowing are contemplated, it remains important to recognize that the diversity among young learners must significantly impact the design of an effective educational program to adequately meet the specific needs of all learners. 
Learning to proficiently read a variety of texts with understanding and to enjoy reading are both essential to success, as expressed by the American Federation of Teachers (AFT, 2006), when they stated the following.

Reading is one of the skills most crucial for a child's success in school and in life. If children don't learn to read with comprehension early enough, their education is at risk. If they don't learn to read effortlessly enough to render reading pleasurable, their chances for a fulfilling life by any measure, whether academic achievement, financial stability or job skills are tremendously diminished. (p. 3)

According to Johnson (1999), "because reading is at the heart of every child's learning, it has been a principal educational focus for more than a century" (p. 4), and will continue to "spark public debate" (p. 4). Attributed to research conducted more recently during the mid-1960s, this controversial debate again achieved national recognition when two very different reading instructional approaches, skills-based versus meaning-based, were compared (Johnson, 1999). Fifty years later, the debate continues to centralize on how best to effectively educate young learners in reading, particularly as it relates to a comprehensive educational plan that encompasses curriculum, instruction, and assessment (Allington, 2003).

\section{Impact of Federal Legislation on the Reading Education of Young Learners}

Determining one standard effective reading educational plan that will support the complexities of curriculum, instruction, and assessment for all young learners in their development toward becoming proficient readers is a problem considering the broad concept of proficient reading ability. Approximately every 30 years, Allington has cautioned (2000), there emerges a highly public debate regarding effective reading instruction and assessment that manifests itself in the media and legislative policy making. 
After recently embarking upon a new cycle of drastic legislative reforms leading to a national policy that addresses beginning reading education, in what Allington (2003) has referred to as a federalization of the education system, disagreements regarding an appropriate curriculum have again been resurrected. The debates are lively and the decision makers passionate about their agendas, but are the current legislative changes enacted by policy makers supporting or stifling our young learners, as educators strive to implement these radical reforms in classrooms across the nation?

In recent times, it has not been difficult to convince American citizens of the urgency in reforming public education. After all, in her contribution to the Afterword: The Age of Pluralism written within Turning Points in Curriculum: A Contemporary American Memoir, Wilma Longstreet stated, "Most of the public appears convinced American education is in a deplorable state and needs radical fixing for the sake of the nation and for the future of our children" (in Marshall, Sears, \& Schubert, 2000, p. 244). Policy makers, having convinced the general public of this notion, scurried just prior to the turn of this century to legislate massive education reform in an attempt to fix the failing American public school system. Have we embarked upon truly fixing the problem or have we in fact created a new dilemma in public education, one in which reform has been mandated at a high price? This high price, according to Kohn and Henkin (2002), is one that many educators contest is unjust, as they fear it will only serve to widen even more the achievement gap between economically advantaged and disadvantaged learners.

In 1997, based on the urgency to reform public education and under the recommendation of Congress, a national panel was convened to "assess the status of research-based knowledge, including the effectiveness of various approaches to teaching 
children to read" (NICHD, 2000, p. 1-1). This 14-member national panel, commonly referred to as the National Reading Panel and consisting of, as specified by Congress, "leading scientists in reading research, representatives of colleges of education, reading teachers, educational administrators, and parents" (NICHD, p. 1-1), swiftly published the frequently contested Report of the National Reading Panel: Teaching Children to Read (NICHD). Since its publication in December 2002, the National Reading Panel Report has tremendously influenced the development of federal, state, and local legislative policies regarding the reform of reading curriculum, instruction, and assessment (Allington, 2003).

Considered one of the most controversial public educational reforms to date, an early major effect of the National Reading Panel Report was the reauthorization of the Elementary and Secondary Education Act (ESEA) of 1965 (Kim \& Sunderman, 2005). Through the reauthorization of the ESEA, the federal education law became more commonly known as the NCLB Act of 2001, and has also served to completely replace the former Reading Excellence Act (REA) of 1998 (Olson \& Viadero, 2002). Written and funded to add reform policy to the ESEA, the REA was originally crafted specifically to target underachieving and high-poverty schools across the nation where reading achievement was low (Reutzel \& Mitchell, 2005). Once the ESEA was reauthorized as NCLB, which provided for underachieving and high-poverty schools, the need for the REA was eliminated (Olson \& Viadero, 2002).

Public education policy is now guided by the comprehensive NCLB Act of 2001, for which recommendations of the National Reading Panel have been applied to support the strict policy standards written into this federal legislation (Allington, 2003). From the 
NCLB legislation, a redesign of beginning reading education has been established, stated Allington (2003), in which compliance would become evidenced through a rigid federally mandated testing program. Robelen (2002) has added that state departments of education, school districts, and schools across the nation were rewarded for compliance with the legislation through federal and state funding, and most notably via the federal Reading First Initiative.

To receive federal Reading First grant funds, strict adherence to a prescribed plan of curriculum, instruction, and assessment had to be very closely followed specifically for students placed in kindergarten, first, second, and third grades (Olson \& Viadero, 2002). In the Reading First plan, according to Olson and Viadero, educators of young learners were required to use a prescribed curriculum, and employ "scientifically-based research" (p. 1) for guiding their professional decisions regarding the assessment of reading achievement, as well as the delivery of systematic and explicit initial core and intensive intervention instruction provided within the classroom. These standards include beginning reading instruction that focuses on the processes of reading acquisition, specifically addressing the five essential components of reading: phonemic awareness, phonics, fluency, vocabulary, and comprehension (NICHD, 2000). It is expected that these five essential components, which support the foundational process of reading acquisition, will be instructed and assessed to support young learners as they develop adequate reading standards that will lead to their proficiency in reading (NICHD, 2000).

The current policy of NCLB is clearly an assessment-driven reform that supports a federal standardized curriculum (Allington, 2000). This standardized curriculum is based on prescribed instructional and assessment practices that have been designed to 
lead to improved achievement on specific standardized tests (Allington, 2000). This was particularly true of the Reading First Initiative, which was granted federal funding to participating elementary schools that strictly followed the prescribed curriculum plan (Manzo, 2005).

The prescriptive nature of the Reading First Initiative was evident in the required use of the Dynamic Indicators of Basic Early Literacy Skills (DIBELS) assessment in schools across the nation participating in this federal initiative (Manzo, 2005). Statistics for the 2007-08 school year indicated that the DIBELS assessment and data reporting system was used in more than 15,000 schools nationwide (University of Oregon Center on Teaching and Learning, 2009). DIBELS, a standardized assessment, is a battery of fluency-based tests that emphasize the skills of phonics and fluency (Manzo, 2005). The irony associated with this assessment, required for administration to all students in kindergarten through third grade who attended Reading First funded schools, is that the developers of DIBELS actually served as key consultants to the U.S. Department of Education for Reading First during the development phase of this federal initiative (Manzo, 2005). In fact, Roland Good, one of the DIBELS developers, participated as a member "on the assessment committee that evaluated 29 early-literacy tests, including DIBELS, his own product" (Manzo, 2005, p. 2).

Young learners who attended Reading First funded schools clearly received an assessment-driven curriculum, where instruction was developed based upon the mandated content of the test (Manzo, 2005). Although the use of DIBELS has spread rapidly since 2003, it is commonly administered in schools that never received Reading First funding as several state departments of education have recommended its use for all students, 
including grade levels beyond third (Torgesen, 2003). The widespread use of DIBELS continues despite the discontinuation of funding for the Reading First Initiative.

Historically, Reading First teachers were held accountable for their students' progress on the DIBELS standardized assessment administered three times a year (Good \& Kaminski, 2005; Torgesen, 2003). Because the DIBELS assessment measures growth primarily in phonics and fluency, it is not difficult to find instruction being delivered that narrowly focuses on isolated phonics and fluency skill development (Manzo, 2005; Venable, 2006), to the exclusion of other essential reading process components. Venable warned against the practice of isolating individual essential components of reading during instruction, and has urged that young learners be provided opportunities to immediately apply their learned skills and concepts to contextual reading. It is unfortunate, declared Venable, when recommendation is made for young learners to first become effective decoders by mastering an isolated set of phonics skills, prior to being provided instruction on how to apply these skills to connected text in combination with reading strategies to support comprehension of the written message.

There is no denying the importance of accountability measures when they are appropriately linked to student achievement. In fact, an effective assessment plan is crucial to educators and learners when used to support appropriate instructional decisions (Ransom, Santa, Williams, \& Farstrup, 1999). In this regard, Ransom et al. stressed that a well-developed assessment plan provides for the collection of systematic and purposeful data that also contribute to informing daily classroom instructional decisions designed to meet the specific and differentiated needs of learners. 
Gordinier and Foster (2004) have agreed that assessment must drive the instructional planning of educators who in turn must tailor their plans to meet the differentiated needs of each learner, and they believe that educators should be provided the autonomy to make critical curriculum decisions. It is unfortunate, according to Gordinier and Foster, that the Reading First Initiative was so prescriptive in determining instructional and assessment practices, but strict compliance was required for participation in, and receipt of, the federal grant funding.

Many concerns have been raised throughout the country in opposition to the types of accountability measures that are directly tied to the current NCLB reform, yet most often the issues are silenced through criticism for attempting to avoid the responsibility of being held accountable to higher standards (Allington, 2003). Despite its creation with the promise of improving the reading achievement of all learners through public education reform, the NCLB Act of 2001 instead appears to be falling far short of that goal (Altshuler \& Schmautz, 2006). As the experts debate the reform issue, many young learners continue to struggle with the complex process of learning to read and develop into proficient readers.

\section{Delimitations of the Study}

The sample of students who participated in this study were chosen from former Reading First funded schools, as the early oral reading fluency assessments identified in this study were mandated for administration to all first through third grade students attending these schools. Student data were collected annually over 3 years; therefore, the sample was delimited to those students who possessed all required data points across this 
time period. The sample did not include students who lacked any of the data points or were retained at any time during the first through third grades.

\section{Definitions of Terms}

The following section includes definitions of terms used throughout this study. Accountability is the implication that schools or teachers are responsible for educational outcomes and should be evaluated, traditionally through examination of students' test scores (Harris \& Hodges, 1995).

Adequate yearly progress is an individual state's measure of yearly progress toward achieving state academic standards, addressing the minimum level of improvement that states, school districts, and schools must achieve each year (LD Online, 2008).

Automaticity refers to the fluent processing of information involved in performing a skilled or complex behavior easily, requiring little attention, effort, or conscious awareness (Harris \& Hodges, 1995; LD Online, 2008).

Comprehension is the process of simultaneously extracting and constructing meaning with an accurate understanding of the intended message, through interaction and involvement with written or spoken language (Harris \& Hodges, 1995; RAND Reading Study Group, 2002). In this study the third grade FCAT-SSS Reading is the indicator designated for measurement of student achievement in reading comprehension (FDOE, 2005).

Content validity is the degree to which a test measures an intended content area as it provides evidence that the test content is representative of a specified behavior domain (Gay \& Airasian, 2000; Harris \& Hodges, 1995). See Chapter 3 for more detail. 
Context represents the sounds, words, or phrases adjacent to a unit of spoken or written language (Harris \& Hodges, 1995).

Correlation is a statistical procedure for analyzing the extent two or more variables tend to vary together, which yields a coefficient expressing the degree of relationship (Harris \& Hodges, 1995).

Correlational research involves collecting data in order to determine whether, and to what degree, a relationship exists between two or more quantifiable variables (Gay \& Airasian, 2000).

Criterion-related, or instrumental, validity provides evidence of accuracy for a measure by comparing it with another measure, which has been demonstrated to be a good estimate of validity (Harris \& Hodges, 1995).

Decoding is the ability to translate a word from print to speech, usually by employing knowledge of sound-symbol correspondences (LD Online, 2008).

Differentiated instruction is tailoring learning experiences through flexible grouping based on the individual needs of students as evidenced through ongoing assessment to determine differences in readiness, interests, and learning styles (LD Online, 2008; Tomlinson, 2000).

Dynamic Indicators of Basic Early Literacy Skills of Oral Reading Fluency (DIBELS ORF) is a standardized progress-monitoring assessment tool that is used as an early predictive measure of reading achievement and was required for administration to all first, second, and third grade students who attended Reading First funded schools within the state of Florida (Good \& Kaminski, 2005; Torgesen, 2003). 
Expression is the modulation and pacing in speech along with the quality of feeling shown to convey meaning (Harris \& Hodges, 1995).

Florida Comprehensive Assessment Test of the Sunshine State Standards (FCATSSS) Reading is a state-mandated reading comprehension assessment administered yearly to all third through tenth grade students attending public school within the state of Florida (Florida Department of Education [FDOE], 2007).

Fluency is the ability to read a text accurately, at the appropriate rate, and with proper phrasing, expression, and comprehension (LD Online, 2008).

A fluent reader is one who reads smoothly, without hesitation, and with comprehension of the text (Harris \& Hodges, 1995). In this study a fluent reader scores in either the low risk or above average ability risk level on the DIBELS ORF assessment and achieves a Level 3, 4, or 5 on the FCAT-SSS in reading comprehension (FCRR, 2009a; FDOE, 2007).

Intonation is the distinctive patterns of pitch that contribute to the meanings of spoken phrases and sentences (Harris \& Hodges, 1995).

Literacy includes the reading, writing, and creative and analytical acts involved in producing and comprehending texts (LD Online, 2008).

Multiple-regression analysis is the statistical process of comparing actual values or scores with predicted values or scores, predicting scores on a criterion variable from scores on multiple predictor variables (Harris \& Hodges, 1995; Hinkle, Wiersma, \& Jurs, 2003).

The NCLB Act of 2001 is the most recent reauthorization of the Elementary and Secondary Education Act of 1965, and contains four basic education reform principles: 
stronger accountability for results, increased flexibility and local control, expanded options for parents, and an emphasis on teaching methods based on scientifically-based research (LD Online, 2008).

An oral reading fluency assessment is an individually administered test used to assess oral reading fluency performance (Harris \& Hodges, 1995). In this study the first, second, and third grade DIBELS ORF indicators are designated for measurement of student ability in oral reading fluency (Torgesen, 2003).

Outcome assessments are generally administered at the end of the school year to measure student academic progress and determine the overall effectiveness of the instructional program (Torgesen, 2006). In this study the third grade FCAT-SSS Reading is such an assessment, used to measure student achievement in reading comprehension (FDOE, 2005).

Phonemic awareness is the ability to notice, think about, and work with the individual sounds (phonemes) in spoken words (Harris \& Hodges, 1995; LD Online, 2008).

Phonics is the understanding and use of the alphabetic principle that stresses sound-symbol relationships, emphasizing the predictable relationship between phonemes (the sounds in spoken language) and graphemes (the letters/symbols that represent those sounds in written language), and shows how this information can be used to read or decode words (Harris \& Hodges, 1995; LD Online, 2008).

Phrasing is the way in which words are chosen and grouped in speaking or writing (Harris \& Hodges, 1995). 
Pitch is the rise and fall of the voice when speaking or reading (Harris \& Hodges, 1995).

Progress-monitoring assessments are administered periodically, following instruction, to determine whether students are making adequate progress (Torgesen, 2006). In this study the first, second, and third grade DIBELS ORF is such an assessment, used to measure student oral reading fluency ability (Torgesen, 2003),

Prosodic reading is the ability to use appropriate phrasing and language patterns, pitch and stress, intonation, and expression during reading to convey meaning (Hudson, Lane, \& Pullen, 2005).

Reading accuracy is the ability to recognize and read words correctly (LD Online, 2008).

Reading First was a federal initiative focused on implementing proven methods of early reading instruction in classrooms, by providing participating states and districts funded support to apply scientifically-based reading research and the proven instructional and assessment tools consistent with this research to ensure that all children would learn to read well by the end of third grade (LD Online, 2008).

Reading rate is the speed in which words are read (Harris \& Hodges, 1995; LD Online, 2008).

Scaffolding is the instructional technique employing a gradual release of mentor support while assisting a child with skill or strategy practice at a higher level than the child would be capable of independently, transferring more and more autonomy to the child through successive engagements (Harris \& Hodges, 1995; LD Online, 2008). 
Socioeconomic status represents a person's position or standing in society based on factors such as social class, level of education, income, and occupation (Harris \& Hodges, 1995). In this study socioeconomic status is measured by student eligibility for free or reduced price meals, established by qualification standards of the National School Lunch Program that schools use as eligibility guidelines (U.S. Department of Agriculture [USDA], 2011). Specific to this study, low socioeconomic status was attributed to any student who qualified for free or reduced price meals, while moderate socioeconomic status was attributed to any student who did not meet eligibility requirements for free or reduced price meals.

Stress is the emphasis from increased force of breath that makes a syllable, word, or group of words stand out (Harris \& Hodges, 1995).

Vocabulary refers to the words for which a reader knows and understands their meaning (LD Online, 2008).

Word recognition is the process of determining the pronunciation and some degree of meaning to identify a word in written or printed form (Harris \& Hodges, 1995).

\section{Overview of Remaining Chapters}

A review of relevant literature related to the reading development in young learners is presented in Chapter 2. A description of the methods implemented in the study is detailed in Chapter 3. A report of the research findings achieved in this study is provided in Chapter 4. A summary, including results of the study, conclusions drawn, and implications for educational theory, policy, and practice, is presented in Chapter 5. 


\section{CHAPTER II}

\section{REVIEW OF THE LITERATURE}

A review of the literature related to the reading development in young learners is addressed in this chapter, followed by federal accountability measures associated with early reading achievement. Also presented are several studies where the correlation between oral reading fluency assessments and state-mandated reading comprehension achievement tests are analyzed throughout the states of Florida, Delaware, Pennsylvania, and Tennessee. Finally, a brief discussion concludes how the literature relates to the current study, which was designed to investigate the extent a relationship exists between oral reading fluency ability and achievement in reading comprehension using several early reading assessments.

\section{Curriculum, Instruction, and Assessment in Early Reading}

A strong educational plan in reading includes reciprocity between curriculum, assessment, and instruction (Ransom, Santa, Williams, \& Farstrup, 1999). As Cobb (2003) pointed out, "the relationship of curriculum, assessment, and instruction must be integrated and reciprocal", as all are "critical components of effective teaching and learning" processes (p. 386). Each component is integral to a young learner's academic development. While the curriculum serves as indicator of what students are expected to learn, assessment provides for the measurement of students' learning, and instruction guides the identification of a comprehensive plan for delivering what students are expected to learn (Cobb, 2003). High quality reading education is dependent on the appropriate combination of curriculum, assessment, and instructional components during the teaching and learning process. 
Through the current No Child Left Behind (NCLB) legislation, strict policy standards for reading education have been established along with a dramatic increase in accountability to measure the progress of reading achievement in public education (Manzo, 2002; Robelen, 2002). Accountability measures include the use of high-stakes standardized tests that are associated with punitive actions when students fail to produce adequate achievement (Kohn \& Henkin, 2002).

The Florida Comprehensive Assessment Test of the Sunshine State Standards (FCAT-SSS) Reading is a state-mandated reading comprehension assessment administered yearly to all third through tenth grade students attending public school within the state of Florida (Florida Department of Education [FDOE], 2007). If students are to be held accountable for their performance on the FCAT-SSS Reading, then appropriate progress monitoring assessments to guide effective instructional planning must be utilized throughout the school year to support adequate achievement in reading comprehension on the FCAT-SSS Reading (FDOE, 2007; Torgesen, 2003). Fuchs and Fuchs (1999) have warned there must exist a careful selection of assessment to "ensure the production of accurate, meaningful, and useful information" (p.661) that will lead to providing support toward developing the most effective and comprehensive educational plan possible.

In addition to the FCAT-SSS Reading, young third grade learners in Florida who attended schools receiving grant funding from the federal Reading First Initiative were also administered the Dynamic Indicators of Basic Early Literacy Skills in Oral Reading Fluency (DIBELS ORF), a standardized progress-monitoring assessment tool that measures oral reading fluency ability (Torgesen, 2003). Despite the fact that during the 
fall of 2009 the Florida Department of Education ceased dispersing all Reading First funding to districts statewide for their schools that had formerly participated in this initiative, progress-monitoring continues to be required for all struggling readers throughout the state (FCRR, 2009b; FDOE, 2007).

Struggling readers deficient in their development of reading fluency, an essential component of reading, must be closely monitored for progress (FCRR, 2009b; NICHD, 2000). Along with the required progress monitoring of fluency development in struggling readers, teachers must provide daily intervention instruction to students who demonstrate a deficiency in this essential component of reading, as mandated by Florida State Board Rule 6A-6.054, K-12 Student Reading Intervention Requirements (Florida Department of State [FDOS], 2010).

Unfortunately, varied views exist among educators for what constitutes effective comprehensive reading fluency development, and precisely how that development affects a young learner's ability to comprehend text efficiently enough to become a proficient reader. This creates a dilemma as educators work closely with their young learners to support their reading fluency development. Some instructional practices may be compromised when educators and students are held accountable by an oral reading fluency assessment measure such as DIBELS, unless it can be determined to provide significant predictive ability toward successful achievement on the state-mandated highstakes standardized test in reading comprehension, the FCAT-SSS Reading.

Not unique to Florida, DIBELS ORF was the progress-monitoring assessment used in most Reading First funded schools across the nation (Manzo, 2005). For that reason, there have been numerous research studies conducted throughout the United 
States addressing the predictive ability of oral reading fluency assessment measures toward achievement on standardized state reading comprehension assessments (Buck \& Torgesen, 2002; Hintze \& Silberglitt, 2005; Kloo, 2006; Riedel, 2007; Roehrig, Petscher, Nettles, Hudson, \& Torgesen, 2008; Uribe-Zarain, 2006). Many of the studies have confirmed some predictive ability, including Buck and Torgesen's research conducted in Florida (Hintze \& Silberglitt, 2005; Kloo, 2006; Riedel, 2007; Roehrig et al., 2008; Uribe-Zarain, 2006). The problem this researcher found is that most of the studies failed either to disaggregate the data according to racial/ethnic demographic student subgroups or secure a large enough sample of students to adequately represent the diverse subgroups.

The 52 schools that previously received Reading First funding, as members of Cohorts One, Two, and Three, are located within lower socioeconomic areas of this targeted South Florida school district and contain large populations of racial/ethnic minority students and students from low-income families; therefore, data disaggregation provided greater clarity as to the predictive ability of the DIBELS ORF assessment to the FCAT-SSS Reading assessment for these diverse subgroups of learners. A similar study conducted by Uribe-Zarain (2006) in Delaware, that focused on data disaggregation of student subgroups determined there to be discrepancies in the relationship between performance as measured on both the DIBELS assessment and their state-mandated standardized assessment in reading for student demographic subgroups of race/ethnicity and socioeconomic status. This previous finding by Uribe-Zarain was significant to exploring the effectiveness of oral reading fluency progress-monitoring assessments, such as the DIBELS ORF, toward predicting performance on the FCAT-SSS Reading outcome 
assessment, especially for these specific demographic populations of students attending school in South Florida. This information proves vital to further examining the achievement gap that continues to plague academically and economically disadvantaged learners.

\section{The Achievement Gap in Reading Development}

Despite the research that currently exists in support of oral reading fluency ability toward predicting achievement in reading comprehension, the overall achievement gap in reading development across the nation continues to widen significantly (FDOE, 2009; Gamse, Jacob, Horst, Boulay, \& Unlu, 2008; Kim \& Sunderman, 2005; Schott Foundation for Public Education [SFPE], 2010). The Matthew effect and how the phenomenon impacts the education of young learners who exhibit varying degrees of ability along their individual continuum of reading development provides significant relevance to the widening achievement gap.

The relationship between the Matthew effect and the achievement gap is evidenced through Stanovich's (1986) recognition that higher-achieving learners tend to continue experiencing academic success, while struggling learners often remain on a path of academic failure. Unless struggling learners receive effective academic support, the achievement gap will continue to widen between these groups of learners over time, and in fact, according to Kim and Sunderman (2005), widening of the achievement gap seems to have perpetuated despite the efforts of NCLB and its primary goal of supporting learners in low achieving schools.

The concept of the Matthew effect in academic achievement was not a new phenomenon to Stanovich (1986), as he referenced its origin back to R. Merton who 
published a study in 1968 related to science academia and recorded these effects in science. Stanovich indicated that Merton credited the term, Matthew effect, to the Gospel according to Matthew: "For unto every one that hath shall be given, and he shall have abundance: but from him that hath not shall be taken away even that which he hath" (XXV:29).

The general interpretation of the Matthew effect is the "rich get richer" (p. 381), or as Stanovich (1986) specifically related to reading, the successful reader becomes more proficient during the developmental process, as past achievement provides the foundation for building even greater achievement. As the successful reader gains more proficiency over time during the learning process, the less able reader often experiences more difficulty meeting with success, and therefore trails further behind his or her more successful peers. The less able reader, who continues to lack sufficient progress in reading, quickly begins to feel the effects of failure, and struggles with future attempts at learning to read. Struggling learners, who begin to fall further behind their more able peers, typically become signified with the phrase the "poor get poorer" (Stanovich, 1986, p. 382).

According to Stanovich (1986), there is much reciprocity in Matthew effects of education. When young learners bring an elaborate knowledge background to the classroom, they tend to quickly and easily build upon that solid foundation. Environments rich with oral and written linguistic opportunities provide effective experiences for young learners to build background knowledge, yet the opposite is true for their linguistically disadvantaged peers who lack exposure to these rich opportunities both at home and in school (Wolf, 2007). Linguistically disadvantaged young learners tend to continue 
experiencing difficulty without a solid foundation in place for which to build future knowledge (Stanovich, 1986). Children possessing larger foundations of expertise, according to Stanovich, can increase their learning with ease and at a much more rapid pace than their less able peers.

In reading, this rich and elaborate background, Stanovich (1986) has stated, can translate into one's knowledge of vocabulary, content, concepts, and skills, which in turn can be applied efficiently to the process of reading and understanding connected text. Another aspect of the Matthew effect that warrants consideration, according to Stanovich, is the importance for students to be surrounded by higher ability peers. When all members of the classroom are of lower ability, growth and development are much less likely to occur among members of the group. This has presented a problem for young learners who attended Reading First funded schools, because the Reading First Initiative originated to target students attending lower achieving schools. Lower achieving schools tend to be located in lower socioeconomic areas and most often contain large numbers of racially/ethnically diverse student populations with limited foundational development in literacy, therefore large numbers of minority students have been placed most at risk for failure of this initiative.

The recently released 2010 Schott 50 State Report on Black Males in Public Education (SFPE, 2010) has evidenced continuation of the widening achievement gap, while the Reading First Initiative did little to reverse this trend (Gamse et al., 2008; Kim $\&$ Sunderman, 2005). As evidenced in this report, widening of the achievement gap has continued through high school. Examining the disparity of the Black male student population, the Schott Report (SFPE, 2010) reveals the rapidly decreasing rate at which 
Black male students are graduating from high school on a national scale, consistently decreasing by far greater numbers than any other racial or gender subgroup population.

Although the Black male student population in some states has maintained greater high school graduation rates, the national average during the 2007-08 school year realized only $47 \%$ of Black male students graduating, in comparison to $78 \%$ of White male students, representing a 31\% difference (SFPE, 2010). Within the state of Florida a far worse trend is presented, with $10 \%$ less than the national average of Black male students graduating high school at a rate of only $37 \%$, which represented the nation's second lowest Black male student graduation rate (SFPE, 2010). The South Florida school district in which this current study will be conducted ranked fifth highest nationally of districts with the largest Black male student population according to the Schott Report, yet only recognized a slightly better than state average graduation rate (37\%) of 39\% district-wide. This 2\% difference between district and state Black male student graduation rates remains insignificantly small in comparison, as the district maintains a rate that is still well below the national average by a difference of $8 \%$.

The conclusion reached in the Schott Report is that "the American educational system is systematically failing Black males" (SFPE, 2010, p. 37). This trend must be reversed in every state throughout the nation, and schools held accountable for providing equal and effective educational opportunities that address the needs of all students, including diverse populations, "to ensure educational outcomes are not identifiable by race or gender" (SFPE, 2010, p. 2). While a large number of students continue to experience difficulty acquiring proficiency in reading, most often these lower achieving numbers are overrepresented by students of racial/ethnic minority groups from low- 
income families (Allington, 2000; SFPE, 2010). A closer look at the progress monitoring of reading achievement among diverse student populations is warranted, to support the selection of assessment tools that will consistently, accurately, and effectively measure growth in reading achievement across all gender, racial/ethnic, and socioeconomic populations. The more we examine each essential component of reading instruction, as they relate to proficient reading development, the more effective educators will be at addressing the differentiated needs of all learners (Wolf, 2007).

\section{The Reading First Initiative of NCLB}

In the fall of 2003, 25 public elementary schools located in this targeted South Florida school district were awarded the Reading First grant, becoming members of Florida's Cohort One of the Reading First Initiative (Torgesen, 2003). The majority of these Cohort One Reading First funded schools were located in lower socioeconomic areas of the district and contained large numbers of racial/ethnic minority students. As promised, federal grant funding for the Reading First Initiative provided additional intervention programs, assessments, and personnel to monitor student progress and provide professional development to educators as well as targeted differentiated instruction to young learners. Several years later, not much has changed to close the achievement gap that existed locally among these Cohort One Reading First funded schools and other non-Reading First schools situated within higher socioeconomic areas of this South Florida school district, as evidenced by Florida's A+ Plan (Florida Department of Education [FDOE], 2007, 2009).

Despite the efforts of the current federal NCLB legislation, which originated to assist the most struggling learners (Olson \& Viadero, 2002), there does not appear to be 
widespread success with closing the achievement gap nationally either (Kim \& Sunderman, 2005; SFPE, 2010). Although the intent of the federal NCLB legislation was to provide significant support to lower performing schools, which occurred through the Reading First Initiative, according to school grading records, significant progress was not achieved at these targeted schools across the state (FDOE, 2009). The time has come to seriously reevaluate the efforts of NCLB, and identify alternative actions that will best support struggling learners so that ultimately the elimination of, and more realistically the reduction in, the achievement gap can be realized.

Five years overdue, the federal public education legislation, NCLB Act of 2001, was slated for reauthorization in early 2007 (U.S. Department of Education [USDOE], 2008). The original intent of the NCLB legislation was to significantly increase reading achievement among learners attending public schools across the nation, by instituting strict policy standards for reading education (NICHD, 2000). A substantial increase in support provided to lower performing schools was included in the legislation through the federal Reading First Initiative (Torgesen, 2003).

Despite the efforts that have been instituted toward this end, the progress has fallen far short of its goal (Altshuler \& Schmautz, 2006), as closing the achievement gap between academically and economically advantaged and disadvantaged learners has not been realized (Kim \& Sunderman, 2005; SFPE, 2010). Although reauthorization of NCLB will require thorough investigations into present practice and how to adjust policy to significantly increase learners' progress in reading achievement, each component of the policy will require scrutiny for its effectiveness at realizing this goal. 
This researcher has contributed to the evaluation process by addressing the effectiveness of oral reading fluency progress monitoring assessments, which continue to be used despite the absence of Reading First funding, toward predicting achievement in reading comprehension. Educators must know if these oral reading fluency assessment measures are appropriately guiding their curricular decisions in the classroom to provide young learners the most effective reading education possible, with the ultimate goal of supporting the proficient reading development of learners across all demographic subgroups.

\section{Reading Fluency Development in Young Learners}

Developing proficient readers requires both explicit instruction and learning in all essential components of reading instruction, but Wolf (2007) has recognized that some young learners need greater support in one or more components. The more learned about each of the reading components, the more effective our teaching will become (Wolf, 2007). Despite the fact that reading fluency, just one essential component of reading instruction, has nationally commanded the attention of educators this past decade through the NCLB Act of 2001 (National Institute of Child Health and Human Development [NICHD], 2000), Rasinski (2005) has reminded us that almost thirty years ago and long before NCLB, Allington (1983) acknowledged the impact reading fluency had on effective literacy development. Although historically the research addressing the importance of reading fluency on literacy development has been abundant, Allington (2001) noted that much less research has been conducted on the complex effects of reading fluency. 
Many researchers agree that if young learners are to develop appropriate reading fluency, their instruction, practice, and assessment of fluency must interactively and comprehensively incorporate all three of its essential elements: reading rate, reading accuracy, and prosodic reading (Allington, 1983, 2001; Hudson, Lane, \& Pullen, 2005; Rasinski, 2004; Stahl, Heubach, \& Holcomb, 2005; Valencia et al., 2010). Reading rate and reading accuracy consist of the speed with which one reads the words correctly, while prosodic reading incorporates the use of appropriate phrasing and language patterns, pitch and stress, intonation, expression and volume, smoothness, and pace during the oral reading process (Allington, 1983; Hudson et al., 2005; Rasinski, 2004). Reading rate and reading accuracy are quantitatively measured objectively using a formula that includes the number of words read correctly for a specified number of minutes (Hudson et al., 2005). Prosodic reading is measured more subjectively through qualitative measurement using a quantitative rubric protocol for each prosodic component: phrasing and language patterns, pitch and stress, intonation, expression and volume, smoothness, and pace (Allington, 1983; Hudson et al., 2005; Rasinski, 2004).

Even though there is heightened awareness of the importance for providing fluency instruction and practice opportunities to young learners, what remains less certain is how significant the relationship is between reading fluency development and the overall ability to read with proficiency allowing for critical comprehension of text. Often the prosodic reading element is neglected, and emphasis on fluency development is placed primarily on reading rate and reading accuracy (Hasbrouck \& Tindal, 2006; Hudson et al., 2005). This results in a very narrowed definition and understanding of 
fluency, which can lead to providing insufficient support to young learners in the process of becoming more automatic and proficient readers.

Although many non-proficient readers exhibit impairment in both reading fluency and comprehension of text, some non-proficient readers are capable of reading text fluently with automaticity yet struggle to understand what they read (Hudson et al., 2005; Rasinski, 2004). For fluent readers who demonstrate the capacity for identifying and reading words quickly and accurately with minimal effort, this automaticity affords them greater cognitive capacity, which can then be devoted to higher-level thinking, required for comprehending and understanding text (NICHD, 2000; Stanovich, 1986).

It is apparent that fluent readers are generally capable of identifying and reading words more quickly and accurately, in order to focus their attention on the meaning of the textual message (NICHD, 2000; Stanovich, 1986), but there is no guarantee that learners who demonstrate automaticity in recognizing and reading words will successfully comprehend the written message (Hudson et al., 2005; Rasinski, 2004). Allington (1983), throughout the past 27 years, and more recently Pikulski and Chard (2005), have cautioned when providing fluency instruction and practice opportunities, comprehension of text should be emphasized, because a strong correlation exists between effective reading fluency and reading comprehension (Pikulski \& Chard, 2005).

Word reading ability impacts reading comprehension, as differences in word reading skills creates skill differences in comprehension (Perfetti, 2007). When reading instruction focuses on letter-, sound-, and word-level skills, lower-order literacy competencies are developed, but when reading instruction focuses on searching texts for information and making inferences, higher-order literacy competencies are developed 
that lead to the proficient comprehension of complex texts (Pressley, 2002). If greater emphasis is placed on lower-order literacy skill competencies during reading instruction, development of higher-order literacy skill competencies are compromised (Pressley, 2002). While the compromise associated with an instructional focus on lower-order reading skills may lead to effective word recall, it often prevents readers from fully understanding the text they read, compromising development of higher-order reading skills (Pressley, 2002).

Significant concern arises when the prosodic element of fluency is neglected not only during instruction and independent practice, but also during the assessment of fluency. According to Hudson et al. (2005), the lack of attention provided to the development of prosodic skills can directly contribute to the creation of learners who are capable of reading quickly and accurately, yet exhibit poor comprehension of text. When effectively applied to the oral reading of text, prosodic skills signify the reader's proper use of volume, phrasing, language patterns, smoothness, pace, and natural intonation, which then each contribute to activating the appropriate expression during reading (Allington, 1983; Hudson et al., 2005; Rasinski, 2004). These complex prosodic skills provide the reader support with making sense of the language and structure of text (Hudson et al., 2005), making it clear that a reciprocal relationship exists between prosody and reading comprehension (Allington, 1983, 2001; Hudson et al., 2005; Rasinski, 2004).

With a reciprocal relationship established between prosody and reading comprehension (Allington, 1983), it is evident that prosody becomes the essential element of fluency development, which most contributes to the understanding of text 
(Hudson et al., 2005), yet is most often neglected. Overwhelmingly, the research supports claims that fluency instruction, practice opportunities, and assessment measures must incorporate the prosodic element interactively with the elements of rate and accuracy, to support appropriate fluency development that ultimately leads to an understanding and comprehension of the written message (Allington, 1983; Hudson et al., 2005; Rasinski, 2004; Valencia et al., 2010). It is the construction of meaning from text and understanding what is written that remains the ultimate goal of reading (Snow, Burns, and Griffin, 1998), or as Durkin (1993) claimed to be "the very essence of reading" (p. 12).

Hudson et al. (2005) cautioned that although readers are expected to employ prosodic skills automatically when reading, emphasis is not always devoted to assisting learners with incorporating these skills in reading during instruction, practice opportunities, and assessment experiences. For proficient readers, prosodic skills often develop automatically and naturally through exposure to good models of oral reading, which they internalize and apply during their independent reading practice. However, without appropriate fluency experiences struggling readers often fail to recognize the importance of prosody and when lacking these skills will generally choose to avoid reading altogether (Hudson et al., 2005; Rasinski, 2004).

Hudson et al. (2005) have warned that struggling readers need significant scaffolded support during instruction and practice opportunities to effectively develop prosodic skills. As poor prosody frequently presents confusion for the reader due to inappropriate or meaningless expression or faulty groupings of words during the reading 
process, readers who exhibit poor prosody generally fail to make sense of what is being read, which then leads to their avoidance of reading (Hudson et al., 2005).

As so often happens, one essential element of fluency, such as a rapid reading rate, may be emphasized during instruction, but this should be avoided according to Rasinski (2000), because fluent reading for understanding of text should be the primary goal when working toward effective fluency development. Rasinski (2004) has cautioned that when the speed of reading is overemphasized, and prosodic meaningful reading is underemphasized, there will be many young learners who are capable of reading fast, yet understand very little of what they read.

Although the research on reading fluency development has grown over the last decade, much uncertainty continues to exist. Reading fluency development is a complex process. The instruction, practice, and assessment of fluency should be strategically provided to young learners, emphasizing all three essential elements of reading fluency: rate, accuracy, and prosody. Educators continue to be held accountable for ensuring their young learners develop appropriate reading fluency as they work toward becoming proficient readers, but there is clearly a gap in the available research on the complexity of reading fluency development and the significance of the relationship of fluency to proficient reading, as defined by achievement in reading comprehension (NICHD, 2000).

\section{Federal Accountability Targeting Early Reading Achievement}

The existing federal policy of the NCLB Act of 2001 places heavy emphasis on the accountability of reading achievement in public education (NICHD, 2000), and with increased accountability has come the frequent assessment of learners. With a renewed interest in reading fluency deeply embedded in the reforms of NCLB, standardized 
testing of fluency has become common practice as a way to measure and promote accountability for early reading progress (NICHD, 2000; Torgesen, 2003). In Reading First funded schools within the state of Florida, the DIBELS assessment was mandated for administration to young learners as a periodic progress-monitoring tool for measuring oral reading fluency development as an early predictor of reading success (Torgesen, 2003).

The score achieved on the DIBELS ORF assessment, reported in words read correctly per minute, reflects only the rate and accuracy of reading sustained for one minute (Good \& Kaminski, 2005). Although the sixth edition of the DIBELS assessment (Good \& Kaminski, 2005) contains an optional comprehension-scoring subtest measure of Retell Fluency (RF), schools that participated in the Reading First Initiative within the state of Florida did not administer this measure (Hudson et al., 2005; Torgesen, 2003). Because scoring of the DIBELS ORF subtest in Florida has historically been reported solely on reading rate with accuracy, the data are limited to the number of words read correctly per minute (Torgesen, 2003).

The absence of data reflecting the development of reading prosody, which contributes to comprehension, implies that the prosodic element is less significant to fluency development than reading rate and accuracy (Allington, 1983; Hudson et al., 2005; Rasinski, 2004). Although becoming a fluent reader is critical to proficient and motivated reading, fluency assessments that isolate these two measured elements often lead educators to narrowly focus on supporting improvement in their students' rate and accuracy scores (Hasbrouck \& Tindal, 2006; Valencia et al., 2010). This practice further encourages educators to limit reading fluency instruction and practice experiences solely 
in these measured elements. Improper instruction and application that specifically targets rate and accuracy can result in children reading too quickly, focusing on reading the words fast with minimal attention to the content of the text for which they should be reading to understand (Stahl et al., 2005). Rasinski (2000) cautioned when reading is paced too quickly, the reader often experiences difficulty processing the content of the text, causing comprehension to be severely compromised.

Frequently monitoring the reading progress of young learners is vital to providing effective reading instruction that supports adequate proficient reading development. Because monitoring the fluency progress in beginning reading has historically been measured by the rate at which words are read correctly (Allington, 2001), rapid reading rate is often emphasized (Rasinski, 2004). As young learners are encouraged to read fast, this practice often leads to the inadvertent creation of automatic word callers, who while able to read words with rapid automaticity may experience difficulty understanding and comprehending what they read (Rasinski, 2000; Stahl et al., 2005; Valencia \& Buly, 2004). With oral reading fluency used to monitor the progress of early reading development, it is imperative to determine if there is a relationship between oral reading fluency ability and reading comprehension achievement, especially for racially and ethnically diverse young learners from low-income families, and if there is to further determine how significant the relationship is between these measures.

In school districts throughout the state of Florida and across the nation, oral reading fluency assessments continue to be administered periodically throughout the year to monitor the reading progress of young learners (Florida Center for Reading Research [FCRR], 2009a; Torgesen, 2003). Third graders who attended Reading First funded 
schools within the state of Florida were administered the DIBELS ORF as a progressmonitoring assessment three times during the school year (as a pre-, mid-, and post-test); therefore, teachers used the assessment data to guide and plan instructional practices (Torgesen, 2003). A significant problem associated with fluency development arises when educators are held accountable for their young learners' successful progress on standardized assessments such as the DIBELS ORF, which has led to increased attention on isolated instruction in oral reading fluency. Although Florida public school districts are mandated through state legislation (State Board Rule 6A-6.053 in Florida Statute Section 1011.62) to implement a comprehensive core reading program that incorporates all essential components of reading instruction (Florida Department of State [FDOS], 2011), teachers often find it difficult to deliver a comprehensive, balanced reading instructional model when heavy emphasis has been placed on the accountability of achievement in isolated skills.

State mandated for implementation in all public elementary schools throughout Florida, the comprehensive core basal reading program provides for balanced methods that target all essential components of reading instruction (FDOS, 2011). Daily lesson plans provide guidance for instructing the essential foundational reading components of oral language, phonemic awareness, phonics, fluency, vocabulary, and comprehension (FDOS, 2011). Despite the balanced instructional lesson plans provided through the comprehensive core reading program, teachers often compromise a balanced instructional delivery by emphasizing isolated skill instruction. Teachers rely on isolated skill instruction to promote greater student achievement in skills that are frequently monitored 
for progress, such as oral reading fluency, as assessed on the DIBELS ORF (Manzo, 2005; Venable, 2006).

In addition to DIBELS, Florida students have also been administered the FCATSSS Reading, which is mandated for annual administration as an outcome assessment tool for measuring achievement in reading comprehension (Florida Department of Education [FDOE], 2007). The FCAT-SSS Reading provides measurement of young learners' achievement in selected reading benchmarks (skills and competencies) of the state reading standards, Florida's curriculum framework, (FDOE, 2007). Within the state of Florida the FCAT-SSS Reading is used not only to measure student learning, but is also used for accountability purposes to specifically report the "educational status and annual progress for individual students, schools, districts, and the state" (FDOE, 2007, p.13).

Although the FCAT-SSS Reading is the state-mandated standardized assessment used to measure achievement in reading comprehension, the skills and competencies measured on this test are restricted to select reading benchmarks (FDOE, 2007). A much more complex process is executed during comprehension, which is grander in scope than the limited benchmarks that are measured in the restricted multiple-choice format presented on the FCAT-SSS Reading (Durkin, 1993; Harris \& Hodges, 1995; RAND Reading Study Group, 2002).

The full scope of comprehension involves the complex process of simultaneously extracting and constructing meaning with an accurate understanding of the intended message, through interaction and involvement with written or spoken language (Harris \& Hodges, 1995; RAND Reading Study Group, 2002). More specifically during reading, 
comprehension involves the intentional thinking that takes place between the text and the reader that leads to the construction of meaning (Durkin, 1993). Despite the expanded scope of comprehension, the FCAT-SSS Reading is used as a standardized measure of reading comprehension achievement throughout the state, and is therefore the assessment employed in this study (FDOE, 2007).

In school districts throughout the state of Florida, there are alternative standardized assessments designated for use as criteria for promotion from Grade 3 to Grade 4 in addition to the FCAT-SSS Reading (FDOE, 2007). With such stringent promotion criteria, effective progress-monitoring data needs to be identified early to guide educators in planning differentiated instruction for their young learners. In Reading First funded schools, the DIBELS ORF progress-monitoring assessment served the role as early predictor of reading achievement (Torgesen, 2003). If the DIBELS ORF progress-monitoring assessment is to be used as an effective early predictor of performance on the FCAT-SSS Reading outcome assessment, then support of this practice must be clearly evidenced through a significantly positive correlation between the DIBELS ORF and the FCAT-SSS Reading assessment measures for all young learners.

\section{Early Predictors of Reading Achievement}

One specific area where the research continues to grow is related to accountability when oral reading fluency is used as a progress-monitoring assessment to predict reading achievement. Several research studies have highlighted the use of oral reading fluency assessments as predictors of performance on state-mandated, standardized tests of reading comprehension (Buck \& Torgesen, 2002; Kloo, 2006; Riedel, 2007; Roehrig, 
Petscher, Nettles, Hudson, \& Torgesen, 2008; Uribe-Zarain, 2006), and found there to be a high correlation of student achievement between these types of assessments.

Release of the Reading First Impact Study: Final Report (Gamse, Jacob, Horst, Boulay, \& Unlu, 2008) has brought recent attention to previous findings of correlations in student achievement between early reading assessments used in Reading First funded schools. Commissioned to address the impact of the Reading First Initiative on classroom instruction and student achievement, this national study focused on 248 schools in 13 states, including 17 school districts and one statewide Reading First program (Gamse et al., 2008). Data collection spanned across 3 years from 2004-2007, and was used to analyze the impact of early reading instruction in the five essential components (phonemic awareness, phonics, fluency, vocabulary, and comprehension) and student achievement as measured primarily by performance on the Reading Comprehension subtest of the standardized, norm-referenced Stanford Achievement Test, Tenth Edition (SAT-10; Gamse et al., 2008).

Following years of funding through Reading First, Gamse et al. (2008) concluded that although the Reading First Initiative produced a positive and statistically significant impact on the amount of time spent instructing the five essential components of reading in Grades 1 and 2, the initiative failed to produce a statistically significant impact on student achievement in reading comprehension test scores for Grades 1, 2, or 3 (Gamse et al., 2008). These national findings impacted the Reading First Initiative, with funding being completely ceased both at the national level as well as within the state of Florida immediately following the conclusion of the 2008-09 school year. Although Reading First funding has been discontinued across the nation, it will take years to determine the 
effects of this initiative within our schools. Despite the cut in Reading First funding, instructional and assessment practices have been impacted nationally by the 6 years the Reading First Initiative was implemented, from 2003-2009 (Gamse et al., 2008). Oral reading fluency assessments continue to be administered to struggling readers attending Florida public schools as a progress monitoring measure toward achievement on the FCAT-SSS Reading (FCRR, 2009a).

Despite the findings of the Reading First Impact Study: Final Report (Gamse et al., 2008), many states, including Florida, use their own standards-based assessment when measuring student reading achievement that leads to high-stakes decisions regarding student placement and school funding. A more critical look at state-mandated reading assessments is vital toward determining whether oral reading fluency measures significantly correlate to the state-mandated tests powerfully enough to predict reading comprehension achievement, and be considered effective progress-monitoring measures.

In the following sections, findings are presented from studies conducted throughout four states (Florida, Delaware, Pennsylvania, and Tennessee) in which the researchers used oral reading fluency assessments to determine if a correlation exists between this progress-monitoring measure and their specific state-mandated achievement assessments in reading comprehension.

\section{ORF and Reading Achievement Assessments in Florida}

Buck and Torgesen (2002) sought to determine the predictive ability of oneminute measures of oral reading fluency toward achievement in reading, as measured on a state-mandated high-stakes test for third grade students. The Standard Reading Passages (SRP): Measures for Screening and Progress Monitoring from Children's Educational 
Services, Inc. (SRP ORF) was administered as the oral reading fluency assessment. The FCAT-SSS Reading was administered as the state-mandated high-stakes test.

The study conducted by Buck and Torgesen (2002) occurred during the 2001-02 school year; therefore, the state of Florida did not yet require administration of the DIBELS ORF assessment. Administration of the DIBELS ORF assessment did not begin statewide until the fall of 2003 when the Reading First Initiative was first implemented in Florida. As a result, in this earlier study conducted by Buck and Torgesen, the SRP ORF assessment measure was used, rather than the DIBELS ORF.

Buck and Torgesen (2002) used a sample that included 1,102 third grade students attending 13 schools within one northern Florida public school district. The sample student population included $49 \%$ girls and $51 \%$ boys. The racial/ethnic background of the students included $83 \%$ White, $7 \%$ African American, and 6\% Hispanic. Only 1\% of the students were considered limited English proficient and 19\% were identified as receiving exceptional student education services. Students of low socioeconomic status, as measured by receiving free or reduced lunch, represented $46 \%$ of the sample.

Buck and Torgesen (2002) used the Pearson $r$ correlation coefficient to measure the correlated value between the two early reading assessment variables, the SRP ORF and the FCAT-SSS Reading. When all sample values were correlated, there was a significant correlation achieved at $r=.70, p<.001$. Buck and Torgesen also broke down the percentage of students who dichotomously fell into categories for the FCAT-SSS Reading performance (i.e., adequate and inadequate) as well as the percentage of students who dichotomously fell into categories for the SRP ORF performance (i.e., low risk-pass and high risk-fail). Based on these percentages, the researchers then conducted a 
sensitivity and specificity calculation for these particular scores, again including all of the students in the sample. Sensitivity and specificity calculations were not conducted for students who scored in the some risk on-level midrange of the SRP ORF measure, because the researchers stated that these students scoring in the mid range on the SRP ORF would be equally as likely to perform adequately or inadequately on the FCAT-SSS Reading (Buck \& Torgesen, 2002).

Correlation coefficients were then reported according to racial background, $r=$ $.70, p<.001$ for White students, $r=.62, p<.001$ for African American students, and $r=$ $.78, p<.001$ for Hispanic students (Buck \& Torgesen, 2002). The conclusion that Buck and Torgesen made regarding the disaggregated findings on racial subgroups is that for minority children, in particular African Americans, performing well on the SRP ORF assessment did not provide for a strong indicator of success on the reading portion of the FCAT-SSS Reading. Buck and Torgesen concluded their study by stating, "that the data relating to race/ethnicity must be regarded as very preliminary because of the small number of students in minority classifications" (p. 4). This finding could not be generalized to the population of third grade students within the state of Florida. Buck and Torgesen pointed out the need for further testing of these predictive interactions, between oral reading fluency and FCAT-SSS Reading measures once data from a more diverse sample of students became available.

Buck and Torgesen (2002) also conducted a multiway frequency analysis to determine whether the interaction between racial/ethnic background (i.e., African American vs. White) and predictive accuracy for the SRP ORF scores to the FCAT-SSS Reading scores were statistically reliable. Again for the two dichotomous variables SRP 
ORF (i.e., low risk-pass and high risk-fail) and FCAT-SSS Reading (i.e., adequate and inadequate) measures, for the 701 White and African American students, the interaction between these variables was not significant, $\chi^{2}(1)=0.209, p=.65$ (Buck \& Torgesen, 2002). There was not a significant difference in the relationship between African American and White students when analyzing the predictive relationship of the SRP ORF on FCAT-SSS Reading scores.

Buck and Torgesen (2002) conducted a similar multiway frequency analysis using the SRP ORF, FCAT-SSS Reading, and race/ethnicity (i.e., Hispanic and White students) to determine if the predictive relationship between SRP ORF and FCAT-SSS Reading scores were significantly different depending on their racial/ethnic background. A significant effect was not found, $\chi^{2}(1), 0.45, p=.50$, which suggests that SRP ORF scores predict FCAT-SSS Reading scores equally well for these two separate racial/ethnic groups (Buck \& Torgesen, 2002). Buck and Torgesen claimed that these findings were likely a result of a small sampling of minority students, as White students accounted for $83 \%$ of the sample, and that greater diversity is necessary in future studies. Before Buck and Torgesen disaggregated the data into racial/ethnic subgroups, they analyzed the data for all subgroups combined, and a significant interaction between FCAT-SSS Reading and SRP ORF, $\chi^{2}(1)=372.11, p<.0001$ was reported. This strongly supported their prior conclusion that SRP ORF scores significantly predict FCAT-SSS Reading scores, in the absence of large racially/ethnically diverse student populations (Buck \& Torgesen, 2002).

Buck and Torgesen's (2002) research, conducted in the spring of 2002, provided the foundation for which this researcher chose to further pursue. With implementation of 
the Reading First Initiative and administration of the DIBELS ORF as a progress monitoring assessment beginning shortly following this research, the data necessary to explore the predictive power of the DIBELS ORF assessment toward reading comprehension achievement as measured by performance on the state-mandated FCATSSS Reading became readily available. While Buck and Torgesen indicated their study lacked a sample size adequate to determine an accurate correlation, especially for the African American subgroup, sufficient samples of this minority population became readily available in South Florida Reading First funded schools (FDOE, 2008b).

Several years following the Buck and Torgesen study (2002), similar research was conducted in Florida that focused on the predictive power of an oral reading fluency measure on two reading comprehension measures (Roehrig, Petscher, Nettles, Hudson, \& Torgesen, 2008). Roehrig et al. secured a much larger sample of just over 16,000 third grade students throughout the state of Florida who participated in the Reading First Initiative. This sample included a greater number of racially/ethnically diverse students than Buck and Torgesen's (2002) study. The sample subgroups were identified as $36 \%$ White, 36\% African American, 23\% Latino, 3\% Multiracial, 1.5\% Asian, and less than $1 \%$ Native American (Roehrig et al., 2008). The Roehrig et al. sample reflected an African American subgroup of 36\%, which was 29\% greater than the African American subgroup of $7 \%$ that was reflected in the earlier Buck and Torgesen sample.

During the 2004-05 school year, Roehrig et al. (2008) collected student data generated from the DIBELS ORF progress-monitoring measure, the FCAT-SSS Reading, and the Stanford Achievement Test, Tenth Edition (SAT-10) Reading. The DIBELS ORF data were analyzed for their predictive power on the FCAT-SSS Reading and the SAT-10 
Reading, both standardized assessments measuring achievement in reading comprehension that were administered to all third grade students in the state of Florida at that time (Roehrig et al., 2008). The study focused on identifying students at risk for below grade-level reading achievement, but overlooked the performance of rapid readers who achieved high scores on the DIBELS ORF measure (Roehrig et al., 2008). Rapid readers often exhibit difficulty in comprehending text as they focus on word calling, disregarding the context of the written message; therefore, this population of students presented a concern and was addressed in this current study.

An additional concern stemming from the Roehrig et al. (2008) study is the administration cycle of DIBELS when used as a progress-monitoring assessment. Beginning with the 2003-04 school year, and continuing through the 2005-06 school year, DIBELS was administered four times during each school year (Fall, Winter 1, Winter 2, and Spring administrations) in the state of Florida (Torgesen, 2003). DIBELS administration was reduced to three times each school year (Fall, Winter, and Spring administrations) beginning in the 2006-07 school year and continuing through the 200809 school year (Torgesen, 2003). The Roehrig et al. study was conducted during the 2004-05 school year when the DIBELS ORF assessment was administered four times that year. In fact, the authors of DIBELS calibrated the risk-level cut scores based on administration of three times a year (Good \& Kaminski, 2005), however in Florida the cut scores were recalibrated to better reflect administration at four times a year (Torgesen, 2003).

The critical need was evident to further the research previously conducted by Buck and Torgesen (2002) and Roehrig et al. (2008), modifying portions of their research 
methods to more closely replicate the mandates of Reading First schools throughout Florida. Modifying the Buck and Torgesen research required the DIBELS ORF to be substituted for the SRP ORF, and the diverse subgroup sample sizes to adequately resemble the typical student population who attended Reading First funded schools in South Florida. Even though Roehrig et al. included a much larger diverse sample than Buck and Torgesen, the African American sample used in Roehrig et al.'s study did not adequately represent the much larger African American population who attended Reading First funded schools in South Florida.

When the Roehrig et al. (2008) study was conducted the DIBELS ORF assessment was administered four times a year, in contrast to the more recent administration schedule of three times a year, as based on recommendation of the DIBELS assessment developers (Good \& Kaminski, 2005). This administration discrepancy created a need to modify that portion of the research as well. Using DIBELS ORF data collected three times a school year adequately addressed the requirements mandated by the Florida Reading First assessment plan (Torgesen, 2003), and followed recommendations of the DIBELS developers (Good \& Kaminski, 2005). Analysis results vary according to calibrations that exist between the risk-level cut scores for the DIBELS ORF assessment depending on the exact number of data reference points, three or four, reported during each school year.

Neither the Buck and Torgesen (2002) or Roehrig et al. (2008) research studies allowed for generalization across the population of students who attended Reading First funded schools in South Florida. There must be more closely matched methods employed 
when analyzing the power of the DIBELS ORF progress-monitoring assessment for predicting reading comprehension achievement on the FCAT-SSS Reading measure.

\section{ORF and Reading Achievement Assessments in Delaware}

Members of the Education Research and Development department at the University of Delaware sought to determine if a relationship existed between performance on the DIBELS ORF progress-monitoring assessment and the reading portion of the state-mandated Delaware Student Testing Program (DSTP) assessment for third grade students (Uribe-Zarain, 2006). The purpose was to establish if the DIBELS ORF assessment could be used as a reliable predictor of reading performance on their state-mandated test, the DSTP in reading comprehension (Uribe-Zarain, 2006). UribeZarain included an analysis using disaggregated data of specific subgroups, which consisted of students from varied racial/ethnic and socioeconomic backgrounds.

Participants of this study included 652 third grade students in Delaware who attended nine different schools throughout the state and participated in the Reading First Initiative during the 2004-05 school year (Uribe-Zarain, 2006). From the sample of 652 third grade students 50\% were girls and 50\% were boys, $15 \%$ were classified as special education students, less than 3\% were considered limited English proficient, and 59\% were considered of low-income status classified by eligibility for free or reduced lunch (Uribe-Zarain, 2006). The racial composition consisted of 47.2\% African American, 44.3\% White, 6.6\% Hispanic, 1.4\% Asian, and 0.5\% American Indian (Uribe-Zarain, 2006).

Results of Uribe-Zarain's (2006) study indicated an overall significant correlation $(\mathrm{r}=.61, p<.01)$ between the students' DIBELS ORF scores and reading portion of the 
state test (DSTP) when the data were analyzed for the entire third grade sample of students. Uribe-Zarain identified two groups of students who did not perform as was expected. Of these two groups, one included students who were characterized as being false positive (see Figure 1), as they failed the DIBELS ORF progress-monitoring assessment yet performed satisfactorily on the reading DSTP criterion-referenced outcome assessment (Uribe-Zarain, 2006). The other group included students characterized as being false negative (see Figure 1), as they passed the DIBELS ORF progress-monitoring assessment yet failed the reading DSTP criterion outcome assessment (Uribe-Zarain, 2006).

\begin{tabular}{|c|c|c|}
\hline Assessments & DIBELS ORF - Passed & DIBELS ORF - Failed \\
\hline DSTP Comprehension - Passed & & False Positive \\
\hline DSTP Comprehension - Failed & False Negative & \\
\hline
\end{tabular}

Figure 1. False positive and false negative classifications based on pass/fail of the DIBELS ORF and DSTP Reading Comprehension assessments.

These two groups of students, falling into the false positive and false negative categories, have likely been provided inadequate instruction based on their performance on the DIBELS ORF progress-monitoring assessment. The critical implications are that some students would receive intervention instruction based on the results of their failing score on the DIBELS ORF assessment, even though they may not have needed intervention instruction. Likewise, other students who did not receive intervention instruction based on the results of their passing score on the DIBELS ORF assessment may have actually been in need of intervention instruction. Although correlations have been established in similar research studies, they are often conducted for the general student population combined, with no regard for the specific subgroups of diverse 
populations. These correlational interpretations may overlook many other students for which there may not be a large enough sample, such as the ethnic/racial minority and low socioeconomic status subgroups for which Uribe-Zarain (2006) has disaggregated the data and further analyzed.

Uribe-Zarain's (2006) disaggregation and analyses of the data into subgroups, to determine if certain demographic groups achieved better performance results than others, were powerful. By disaggregating the data into specific subgroups, according to racial/ethnic composition and socioeconomic status, the results of the correlation coefficients varied widely. Prior to the data disaggregation of these two subgroups, Uribe-Zarain obtained a strong correlation between performance on the DIBELS ORF assessment and the DSTP assessment in reading, but when the data were disaggregated for these two demographic subgroups the correlations proved far weaker. Uribe-Zarain determined that the majority of the false negative cases were the African American students, and the majority of the false positive cases were students from low-income families.

Given the significance of this finding in Uribe-Zarain's (2006) research, data disaggregation was conducted in the current study. Data disaggregation by subgroups of students is of special concern because Adequate Yearly Progress (AYP) is a federal mandate, as part of the NCLB Act of 2001, which requires schools to demonstrate progress among all subgroups of students (FDOE, 2007), including the specific types of student subgroups reported in Uribe-Zarain's research. If past research studies have missed this vital piece of disaggregated data analyses, this could have severely affected the reported correlation results. By disaggregating the data according to student 
subgroups that included larger diverse populations, the reported results would have likely been quite different, and warrant further exploration.

At the conclusion of Uribe-Zarain's (2006) report, the researcher cautioned that although all assessment data analyzed were obtained during the spring of 2005 , the DSTP performance level cut scores for third grade reading were revised. Current and past cut scores for the DSTP can be found on the Delaware Department of Education website (Uribe-Zarain, 2006).

\section{ORF and Reading Achievement Assessments in Pennsylvania}

Kloo (2006) conducted this study primarily to determine if there was a statistically significant relationship between the data obtained from two early reading assessments. Kloo further examined the predictive ability of the first assessment, designated as a progress-monitoring measure, toward the second assessment, designated as a high-stakes outcome measure. Data for these two assessments were retrieved from 145 schools located within the state of Pennsylvania that participated in the federally funded Reading First Initiative (Kloo, 2006).

Kloo (2006) employed the DIBELS ORF subtest as the progress-monitoring assessment and the Pennsylvania System of School Assessment (PSSA) as the standardized criterion-referenced outcome reading assessment. Kloo disaggregated her data into subgroups by racial/ethnic background and socioeconomic status to determine the predictive ability of DIBELS ORF to the PSSA. These types of disaggregated data analyses according to student demographic subgroups have been similarly conducted in other related research and proved to indicate significant differences in the predictive ability of the DIBELS ORF assessment toward other state-mandated high-stakes reading 
tests (Uribe-Zarain, 2006). Although large scale statistical analyses employing disaggregated data among student subgroups, specifically between the DIBELS ORF and the FCAT-SSS Reading assessments, have previously been conducted in Florida (Roehrig et al., 2008), the sample size for some of the diverse subgroups have been particularly low.

Kloo (2006) focused on longitudinal data over three grade levels (Grades 1, 2, and 3), and used a variety of the DIBELS fluency subtests measured at three different times throughout each grade level. The analyses that Kloo conducted included several of the DIBELS subtests her sample of students were administered as first and second graders, including the Phoneme Segmentation Fluency (PSF) subtest and the Nonsense Word Fluency (NWF) subtest in addition to the Oral Reading Fluency (ORF) subtest. The ORF assessment was the only DIBELS subtest administered to third graders. Kloo analyzed the DIBELS subtest data longitudinally for the same set of students at Grades 1, 2, and 3 to determine correlation between all of these DIBELS subtests, as well as the predictive ability of the DIBELS subtests to the PSSA outcome assessment measure administered at third grade. Kloo determined that some of the DIBELS subtest data provided more predictive power than other subtests.

Kloo (2006) reported the true positive and true negative data (see Figure 2) as well as the false positive and false negative data (see Figure 2) she obtained when determining the relationship of the predictor measure (DIBELS) to Pennsylvania's highstakes reading outcome measure (PSSA). The true positive and true negative relationships clearly identified those students for which the DIBELS measure provided a strong predictive relationship for performance on the PSSA (Kloo, 2006). There were 
many students for whom this predictive relationship was established, but these are the students who most obviously can be predicted to perform nearly the same on each of these two measures (Kloo, 2006).

\begin{tabular}{|c|c|c|}
\hline Assessments & DIBELS ORF - Passed & DIBELS ORF - Failed \\
\hline PSSA Comprehension - Passed & True Negative & False Positive \\
\hline PSSA Comprehension - Failed & False Negative & True Positive \\
\hline
\end{tabular}

Figure 2. True positive, true negative, false positive, and false negative classifications based on pass/fail of the DIBELS ORF and PSSA Reading Comprehension assessments.

Kloo (2006) analyzed data obtained from several subtest measures of the DIBELS assessment across three grade levels (first through third), and how the subtests contributed to the predictive ability of reading success on the PSSA outcome measure administered at third grade. It was determined by Kloo that several of the subtest assessments did not produce high predictive power. Kloo found that the DIBELS subtests of PSF and NWF were found to produce high numbers of false positives and false negatives, and did not correlate significantly to achievement on the PSSA.

The data that Kloo (2006) analyzed did not produce a significant correlation between some of the DIBELS subtests when compared to the PSSA, despite the claim of the DIBELS authors with regard to its highly predictive power of performance on highstakes tests (Good \& Kaminski, 2005). Although Kloo found that the DIBELS ORF subtest was better correlated to the PSSA measure, there were still many false negatives and false positives. Kloo stated statistically these false negatives and false positives produced an acceptable amount, but practically speaking it was unacceptable. Kloo's concern that, even if for a modest number, these mislabeled students would either not receive reading intervention instruction when needed or would receive reading 
intervention instruction when not needed. Kloo reiterated that, for practical purposes, teachers would not be happy with this rate of student misidentification.

\section{ORF and Reading Achievement Assessments in Tennessee}

In this study, conducted by Riedel (2007), the primary differences when compared to the four previous studies conducted by Buck and Torgesen (2002); Kloo (2006); Roehrig, Petscher, Nettles, Hudson, and Torgesen (2008); and Uribe-Zarain (2006) related to the sample of students and the standardized reading comprehension tests administered. Riedel's sample in this study did not include third grade students, and as such did not incorporate the use of a high-stakes state-mandated reading comprehension test as did the other researchers. Although Riedel used data from two standardized tests of reading comprehension, they were not mandated for use by the Tennessee Department of Education.

During the course of Riedel's (2007) research, he indicated that the developers of the DIBELS assessment stated the DIBELS fluency assessment facilitates the prediction of future reading difficulty (Good \& Kaminski, 2005). Although Riedel found consistent agreement in previous research supporting the fact that comprehension of text is the major goal of reading, he found just as much opposition to the value of using DIBELS fluency data as an adequate indicator for predicting reading comprehension achievement (Riedel, 2007).

After critically evaluating the current research, Riedel (2007) found evidence to support a correlation between performance on the DIBELS ORF subtest and reading comprehension assessments, among older students in third grade. Riedel noted the absence of research however, for determining this type of relationship among younger 
students in first and second grades, and the impact that data obtained from other fluency subtests of DIBELS, typically administered to younger students, had upon predicting the performance of primary level students on measures of reading comprehension.

Riedel's (2007) sample included 1,518 first grade students attending school in an urban setting within the Memphis City Schools, itself a large urban school district in Tennessee. His sample consisted mostly of African American youngsters, which comprised $92 \%$ of his sample $(n=1,395)$. There was equivalent representation by gender with 760 female students and 758 male students. A large portion of the sample consisted of children living in poverty, with $85 \%$ of them qualifying for free or reduced-cost lunch. The English Language Learner (ELL) population in this school was low; therefore, Riedel's sample contained only 59 ELL students of the original sample of 1,518.

Even though Riedel (2007) began with 1,518 participants, because of assessment data availability, his final research resulted in a sample of 1,224 when analyzing the predictive ability of the Group Reading Assessment and Diagnostic Evaluation $(\mathrm{GRA}+\mathrm{DE})$ results from the DIBELS data, and a sample of 1,054 when analyzing the predictive ability of the TerraNova Reading subtest results from the DIBELS data.

Riedel (2007) administered three sets of assessments to his sample participants. The first set of assessments, administered individually to participants, were the DIBELS Letter Naming Fluency (LNF), Phoneme Segmentation Fluency (PSF), Nonsense Word Fluency (NWF), Oral Reading Fluency (ORF), and Retell Fluency (RF) subtests (Riedel). These DIBELS subtests were administered three times during first grade: in the beginning of the year, in the middle of the year, and at the end of the year (Riedel, 2007). The second set of assessments, administered to participants in a group, were the 
GRA+DE, which tests overall reading ability using subtests for vocabulary and comprehension (Riedel, 2007). The GRA+DE assessment was administered once at the end of first grade (Riedel, 2007). The final assessment, administered to participants in a group was the TerraNova Reading subtest, which measures reading comprehension (Riedel, 2007). The TerraNova assessment was administered once at the end of second grade, as this original sample of first grade students became second graders (Riedel, 2007).

The DIBELS and GRA+DE assessments were administered to the participants during their first grade school year (2003-04); however, the TerraNova assessment was not administered until the following school year (2004-05) when these former first grade students were promoted to second grade (Riedel, 2007). According to Riedel, the reason for administering two different reading comprehension assessments, the GRA+DE and TerraNova, was twofold. First, in this school district the TerraNova assessment was not required for administration to all first grade students; therefore, some first grade students did not have TerraNova results (Riedel, 2007). Second, the GRA+DE assessment was not administered during the 2004-05 school year, when this sample of students entered second grade, therefore administration of the TerraNova was required to determine second grade results (Riedel, 2007). Also by administering the TerraNova in second grade, Riedel was able to analyze the data over a longer period of time, capitalizing on longitudinal results.

When DIBELS proved to be a poor predictor of comprehension for some students, Riedel (2007) initially employed Receiver Operating Characteristic (ROC) analyses to determine which of the DIBELS fluency subtests would serve as the most 
effective predictor variables. Most commonly used in medical research, ROC analyses provide support determining which predictor variables, among several, are most optimal to research models. ROC analyses supported Riedel's decision to narrow his selection to two DIBELS subtest measures, NWF and ORF, as predictors of achievement in reading comprehension. Riedel conducted further analyses using ANOVA, chi-square, and logistic regression. He also computed Pearson correlation analyses separately between each of the DIBELS subtests and the reading comprehension measures to determine the strength of their relationships (Riedel, 2007).

Riedel (2007) found the ORF subtest, when administered to first grade students, proved to be the best DIBELS subtest predictor, as well as the most strongly correlated for both the first grade and second grade reading comprehension measures. Of little surprise to Riedel, the first grade DIBELS ORF scores better predicted Grade 1 comprehension (79.5\%) than comprehension in Grade $2(71.8 \%)$, although the relationship remained high even in second grade. The remaining DIBELS subtests of LNF, PSF, NWF, and RF provided much less predictive ability of achievement on the reading comprehension measures (Riedel, 2007). Even when Riedel added the RF subtest to the ORF, the increase in predictive ability only rose by $0.2 \%$ at Grade 1 and $0.6 \%$ at Grade 2. In the time it takes to administer the RF subtest, the slight rise in predictive ability does not warrant its administration, especially given the common concern that assessment takes precious time away from instruction (Riedel, 2007).

Additional variables of vocabulary, gender, and socioeconomic status were examined by Riedel (2007) to determine their contribution to the misclassification of the comprehension status for some students in the sample. Riedel determined that vocabulary 
made a significant difference between those groups who performed well on DIBELS ORF, yet varied in their achievement in reading comprehension. As might be expected, the group of students who demonstrated poor comprehension produced significantly lower scores in vocabulary than did the group who exhibited satisfactory comprehension (Riedel, 2007). Riedel also found that for students who performed poorly on DIBELS ORF, but maintained satisfactory comprehension, they likewise scored significantly higher in vocabulary than those students who scored poorly in comprehension. Gender and socioeconomic status provided much less significance to the findings, according to Riedel, than did vocabulary ability. Riedel found that DIBELS ORF proved to be a statistically significant predictor of reading comprehension, however when he combined vocabulary with DIBELS ORF the statistical significance as a predictor rose only slightly from $79.5 \%$ to $82.7 \%$.

Even for younger students, such as the first and second graders in this study conducted by Riedel (2007), the longitudinal collection and analyses of data appears to be a key factor in determining the sustainability of the relationship between oral reading fluency and reading comprehension.

\section{Impact of the Federal Reading First Initiative}

The key findings of the research team that released the Reading First Impact Study: Final Report have raised significant concerns for schools that participated in the Reading First Initiative (Gamse, Jacob, Horst, Boulay, \& Unlu, 2008). Gamse et al. concluded that following years of funding through Reading First, although nationally there has been a consistent positive effect on the instruction of early reading, there has been no statistically significant impact on achievement in reading comprehension. 
Due to this significant finding, this researcher decided to include a longitudinal aspect into this current study as well. It was imperative to identify potential reading deficiencies and begin focusing on differentiated intervention instruction that targets the specific needs of students as early as possible (Buck \& Torgesen, 2002; Hintze \& Silberglitt, 2005). The earlier intervention needs are identified, the greater likelihood the reading deficiencies can be remedied (Juel, 1988).

As this researcher focused on a sample of older third grade students required to pass a state-mandated reading comprehension test at the end of third grade, longitudinal analyses of data obtained from this group of students one and two years prior, as first and second graders, provided the guidance necessary for identifying and supporting their academic needs earlier. Although this researcher had previously considered administering the DIBELS Retell Fluency (RF) subtest along with the ORF subtest, based on Riedel's conclusions the RF subtest did not substantially affect the relationship between the DIBELS ORF and reading comprehension measures as might be expected. The saturation of student assessment is a critical issue within the school district in which this researcher conducted this study. As such, analyses were limited to the use of archived data obtained from assessments that were previously required for administration within Reading First funded schools throughout the district.

Although there is a growing body of research that closely matches this topic, the conflicting analyses cause concern. As some research provides convincing evidence that the DIBELS ORF assessment provides valuable data toward predicting reading comprehension achievement, other research negates its contributable value. It was this researcher's plan to clarify the value of the DIBELS ORF assessment for progress- 
monitoring and instructional planning, depending on how closely it related to and predicted performance on the FCAT-SSS Reading as a measure of reading comprehension achievement for third grade students.

\section{Summary}

Reading fluency development is a complex process, yet precisely how fluency development, an essential component of reading instruction, affects proficient reading as measured by achievement in reading comprehension, remains unanswered. A gap in the research, addressed in this current study, focused on how the DIBELS ORF assessment as measured in first, second, and third grades correlated to, and provided as a predictor for, reading comprehension achievement as measured by the FCAT-SSS Reading for the same students as third graders.

This researcher has often administered oral reading fluency assessments and listened to young learners read the passages where rapid reading continues to dominate, despite numerous miscues in word recognition. Often times the miscues have been very careless substitutions, for which it has been suggested these errors can be attributed to the speed at which the passages are read. Additionally, these same young learners have read oral reading fluency passages with inaccurate phrasing and have devoted minimal attention to appropriate expression and intonation. It appears as though many of these rapid readers have been focused more intently on word-level skills, reading the passages word-by-word, rather than focusing on the overall message of the text. Whenever this occurs, reading for meaning is clearly lost.

If students are unable to comprehend the text of oral reading fluency assessment passages, this same behavior and lack of comprehension may transfer to a variety of 
reading experiences including other assessments. This transfer may even occur during the administration of state-mandated reading comprehension achievement tests, which also serve as high-stakes accountability measures that are accompanied with punitive outcomes. Young learners who score well on oral reading fluency assessments, by virtue of achieving a highly elevated score based on the number of words read correctly per minute, may not perform as well on tests of reading comprehension, if similar rapid reading behaviors are applied, as likely comprehension will be compromised.

Among the research previously conducted to determine if a correlation exists between an oral reading fluency assessment, such as the DIBELS ORF, and statemandated high-stakes standardized reading comprehension tests administered in third grade, such as the FCAT-SSS or the DSTP or the PSSA, it has been determined there are many students who have produced false positive and false negative data when analyzing the predictive ability of one assessment toward the other (Buck \& Torgesen, 2002; Kloo, 2006; Roehrig, Petscher, Nettles, Hudson, \& Torgesen, 2008; Uribe-Zarain, 2006). Students who produced false positive and false negative data were often members of the racial and ethnic minority and lower socioeconomic status subgroups, which when represented in previous research studies produced a large number of members (Buck \& Torgesen, 2002; Kloo, 2006; Roehrig et al., 2008; Uribe-Zarain, 2006). For these groups of students, who have been incorrectly identified as either a struggling reader or a proficient reader according to their performance on the oral reading fluency assessment when compared to their performance on the state high-stakes outcome reading assessment (FCAT-SSS or DSTP or PSSA), there should be concern. Great emphasis has been placed upon the utility of the oral reading fluency instrument to predict future 
success on state-mandated high-stakes standardized achievement tests in reading comprehension; therefore, it is imperative that further research be conducted to address the correlation of achievement for these specific diverse subgroups.

This researcher's current study likewise addressed the extent that a correlation exists between oral reading fluency ability and achievement in reading comprehension, as well as the predictive power that oral reading fluency development provides toward reading comprehension achievement. Specific modifications to the original design of the aforementioned studies conducted by Buck and Torgesen (2002), Kloo (2006), Riedel, (2007), Roehrig et al. (2008), and Uribe-Zarain (2006) are reflected in this current study and identified in Chapter 3.

This researcher has analyzed data obtained from the DIBELS ORF assessment and the state-mandated standardized FCAT-SSS Reading assessment, as was required for administration in Reading First funded schools within the state of Florida. Additionally, this researcher disaggregated the data collected from student subgroups based on gender, race/ethnicity, and socioeconomic status, which produced significant findings in previous research conducted in Florida (Roehrig et al., 2008), Delaware (Uribe-Zarain, 2006) and Pennsylvania (Kloo, 2006). 


\section{CHAPTER III}

\section{METHODS}

A longitudinal, predictive research design was employed in this current nonexperimental quantitative methods study (Johnson, 2001) using archived secondary data to investigate (a) the extent to which oral reading fluency and reading comprehension achievement are related, and (b) the extent to which oral reading fluency ability measured longitudinally in first, second, and third grades predicts achievement in reading comprehension in third grade among a sample of young learners with varied demographic backgrounds.

This chapter begins with a description of the participants in relationship to the population for which the sample was generalized. Description of the instrumentation used to measure the constructs is presented next, followed by origin of the targeted data and the process employed in data collection. The research questions explored in this study, along with the specific statistical techniques employed in the data analyses conclude this chapter.

\section{Participants}

Targeted for this study was a population of 2,744 third grade students attending a cohort of 25 Reading First funded schools within a large urban/suburban South Florida school district during the 2008-09 school year (Florida Department of Education [FDOE], 2008b). Although the intent was to include all 2,744 students as participants in this study, reality prevented many from participating due to attrition, attributed to students missing targeted archived data and/or experiencing previous grade level retentions. The sample was further reduced to 1,663 third grade students who met all participation criteria. 
Ensuring an adequate sample size is critical toward achieving sufficient statistical power (Soper, 2009). The district sample of 1,663 participants provided adequate representation for the population of third grade students administered the Florida Comprehensive Assessment Test of the Sunshine State Standards in Reading (FCAT-SSS Reading) in a large South Florida county (19,567 students district-wide) and throughout Florida (204,251 students statewide; FDOE, 2009).

Based on a probability of alpha equal to .05 , using three predictor variables and an anticipated effect size of .10, it was determined that a sample size of 2,000 would provide a statistical power of .99+ (Hinkle, Wiersma, \& Jurs, 2003). The original estimated sample of 2,000 was further reduced through attrition to 1,663 students who possessed all appropriate archived assessment data and no previous grade level retentions in the first, second, or third grades. If needed, using a sample of as low as 1,000 participants would continue to yield a power of .99+ (Hinkle et al., 2003), therefore the actual 1,663 students provided an effective sample size.

This single cohort of 25 schools was designated as the district's first group to become recipients awarded federal grant funding for participation in the Reading First Initiative. Although the 25 Reading First funded schools of this single cohort were widely scattered encompassing all three geographical areas of the district (north, central, and south), they tended to be located in lower socioeconomic areas, and contained large ethnically and racially diverse student populations. A school-by-school distribution of the 2,744 third grade students attending each of these 25 Cohort One district schools during the 2008-09 school year is represented in Table 1 (FDOE, 2008b). 
Table 1

Population of Third Grade Students Attending Cohort One Schools During the 2008-09 School Year

\begin{tabular}{|c|c|}
\hline Cohort school & Population \\
\hline School 1 & 105 \\
\hline School 2 & 111 \\
\hline School 3 & 131 \\
\hline School 4 & 134 \\
\hline School 5 & 95 \\
\hline School 6 & 94 \\
\hline School 7 & 113 \\
\hline School 8 & 116 \\
\hline School 9 & 175 \\
\hline School 10 & 98 \\
\hline School 11 & 156 \\
\hline School 12 & 65 \\
\hline School 13 & 79 \\
\hline School 14 & 127 \\
\hline School 15 & 81 \\
\hline School 16 & 91 \\
\hline School 17 & 154 \\
\hline School 18 & 58 \\
\hline School 19 & 121 \\
\hline School 20 & 140 \\
\hline School 21 & 106 \\
\hline School 22 & 105 \\
\hline School 23 & 83 \\
\hline School 24 & 54 \\
\hline School 25 & 152 \\
\hline Total students & 2,744 \\
\hline
\end{tabular}


During the 2008-09 school year, 20,089 third grade students were in attendance district-wide, while statewide 208,956 third grade students were in attendance in public schools throughout Florida (FDOE, 2008b). The 1,663 students targeted for participation in this study reflected approximately $8 \%$ of the district-wide third grade student population and just a little less than $1 \%$ of the statewide third grade student population in 2008-09.

The sample of 1,663 students in this current study included all eligible students in the cohort who maintained a third grade placement during the spring of 2009, and experienced no prior retentions in first, second, or third grades. Third grade students of this cohort were excluded from the sample if they did not fit all the variables listed. Because this current study employed only secondary data analyses, the sample was further limited to the availability of archived student data.

Of the 1,663 students targeted in this study, the criteria required four data assessment points, coded as assessments (a), (b), (c), and (d), and defined as follows:

(a) first grade DIBELS ORF assessment administered in the spring of 2007,

(b) second grade DIBELS ORF assessment administered in the spring of 2008,

(c) third grade DIBELS ORF assessment administered in the spring of 2009, and

(d) third grade FCAT-SSS Reading administered in the spring of 2009.

The sample included only those students who had valid data for all four of the specific assessments listed above. All assessment data were collected during the identified grade levels that correlated to the specific school years indicated.

This large South Florida school district currently represents the nation's sixth largest public school district, serving the educational needs of more than 256,000 students 
in Grades K-12, and is recognized nationally as the largest fully-accredited public school district (National Center for Education Statistics [NCES], 2010; Proximity One, 2010a \& b; Teach in Florida, 2010). Spanning a large geographical area in South Florida, this school district manages a diverse mix of urban and suburban educational sites. The district-wide diversity breakdown of the 256,355 students includes (a) $37.9 \%$ Black, (b) 29.4\% White, (c) $26.1 \%$ Hispanic, (d) 6.6\% Other (3.4\% Asian, 3.0\% Multiracial, and $0.2 \%$ Native American combined; FDOE, 2008b). This is compared to a statewide distribution of (a) $23.0 \%$ Black, (b) $45.3 \%$ White, (c) $25.0 \%$ Hispanic, (d) $6.7 \%$ Other (2.5\% Asian, 3.9\% Multiracial, and 0.3\% Native American combined; FDOE, 2008b). When compared to the State of Florida, this South Florida school district reflects a larger difference in diversity between the Black and White student populations, with a relatively equal percentage of Hispanic and Other (Asian, Multiracial, and Native American combined) student populations, as indicated in Table 2 (FDOE, 2008b).

Table 2

Comparison of State and District Demographics of Student Population In Attendance During the 2008-09 School Year

\begin{tabular}{lcccc}
\hline District / State & Black & White & Hispanic & Other $^{\wedge}$ \\
\hline South Florida District & $37.9 \%$ & $29.4 \%$ & $26.1 \%$ & $6.6 \%$ \\
State of Florida & $23.0 \%$ & $45.3 \%$ & $25.0 \%$ & $6.7 \%$ \\
\hline Diversity difference & $+14.9 \%$ & $-15.9 \%$ & $+1.1 \%$ & $-0.1 \%$ \\
\hline
\end{tabular}

Note. ${ }^{\wedge}$ Other includes Asian, Multiracial, and Native American populations.

The sample distribution of students within the Cohort One schools, contained larger populations of students with diverse backgrounds, providing substantial targeted data required for these analyses, according to the following demographic areas planned 
for subgroup disaggregation: (a) gender (male, female), (b) race/ethnicity (Black, White, Hispanic, Other), and (c) socioeconomic status (low, moderate). As indicated in Table 3, the student diversity among the majority $(68 \%)$ of these Cohort One schools reflected similar patterns of predominantly Black student populations when compared to the White and Hispanic populations (FDOE, 2008b). A very different trend in student diversity was reflected in a smaller number (32\%) of the Cohort One schools, with $16 \%$ of the schools reflecting a more evenly distributed balance between the Black, White, and Hispanic student populations, and another $16 \%$ of the schools reflecting either a Black or White student population of less than $13 \%$ at the school, as indicated in Table 3 (FDOE, 2008b). The majority of the student population within the 25 Cohort One schools were members of low-income families, evidenced by the high percentage of students eligible for free or reduced lunch, as indicated in Table 3 (FDOE, 2008b). All but one of the schools (24) reported greater than $72 \%$ of their students meeting eligibility requirements for free or reduced lunch, and only one school reported just less than $50 \%$ of the student population (47.8\%) eligible for this service (FDOE, 2008b). Greater than $90 \%$ of the student population in half of these Cohort One schools met eligibility for free or reduced lunch (FDOE, 2008b), providing ample data for analyzing the needs of students from lower socioeconomic backgrounds, for whom the available research remains limited. 
Table 3

Demographics of School-wide Student Population Attending Cohort One Schools During the 2008-09 School Year

\begin{tabular}{|c|c|c|c|c|c|c|c|}
\hline \multirow{2}{*}{$\begin{array}{l}\text { Cohort } \\
\text { school }\end{array}$} & \multicolumn{2}{|c|}{ Gender } & \multicolumn{4}{|c|}{ Race/ethnicity } & \multirow{2}{*}{$\begin{array}{c}\text { Free/Reduced } \\
\text { lunch }\end{array}$} \\
\hline & Male & Female & Black & White & Hispanic & Other $^{\wedge}$ & \\
\hline School 1 & $46.0 \%$ & $54.0 \%$ & $69.5 \%$ & $7.9 \%$ & $18.7 \%$ & $3.9 \%$ & $90.3 \%$ \\
\hline School 2 & $49.8 \%$ & $50.2 \%$ & $97.0 \%$ & $0.8 \%$ & $0.5 \%$ & $1.7 \%$ & $88.3 \%$ \\
\hline School 3 & $55.0 \%$ & $45.0 \%$ & $97.7 \%$ & $0.8 \%$ & $0.7 \%$ & $0.8 \%$ & $91.9 \%$ \\
\hline School 4 & $51.5 \%$ & $48.5 \%$ & $40.5 \%$ & $25.3 \%$ & $25.3 \%$ & $8.8 \%$ & $74.5 \%$ \\
\hline School 5 & $55.1 \%$ & $44.9 \%$ & $33.8 \%$ & $28.8 \%$ & $28.7 \%$ & $8.6 \%$ & $74.4 \%$ \\
\hline School 6 & $51.5 \%$ & $48.5 \%$ & $33.9 \%$ & $25.8 \%$ & $32.4 \%$ & $7.9 \%$ & $78.0 \%$ \\
\hline School 7 & $48.0 \%$ & $52.0 \%$ & $88.7 \%$ & $3.7 \%$ & $6.2 \%$ & $1.4 \%$ & $93.9 \%$ \\
\hline School 8 & $52.7 \%$ & $47.3 \%$ & $98.2 \%$ & $0.3 \%$ & $0.9 \%$ & $0.6 \%$ & $91.8 \%$ \\
\hline School 9 & $50.4 \%$ & $49.6 \%$ & $83.8 \%$ & $1.1 \%$ & $11.2 \%$ & $3.8 \%$ & $72.4 \%$ \\
\hline School 10 & $52.2 \%$ & $47.8 \%$ & $10.2 \%$ & $51.8 \%$ & $29.2 \%$ & $8.8 \%$ & $47.8 \%$ \\
\hline School 11 & $52.0 \%$ & $48.0 \%$ & $64.7 \%$ & $6.1 \%$ & $24.4 \%$ & $4.8 \%$ & $85.2 \%$ \\
\hline School 12 & $54.0 \%$ & $46.0 \%$ & $98.0 \%$ & $0.9 \%$ & $0.2 \%$ & $0.8 \%$ & $89.8 \%$ \\
\hline School 13 & $50.3 \%$ & $49.7 \%$ & $97.9 \%$ & $0.2 \%$ & $1.3 \%$ & $0.6 \%$ & $98.5 \%$ \\
\hline School 14 & $55.9 \%$ & $44.1 \%$ & $94.4 \%$ & $1.8 \%$ & $1.4 \%$ & $2.3 \%$ & $95.2 \%$ \\
\hline School 15 & $46.1 \%$ & $53.9 \%$ & $70.5 \%$ & $2.2 \%$ & $26.5 \%$ & $0.8 \%$ & $95.4 \%$ \\
\hline School 16 & $51.3 \%$ & $48.7 \%$ & $94.2 \%$ & $0.9 \%$ & $2.3 \%$ & $2.7 \%$ & $97.5 \%$ \\
\hline School 17 & $51.2 \%$ & $48.8 \%$ & $79.0 \%$ & $2.4 \%$ & $13.7 \%$ & $4.9 \%$ & $91.7 \%$ \\
\hline School 18 & $50.7 \%$ & $49.3 \%$ & $94.7 \%$ & $0.7 \%$ & $3.4 \%$ & $1.1 \%$ & $99.1 \%$ \\
\hline School 19 & $51.8 \%$ & $48.2 \%$ & $33.1 \%$ & $24.0 \%$ & $36.5 \%$ & $6.3 \%$ & $76.9 \%$ \\
\hline School 20 & $51.6 \%$ & $48.4 \%$ & $46.4 \%$ & $12.3 \%$ & $34.9 \%$ & $6.3 \%$ & $73.6 \%$ \\
\hline School 21 & $50.4 \%$ & $49.6 \%$ & $55.7 \%$ & $5.4 \%$ & $36.2 \%$ & $2.6 \%$ & $86.3 \%$ \\
\hline School 22 & $53.8 \%$ & $46.2 \%$ & $96.3 \%$ & $0.1 \%$ & $1.9 \%$ & $1.7 \%$ & $94.1 \%$ \\
\hline School 23 & $53.1 \%$ & $46.9 \%$ & $91.9 \%$ & $0.8 \%$ & $6.0 \%$ & $1.4 \%$ & $89.4 \%$ \\
\hline School 24 & $56.8 \%$ & $43.2 \%$ & $97.3 \%$ & $1.0 \%$ & $0.7 \%$ & $1.0 \%$ & $92.6 \%$ \\
\hline School 25 & $53.6 \%$ & $46.4 \%$ & $86.3 \%$ & $2.3 \%$ & $6.3 \%$ & $5.1 \%$ & $85.2 \%$ \\
\hline
\end{tabular}

Note. ${ }^{\wedge}$ Other includes Asian, Multiracial, and Native American populations. 


\section{Instrumentation}

The two early reading assessments, designated for measuring oral reading fluency ability and reading comprehension achievement, are the Dynamic Indicators of Basic Early Literacy Skills in Oral Reading Fluency (DIBELS ORF) progress-monitoring assessment and the Florida Comprehensive Assessment Test of the Sunshine State Standards in Reading (FCAT-SSS Reading) outcome assessment. These two early reading assessments were mandated for administration in all Reading First participating schools within Florida throughout the 6 years the Reading First Initiative was funded, 2003-2009 (Torgesen, 2003).

\section{DIBELS}

The Dynamic Indicators of Basic Early Literacy Skills (DIBELS), a standardized progress-monitoring assessment tool, contains five oral reading fluency subtests of early pre-reading and reading skills that are used as early predictive measures of reading achievement (Good \& Kaminski, 2005). The five fluency subtests of DIBELS consist of letter-naming fluency, initial sounds fluency, phoneme segmentation fluency, nonsense word fluency, and oral reading fluency.

The Oral Reading Fluency (ORF) assessment was the only subtest of DIBELS required for administration to third grade students at Reading First funded schools within the state of Florida (Torgesen, 2003), and for this study was the only DIBELS subtest data collected and analyzed from prior administration at first and second grades as well. The ORF was administered to each student individually as a first, second, and third grader, in a one-on-one setting according to standardized procedures (Good \& Kaminski, 2005). 
The DIBELS ORF subtest consists of three oral reading fluency passages that are written at a readability level equivalent to student grade placement (Good \& Kaminski, 2005). Students are timed for 1 minute as they read each of the three passages orally. Scores are reported in number of words read correctly per minute. Errors are identified when words are omitted or substituted, and when hesitations occur that last more than 3 seconds (Good \& Kaminski, 2005). The median score achieved, based on the administration of all three passages, is then recorded as the overall DIBELS ORF score, reflecting oral reading fluency ability solely as the rate and accuracy of oral reading sustained for 1 minute (Good \& Kaminski, 2005; Torgesen, 2003).

The sixth edition of the DIBELS ORF assessment also contains an optional comprehension-scoring subtest measure of Retell Fluency (Good \& Kaminski, 2005). Although the Retell Fluency (RF) subtest of DIBELS ORF has been available, schools having participated in the Reading First Initiative within the state of Florida did not administer this assessment measure (Hudson, Lane, \& Pullen, 2005; Torgesen, 2003). Scoring of the DIBELS ORF subtest in Florida was reported solely as words read correct per minute (Torgesen, 2003).

The DIBELS ORF words-correct-per-minute score is further analyzed according to ability risk levels as indicated on the DIBELS Risk Levels Chart (FCRR, 2009a). Each of the four DIBELS ability risk levels comprises a range of words-correct-per-minute scores classified as follows:

- High risk - for students scoring seriously below grade level,

- Moderate risk - for students scoring moderately below grade level,

- Low risk - for students scoring at grade level, and 
- Above average - for students scoring at or above the $60^{\text {th }}$ percentile (FCRR, 2009a).

The range of words-correct-per-minute scores identified as parameters for each of the four ability risk levels, vary by grade levels as well as pre-, mid-, and post-assessment periods conducted during each school year. These DIBELS ORF benchmark goals for first, second, and third grade levels, specific only to the post-assessment period in the spring, are indicated in Table 4 (FCRR, 2009a), as these data were used for the current study. The DIBELS ability risk levels provide a guide for teachers to determine when reading intervention instruction for students is warranted (FCRR, 2009a; Good \& Kaminski, 2005; Torgesen, 2003).

Table 4

Spring Benchmark Goals and Indicators of Risk For DIBELS ORF at Grades 1, 2, and 3

\begin{tabular}{cccc}
\hline \multirow{2}{*}{ Risk level } & \multicolumn{3}{c}{ Range of scores - Words read correctly per minute } \\
\cline { 2 - 4 } indicator & Spring - Grade 1 & Spring - Grade 2 & Spring - Grade 3 \\
\hline High risk & $0-19$ & $0-69$ & $0-79$ \\
Moderate risk & $20-39$ & $70-89$ & $80-109$ \\
Low risk & $40-64$ & $90-108$ & $110-128$ \\
Above average & $65+$ & $109+$ & $129+$ \\
\hline
\end{tabular}

Note. Effective July 2006, Revised September 2006 (FCRR, 2009a)

The DIBELS ORF subtest is based on the Curriculum Based Measurement (CBM) Reading assessments, originally developed at the University of Minnesota Institute for Research on Learning Disabilities (Deno, 1985). Through the CBM Reading assessments, researchers have provided evidence of psychometric quality for both the reliability and validity of DIBELS ORF passages (Good \& Jefferson, 1998; Tindal, 
Marston, \& Deno, 1983). The test-retest reliability of the oral reading fluency measure for most CBM Reading assessments ranges from .92 to .97 (Tindal et al., 1983). Alternate form reliability of different reading passages drawn from the same level ranges from .89 to .94 when alternate reading passages are administered (Tindal et al., 1983).

Criterion-related validity has been established for the CBM Reading assessment measure when correlated with various reading comprehension tests (e.g., WoodcockJohnson Psycho-Educational Battery, Stanford Diagnostic Reading Test) administered at the same time (Good \& Jefferson, 1998). Concurrent evidence of criterion-related validity has been reported in eight separate studies with coefficients ranging from .52 to .91 (Good \& Jefferson, 1998).

\section{FCAT-SSS Reading}

The Florida Comprehensive Assessment Test of the Sunshine State Standards (FCAT-SSS) Reading is administered once a year as a standardized criterion-referenced outcome assessment tool that provides measurement of achievement in reading comprehension. It is used as an indicator of the overall reading achievement for students in Grades 3-10, attending school in Florida (Florida Department of Education [FDOE], 2005, 2007). For third graders in the state of Florida, the FCAT-SSS Reading serves as a high-stakes accountability measure, using the scoring data as criteria for determining promotion to Grade 4. A score of Level 2 or greater on the FCAT-SSS Reading, on a scale of Levels 1 (lowest) through 5 (highest), is required to meet both state and district promotion criteria, and a score of Level 3 (reading proficiency on grade level) or greater is required to meet both state and district grade level expectations (FDOE, 2007, 2008a). 
For third grade students, the FCAT-SSS Reading is administered in a group setting during two 60-minute testing sessions that are scheduled on two consecutive days during the spring of each school year (FDOE, 2005, 2007, 2008c). The third grade FCAT-SSS Reading assessment contains both literary and informational reading passages (FDOE, 2005, 2008c). The passages are written at a readability level equivalent to student grade placement, and consist of $60 \%$ literary and $40 \%$ informational texts (FDOE, 2005, 2008c). There are approximately six to eight passages that vary in length and represent different content areas, (e.g., mathematics, science, social studies, the arts, language arts, and physical education; FDOE, 2005, 2008c). The passages range between 100-700 words, with an average of 350 words per text (FDOE, 2005, 2008c).

Each passage is accompanied by sets of comprehension questions in multiplechoice format that includes four response options, for a total of 50-55 comprehension items in the third grade FCAT-SSS Reading (FDOE, 2005, 2007, 2008c). The content focus of the FCAT-SSS Reading at Grade 3 consists of eight tested reading benchmarks contained within the following four clusters: words and phrases in context; main idea, plot, and purpose; comparisons and cause/effect; and reference and research (FDOE, 2005, 2007, 2008c). Test items within the four clusters on the third grade FCAT-SSS Reading range between $15-20 \%$ in words and phrases in context; $30-55 \%$ in main idea, plot, and purpose; $20-45 \%$ in comparison and cause and effect; and 5-15\% in reference and research (FDOE, 2005, 2008c).

The cognitive complexity level of the test items are based on Norman Webb's Depth of Knowledge, which focuses on expectations made of the test items in relationship to low, moderate, and high levels of complexity (FDOE, 2005, 2008c). The 
third grade FCAT-SSS Reading test items range between $25-35 \%$ at a low complexity level, $50-70 \%$ at a moderate complexity level, and $5-15 \%$ at a high complexity level (FDOE, 2005, 2008c). Due to the substantial infusion of moderate and high complexity level items into the FCAT-SSS Reading, students must employ higher level thinking to achieve optimal performance on the test.

As a standardized achievement test, the FCAT-SSS Reading meets all professional standards of psychometric quality for both reliability and validity (FDOE, 2007). The internal consistency reliability for the FCAT-SSS Reading is reported using Cronbach's alpha method of reliability, which provides an estimate of the reliability of test scores from a single test (FDOE, 2007). The Cronbach's alpha reliability coefficients for the third grade FCAT-SSS Reading remained consistently high at .89 across three consecutive years of administration, 2004-2006 (FDOE, 2007).

The Florida Department of Education has reported content-related and criterionrelated validity for the FCAT-SSS Reading. Content-related validity is the degree to which a test measures an intended content area. Important during test development, content validity is present as the FCAT-SSS Reading assesses content of the Sunshine State Standards and is developed using well-established content validation procedures (FDOE, 2007). These validation procedures are employed to provide evidence of content validity for the FCAT-SSS Reading and include test items written according to the following item specification guidelines developed in 2001:

- test items pilot tested using randomly selected groups of students at appropriate grade levels;

- reading passages and test items reviewed for cultural, ethnic, language, and gender bias; 
- passages and test items reviewed by instructional specialists and practicing teachers across the state of Florida; and

- test items field tested to determine their psychometric properties were included in the test to meet specific rigorous psychometric standards (FDOE, 2007)

Criterion-related evidence of validity is established through the correlation of one test with a criterion. Both the criterion-referenced FCAT-SSS Reading and the FCATNorm Referenced Test (NRT) Reading were administered at the same time during the spring of each school year, and were used for correlation to provide concurrent evidence of criterion validity (FDOE, 2007). During the administration years 2004 through 2006, significantly high correlations between the third grade FCAT-SSS and FCAT-NRT of .83 (2004 and 2005) and .84 (2006) were established, providing evidence of criterion-related validity (FDOE, 2007).

\section{Data Collection}

The data targeted for use in this current study included secondary data archived from the previous administration of two early reading assessments. These assessments were mandated for use in all district schools funded by the Reading First Initiative, and included the DIBELS ORF, administered to all first, second, and third grade students, and the FCAT-SSS Reading, administered to all third grade students (Torgesen, 2003).

Data collection involved gathering and charting the archived student assessment and demographic data previously posted to the District's Data Warehouse, a data collector system that is currently operated and maintained by the school district. The District's Education Technology Services (ETS) Department maintains student assessment and demographic data, and was responsible for supplying the archived student data as requested for use in this study. ETS released the requested archived data 
following written approval by the Institutional Review Board (IRB) in the Research and Evaluation Department of this school district and Florida International University.

\section{Data Analysis Plan}

Two research questions were addressed in this current study. For each research question, a variety of statistical analyses were performed.

\section{Research Question 1}

To what extent does early oral reading fluency ability measured in first, second, or third grade correlate with reading comprehension achievement in third grade?

Hypothesis 1. The early oral reading fluency ability measured in first grade will significantly correlate positively with reading comprehension achievement in third grade, as measured by the FCAT-SSS Reading (FDOE, 2005).

Hypothesis 2. The early oral reading fluency ability measured in second grade will significantly correlate positively with reading comprehension achievement in third grade, as measured by the FCAT-SSS Reading (FDOE, 2005).

Hypothesis 3. The early oral reading fluency ability measured in third grade will significantly correlate positively with reading comprehension achievement in third grade, as measured by the FCAT-SSS Reading (FDOE, 2005).

\section{Research Question 2}

To what extent does the relationship of early oral reading fluency ability and reading comprehension achievement vary by demographic subgroup membership (i.e., gender, race/ethnicity, socioeconomic status) among a diverse sample of students? 
Hypothesis 4. The relationship of early oral reading fluency ability and reading comprehension achievement, as measured by the FCAT-SSS Reading (FDOE, 2005), significantly varies by gender (i.e., male, female).

Hypothesis 5. The relationship of early oral reading fluency ability and reading comprehension achievement, as measured by the FCAT-SSS Reading (FDOE, 2005), significantly varies by race/ethnicity (i.e., Black, White, Hispanic, Other).

A longitudinal, predictive research design was employed in this study using archived secondary data in hierarchical linear regression analyses (Gay \& Airasian, 2000; Hinkle et al., 2003; Johnson, 2001) to investigate (a) the extent to which oral reading fluency ability and reading comprehension achievement are related, and (b) the extent to which oral reading fluency ability measured longitudinally in first, second, and third grades predicts achievement in reading comprehension in third grade. A multiple linear regression analysis, using nonexperimental data, was conducted in which multiple independent variables were used to predict a single dependent variable (Green \& Salkind, 2003; Johnson, 2001; Petrocelli, 2003).

Oral reading fluency ability as measured by the three DIBELS ORF assessments administered at first (a), second (b), and third (c) grades represented the multiple independent, predictor variables. Reading comprehension achievement as measured by the FCAT-SSS Reading administered at third (d) grade represented the single dependent, criterion variable. The multiple correlation $(\mathrm{R})$ coefficient was used to provide a strengthof-relationship index, indicating the degree to which each of the independent, predictor scores correlated with the dependent, criterion score (Green \& Salkind, 2003). 
Once correlation coefficients were established for each predictor variable, a hierarchical linear multiple regression data analytic procedure was performed (Field, 2009; Petrocelli, 2003). Each of the predictor variables (DIBELS ORF scores [a], [b], [c]) were sequentially entered into the regression equation one step at a time to determine which of these predictor variables adds statistically significant amounts of unique or independent variance over and above the selected demographics toward predictability of the criterion variable (Field, 2009; Petrocelli, 2003).

The first independent, predictor variable added to the multiple regression equation was the oral reading fluency data obtained at first (a) grade. Immediately following was entry into the equation of the data obtained at second (b) grade, with the data obtained at third (c) grade entered last. These analyses established how much the prediction is improved by these variables independently and combined (Field, 2009).

The extent of relationships was determined first for the entire sample of participants and then determined for each specific demographic student subgroup of gender, race/ethnicity, and socioeconomic status. Socioeconomic status is defined by eligibility for free or reduced price meals, established by qualification standards of the National School Lunch Program that schools use as eligibility guidelines (U.S. Department of Agriculture [USDA], 2011). Specific to this study, low socioeconomic status was attributed to any student who qualified for free or reduced price meals, while moderate socioeconomic status was attributed to any student who did not meet eligibility requirements for free or reduced price meals. Demographic student data provided additional variables, to further examine the relationship between selected student demographics and achievement as measured by these two early reading assessments. 


\section{Limitations of the Study}

Although the sample of this study was chosen from Reading First funded schools in which the early oral reading fluency data were abundant, obtaining participants from these schools does present a limitation. Reading First funded schools were typically located in lower socioeconomic areas of the district and contained large numbers of racial and ethnic minority students and low-income families. Because one of the demographic subgroups for which the data were disaggregated was based on race/ethnicity, the subgroups of the sample were significantly unequal, as the Black and Hispanic student population attending these targeted schools were far greater in number than the White and Other student populations. Although this presents a possible limitation of the current study, similar research studies have included student samples that significantly lacked racial/ethnic minority and low-income representation. This current study addressed that gap in the research, as the targeted schools serviced large populations of racial/ethnic minority students of low-socioeconomic status.

Reading comprehension is a sophisticated process that involves the reader employing his or her prior knowledge while interacting with the content of the text and the author's intended message (Harris \& Hodges, 1995; RAND Reading Study Group, 2002). Measuring achievement in reading comprehension involves a much more complicated process than simply reading passages and responding to multiple-choice performance tasks to answer select skill-related questions of comprehension. The FCATSSS Reading, designated in this study as the measurement tool for determining reading comprehension achievement is one way of measuring reading comprehension, but presents a possible limitation. 
Although the FCAT-SSS Reading, a state-mandated high-stakes standardized test of reading comprehension, is used to satisfy the accountability measures within all school districts across the state of Florida, it does not provide a comprehensive measure of achievement in reading comprehension. It is acknowledged that this current study was limited to measuring student achievement in reading comprehension through the use of this one standardized traditional multiple-choice formatted testing measure, which was limited by the scope of the comprehension skills assessed.

\section{Summary}

This chapter began with a description of the sample of students who participated in the study, including the conditions for their participation. The selection of the sample was addressed as it related to the scope of the population to whom the results of this study were generalized. Detailed description of the instrumentation used was provided. Next, specific data were identified for collection, and the collection process explained. The chapter concluded with a presentation of the research questions and hypotheses along with the statistical techniques employed for analyzing the collected data. 


\section{CHAPTER IV}

\section{RESULTS}

The results of the study are presented in this chapter, which is organized into three main sections: background of the sample, examination of the hypotheses, and a brief summary of the chapter. To examine the hypotheses, correlational and hierarchical regression analyses were used to test the model of the relationship of early oral reading fluency and reading comprehension. Prediction methods, such as hierarchical regression, are helpful in determining which sets of predictor variables are most closely linked to a specific outcome (Field, 2009; Petrocelli, 2003).

\section{Background of the Sample}

Of the original 2,744 third grade students who had attended a cohort of 25 Reading First funded schools, 1,663 participated in this study. Due to attrition, this represents approximately a $40 \%$ reduction in participating students attributed to missing targeted archived data and/or previous grade level retentions. A school-by-school distribution of the 1,663 student participants is presented below. Additionally examined in the following sections are the participants' demographics (i.e., gender, race/ethnicity, socioeconomic status).

\section{Student Distribution}

A frequency analysis of student distribution among the 25 cohort schools indicated between 35 and 99 participants attended each school with the smallest school population of $2.1 \%(n=35)$ and the largest school population of $6.0 \%(n=99)$ of the total sample. A frequency table of student participants distributed between each of the 25 cohort schools is presented in Table 5. 
Table 5

Frequency Table of Student Population Distribution

\begin{tabular}{|c|c|c|}
\hline Cohort school & $f$ & Percen \\
\hline School 1 & 66 & 4.0 \\
\hline School 2 & 77 & 4.6 \\
\hline School 3 & 80 & 4.8 \\
\hline School 4 & 73 & 4.4 \\
\hline School 5 & 60 & 3.6 \\
\hline School 6 & 49 & 2.9 \\
\hline School 7 & 81 & 4.9 \\
\hline School 8 & 74 & 4.4 \\
\hline School 9 & 96 & 5.8 \\
\hline School 10 & 65 & 3.9 \\
\hline School 11 & 91 & 5.5 \\
\hline School 12 & 40 & 2.4 \\
\hline School 13 & 47 & 2.8 \\
\hline School 14 & 78 & 4.7 \\
\hline School 15 & 49 & 2.9 \\
\hline School 16 & 49 & 2.9 \\
\hline School 17 & 78 & 4.7 \\
\hline School 18 & 38 & 2.3 \\
\hline School 19 & 72 & 4.3 \\
\hline School 20 & 77 & 4.6 \\
\hline School 21 & 72 & 4.3 \\
\hline School 22 & 70 & 4.2 \\
\hline School 23 & 47 & 2.8 \\
\hline School 24 & 35 & 2.1 \\
\hline School 25 & 99 & 6.0 \\
\hline Total & 1,663 & 100.0 \\
\hline
\end{tabular}


Gender. A frequency analysis of gender indicated that male students comprised $51.3 \%(n=853)$ of the sample and female students comprised $48.7 \%(n=810)$ of the sample.

Race/ethnicity. A frequency analysis of race/ethnicity indicated that $72.5 \%(n=$ $1,206)$ of the sample was Black, $8.1 \%(n=134)$ of the sample was White, $15.4 \%(n=$ 256) of the sample was Hispanic, and $4.0 \%(n=67)$ of the sample was Other representing a combination of Asian, Multiracial, and Native American populations.

Socioeconomic status. A frequency analysis of socioeconomic status indicated that $88.6 \%(n=1,473)$ of the sample was of low socioeconomic status and $11.4 \%(n=$ 190) of the sample was of moderate socioeconomic status.

Socioeconomic status is defined by eligibility for free or reduced price meals, established by qualification standards of the National School Lunch Program that schools use as eligibility guidelines (U.S. Department of Agriculture [USDA], 2011). Specific to this study, low socioeconomic status was attributed to any student who qualified for free or reduced price meals, while moderate socioeconomic status was attributed to any student who did not meet eligibility requirements for free or reduced price meals.

Further disaggregation of the demographic variables provides a breakdown of the number of male and female students as well as students of low and moderate socioeconomic status for each of the five racial/ethnic subgroups. This sample consists of a large Black and low socioeconomic population as was earlier identified in this cohort of Reading First schools. These data are displayed in Table 6 and Table 7. 
Table 6

Frequency Table of Gender and Socioeconomic Status By Race/Ethnicity

\begin{tabular}{crrrrr}
\hline Variable & \multicolumn{2}{c}{ Gender } & & \multicolumn{2}{c}{ Socioeconomic status } \\
\cline { 2 - 3 } & Male & Female & & Low & Moderate \\
\hline Race/ethnicity & 610 & 596 & & 1,126 & 80 \\
Black & 76 & 58 & 82 & 52 \\
White & 135 & 121 & 224 & 32 \\
Hispanic & 32 & 35 & 41 & 26 \\
Other^ & & & & \\
\hline
\end{tabular}

Note. ${ }^{\wedge}$ Other includes Asian, Multiracial, and Native American populations.

Table 7

Frequency Table of Socioeconomic Status By Gender

\begin{tabular}{ccc}
\hline Variable & \multicolumn{2}{c}{ Socioeconomic status } \\
\cline { 2 - 3 } & Low & Moderate \\
\hline$\underline{\text { Gender }}$ & & \\
Male & 755 & 98 \\
Female & 718 & 92 \\
\hline
\end{tabular}

Cross tabulation of background demographic variables. In this study,

demographic variables were examined for meaningful relations using inferential statistics through cross tabulation analyses. Inferential statistical procedures are used to make generalizations about a broad population while studying only a sample of that population (Hinkle, Wiersma, \& Jurs, 2003). Chi-square analysis, one type of inferential statistical procedure, allows the researcher to employ data from a sample to draw conclusions and make inferences about corresponding characteristics across the parameters of the broader population (Hinkle et al., 2003). 
A chi-square test is used to compare the distribution of a theoretical or anticipated frequency with a sample or observed frequency (Hinkle et al., 2003). Chi-square analysis was used in this study to test the null hypothesis $\left(H_{0}\right)$ of no significant relationship or difference between the anticipated and observed statistical results of the variable distribution (Hinkle et al., 2003). The degree of freedom (df), usually one less than the number of variables, is equivalent to the number of observations reduced by the number of restrictions placed on them. The statistical probability that the deviation between the observed and the anticipated distribution is due to chance alone is indicated by the $p$ value (Hinkle et al., 2003). You would expect, for example, any deviation to be due to chance alone $1 \%$ or less of the time if using $p<.01$, or $5 \%$ or less of the time if using $p<$ .05 . The calculated chi-square $\left(\chi^{2}\right)$ values for the demographic variable combinations are provided in Table 8 .

Table 8

Demographic Variable Cross Tabulation

\begin{tabular}{lrrr}
\hline Variable combination & $\chi^{2}$ Value & $d f$ & $p$ \\
\hline Gender and Race/ethnicity & 2.370 & 3 & .499 \\
Race/ethnicity and Socioeconomic status & 176.562 & 3 & $<.001$ \\
Socioeconomic status and Gender & .007 & 1 & .933 \\
\hline
\end{tabular}

The results of the chi-square tests indicated statistical significance for one demographic variable combination: race/ethnicity and socioeconomic status, $p<.001$. For the variable combination of race/ethnicity and socioeconomic status, a greater proportion of Black students $(76.4 \%)$ were of low socioeconomic status, when compared to White students $(5.6 \%)$, Hispanic students $(15.2 \%)$, and Other students $(2.8 \%)$. For the 
remaining demographic variable combinations of gender and race/ethnicity $(p=.499)$ as well as socioeconomic status and gender $(p=.933)$ there were no statistical differences between distributions of each sample variable.

\section{Examination of Hypotheses}

Three hypothesized models of predicted reading comprehension achievement were tested using correlational and hierarchical regression analyses. The model hypothesized that early oral reading fluency ability as measured in first grade, second grade, and third grade would be related to third grade reading comprehension achievement.

The condition of multicollinearity, an underlying assumption about correlational and hierarchical regression analyses, was examined prior to testing the model (Petrocelli, 2003). Serious violations of multicollinearity may produce untrustworthy interpretations drawn from the results of this study.

\section{Multicollinearity}

Correlation coefficients provide a measurement index of the relationship between variables that can range from .00 , indicating no relationship, to 1.00 , indicating a perfect relationship (Hinkle et al., 2003). In behavioral science research, correlational coefficients of .10 are interpreted as small effects, while .30 as medium effects, and .50 as large effects (Green \& Salkind, 2003).

When two variables are highly correlated, they basically measure the same phenomenon or construct (Hinkle et al., 2003). Multicollinearity occurs when two or more predictor variables are so highly correlated it is difficult to obtain reliable estimates of their individual regression coefficients (Field, 2009; Petrocelli, 2003). To avoid 
multicollinearity, predictor variables producing correlation greater than .90 between them should either be removed or combined (Green, 1991). High intercorrelations of predictors increase the standard error of the beta coefficients and make assessment of the unique role of each predictor variable difficult (Hinkle et al., 2003). Intercorrelations were checked and no correlation between the predictor variables was found to be greater than 90. Correlation coefficients between the three predictor variables are provided in Table 9.

Table 9

Correlation Coefficients Between the Three DIBELS ORF Assessments

\begin{tabular}{|c|c|c|c|c|c|c|}
\hline \multirow{2}{*}{$\begin{array}{l}\text { Predictor } \\
\text { variables }\end{array}$} & \multicolumn{2}{|c|}{ DIBELS ORF 2007} & \multicolumn{2}{|c|}{ DIBELS ORF 2008} & \multicolumn{2}{|c|}{ DIBELS ORF 2009} \\
\hline & $\begin{array}{c}\text { WCPM } \\
\text { score }\end{array}$ & $\begin{array}{l}\text { Risk } \\
\text { level }\end{array}$ & $\begin{array}{c}\text { WCPM } \\
\text { score }\end{array}$ & $\begin{array}{l}\text { Risk } \\
\text { level }\end{array}$ & $\begin{array}{c}\text { WCPM } \\
\text { score }\end{array}$ & $\begin{array}{l}\text { Risk } \\
\text { level }\end{array}$ \\
\hline
\end{tabular}

DIBELS ORF 2007

$\begin{array}{lcll}\text { WCPM score } & 1 / .866 & .807 / .748 & .749 / .711 \\ \text { Risk level } & .866 / 1 & .731 / .744 & .671 / .646\end{array}$

DIBELS ORF 2008

$\begin{array}{lrrr}\text { WCPM score } & .807 / .731 & 1 / .894 & .862 / .796 \\ \text { Risk level } & .748 / .744 & .894 / 1 & .785 / .775\end{array}$

DIBELS ORF 2009

$\begin{array}{lllr}\text { WCPM score } & .749 / .671 & .862 / .785 & 1 / .921 \\ \text { Risk level } & .711 / .646 & .796 / .775 & .921 / 1\end{array}$

Note. All correlations are significant at the .001 level (1-tailed), $p<.001$. DIBELS is the ORF measure and the ORF score is WCPM (words read correctly per minute). The ORF Risk measurement indicates the Risk Level 1-4. 


\section{Zero-Order Correlations}

Although first, second, and third grade oral reading fluency ability each correlated significantly and positively with third grade reading comprehension achievement, there was a difference in relations as measured between each of the oral reading fluency measures and reading comprehension achievement. Third grade oral reading fluency ability was more strongly related to third grade reading comprehension $(r=.611, p<$ $.001)$, than was second grade oral reading fluency ability $(r=.594, p<.001)$ and first grade oral reading fluency ability $(r=.545, p<.001)$ separately to third grade reading comprehension.

These data indicate that third grade oral reading fluency better relates to third grade reading comprehension achievement than does second or first grade oral reading fluency ability. Table 10 provides detailed correlational statistics regarding the relations between oral reading fluency ability in first grade, second grade, and third grade $(r=$ $.545, .594, .611$, respectively) to reading comprehension achievement in third grade. 
Table 10

Zero-Order Correlation Coefficients For DIBELS ORF Ability and FCAT Reading Achievement

\begin{tabular}{|c|c|c|c|c|}
\hline \multirow[t]{2}{*}{ Variables } & $\begin{array}{l}\text { DIBELS } \\
\text { ORF } 2007 \\
\end{array}$ & $\begin{array}{l}\text { DIBELS } \\
\text { ORF } 2008 \\
\end{array}$ & $\begin{array}{c}\text { DIBELS } \\
\text { ORF } 2009 \\
\end{array}$ & $\begin{array}{c}\text { FCAT } \\
\text { Reading } 2009 \\
\end{array}$ \\
\hline & $\begin{array}{cc}\text { WCPM } & \text { Risk } \\
\text { score } & \text { level }\end{array}$ & $\begin{array}{cl}\text { WCPM } & \text { Risk } \\
\text { score } & \text { level }\end{array}$ & $\begin{array}{cl}\text { WCPM } & \text { Risk } \\
\text { score } & \text { level }\end{array}$ & $\begin{array}{cc}\text { Scale } & \text { Achmt } \\
\text { score } & \text { level }\end{array}$ \\
\hline \multicolumn{5}{|c|}{ DIBELS ORF 2007} \\
\hline WCPM score & $1 / .866$ & $.807 / .748$ & $.749 / .711$ & $.565 / .545$ \\
\hline Risk level & $.866 / 1$ & $.731 / .744$ & $.671 / .646$ & $.513 / .500$ \\
\hline \multicolumn{5}{|c|}{$\underline{\text { DIBELS ORF } 2008}$} \\
\hline WCPM score & $.807 / .731$ & $1 / .894$ & $.862 / .796$ & .628 / .594 \\
\hline Risk level & $.748 / .744$ & $.894 / 1$ & $.785 / .775$ & $.595 / .580$ \\
\hline \multicolumn{5}{|c|}{ DIBELS ORF 2009} \\
\hline WCPM score & $.749 / .671$ & $.862 / .785$ & $1 / .921$ & $.644 / .611$ \\
\hline Risk level & $.711 / .646$ & $.796 / .775$ & $.921 / 1$ & $.587 / .573$ \\
\hline \multicolumn{5}{|c|}{ FCAT Reading 2009} \\
\hline Scale score & $.565 / .513$ & $.628 / .595$ & $.644 / .587$ & $1 / .926$ \\
\hline Achmt level & $.545 / .500$ & $.594 / .580$ & $.611 / .573$ & $.926 / 1$ \\
\hline
\end{tabular}

Note. All correlations are significant at the .001 level ( 1 -tailed), $p<.001$. DIBELS is the ORF measure and the ORF score is WCPM (words read correctly per minute). The ORF Risk measurement indicates the Risk Level 1-4. Reading Achievement is measured by the FCAT and the score is the scale. The FCAT level measurement indicates the Achievement (Achmt) Level 1-5.

\section{Linear Regression Analyses}

Three separate linear regression analyses were conducted to test Hypotheses 1, 2, and 3 by evaluating the prediction of third grade reading comprehension achievement (2009) from oral reading fluency ability as measured in first grade (2007), second grade (2008), and third grade (2009). 
Linear regression analysis for testing $\mathbf{H}_{1}$. Hypothesis 1 stated there would be a significant positive relation between early oral reading fluency ability measured in first grade and reading comprehension achievement in third grade. Results indicate that first grade oral reading fluency ability (DIBELS ORF WCPM Score) was significantly and positively correlated with third grade reading comprehension achievement (FCAT Reading Achievement Level) $R=.545$ at $p<.001$ value. As a result of the regression analysis, $29.7 \%$ of the variance of third grade reading comprehension was accounted for by its linear relationship with first grade oral reading fluency ability. Thus, the research evidence supports Hypothesis 1 . Table 11 provides a summary of the linear regression analysis between first grade oral reading fluency ability (2007) and third grade reading comprehension achievement (2009).

Table 11

Linear Regression Analysis of Relationship Between Third Grade Reading Comprehension Achievement and First Grade Oral Reading Fluency Ability

\begin{tabular}{lcccc}
\hline Variable & \multicolumn{4}{c}{ FCAT Reading 2009 achievement level } \\
\cline { 2 - 5 } & $\beta$ & $R$ & $R^{2}$ & Sig. $F$ change \\
\hline$\underline{\text { DIBELS ORF 2007 }}$ & & & & \\
WCPM score & $.545^{* * *}$ & $.545^{* * *}$ & $.297 * * *$ & $<.001$ \\
Total adjusted $R^{2}$ & $.297^{* * *}$ & & \\
\hline
\end{tabular}

Note. $R^{2}=.297 . * * * p<.001$.

Linear regression analysis for testing $\mathbf{H}_{2}$. Hypothesis 2 stated there would be a significant positive relation between early oral reading fluency ability measured in second grade and reading comprehension achievement in third grade. Results indicate that second grade oral reading fluency ability (DIBELS ORF WCPM Score) was 
significantly and positively correlated with third grade reading comprehension achievement (FCAT Reading Achievement Level) $R=.594$ at $p<.001$ value. As a result of the regression analysis, $35.2 \%$ of the variance of third grade reading comprehension was accounted for by its linear relationship with second grade oral reading fluency ability. Thus, the research evidence supports Hypothesis 2 . Table 12 provides a summary of the linear regression analysis between second grade oral reading fluency ability (2008) and third grade reading comprehension achievement (2009).

Table 12

Linear Regression Analysis of Relationship Between Third Grade Reading Comprehension Achievement and Second Grade Oral Reading Fluency Ability

Variable FCAT Reading 2009 achievement level $\begin{array}{llll}\beta & R & R^{2} & \text { Sig. } F \text { change }\end{array}$

DIBELS ORF 2008

WCPM score $\quad .594 * * * \quad .594 * * * \quad .353^{* * *} \quad<.001$

Total adjusted $R^{2} \quad .352^{* * *}$

Note. $R^{2}=.353 .{ }^{* * *} p<.001$.

Linear regression analysis for testing $\mathbf{H}_{3}$. Hypothesis 3 stated there would be a significant positive relation between early oral reading fluency ability measured in third grade and reading comprehension achievement in third grade. Results indicate that third grade oral reading fluency ability (DIBELS ORF WCPM Score) was significantly and positively correlated with third grade reading comprehension achievement (FCAT Reading Achievement Level) $R=.611$ at $p<.001$ value. As a result of the regression analysis, $37.2 \%$ of the variance of third grade reading comprehension was accounted for by its linear relationship with third grade oral reading fluency ability. Thus, the research 
evidence supports Hypothesis 3 . Table 13 provides a summary of the linear regression analysis between third grade oral reading fluency ability (2009) and third grade reading comprehension achievement (2009).

Table 13

Linear Regression Analysis of Relationship Between Third Grade Reading Comprehension Achievement and Third Grade Oral Reading Fluency Ability

\begin{tabular}{lcccc}
\hline Variable & \multicolumn{4}{c}{ FCAT Reading 2009 achievement level } \\
\cline { 2 - 5 } & $\beta$ & $R$ & $R^{2}$ & Sig. $F$ change \\
\hline DIBELS ORF 2009 & & & & \\
WCPM score & $.611^{* * *}$ & $.611^{* * *}$ & $.373^{* * *}$ & $<.001$ \\
Total adjusted $R^{2}$ & $.372^{* * *}$ & & & \\
\hline
\end{tabular}

Note. $R^{2}=.373 .{ }^{* * *} p<.001$.

\section{Hierarchical Multiple Regression Analyses}

Hierarchical regression analyses were conducted to test Hypotheses 4 and 5 by evaluating the extent a relationship exists between oral reading fluency ability as measured in first grade (2007), second grade (2008), and third grade (2009) and third grade reading comprehension achievement (2009). A hierarchical regression analysis was first performed including all students in this sample prior to disaggregating the data by demographic subgroups. Each of the predictor variables (2007, 2008, 2009 DIBELS ORF WCPM Scores) was sequentially entered into the regression equation one step at a time to determine which of these predictor variables adds statistically significant amounts of unique or independent variance over and above the selected demographics toward predictability of the criterion variable (2009 FCAT Reading Achievement Level; Field, 2009; Petrocelli, 2003). 
The first predictor variable added to the multiple regression equation was the oral reading fluency data obtained at first grade (2007). Immediately following was entry into the equation of the data obtained at second grade (2008), with the data obtained at third grade (2009) entered last. These analyses were conducted to establish how much the prediction is improved by these variables independently and combined (Field, 2009). The extent of relationships was determined first for the entire sample of participants, regardless of demographic subgroup membership. Table 14 provides a summary of the hierarchical regression analysis between first, second, and third grade oral reading fluency ability $(2007,2008,2009)$ and third grade reading comprehension achievement (2009).

Table 14

Hierarchical Multiple Regression Analyses Predicting Third Grade Reading Comprehension Achievement From First, Second, and Third Grade Oral Reading Fluency Ability

\begin{tabular}{lccccc}
\hline Variable & \multicolumn{5}{c}{ FCAT Reading 2009 achievement level } \\
\cline { 2 - 5 } & $\beta$ & $R$ & $R^{2}$ & $\Delta R^{2}$ & Sig. F change \\
\hline Step 1 & & & & \\
DIBELS ORF 2007 & .134 & .545 & .297 & .297 & $<.001$ \\
WCPM score & & & & & \\
Step 2 & & & & \\
DIBELS ORF 2008 & .179 & .604 & .365 & .068 & $<.001$ \\
WCPM score & & & & & \\
Step 3 & & & & & \\
DIBELS ORF 2009 & .356 & .630 & .397 & .032 & $<.001$ \\
WCPM score & .396 & & & & \\
Total adjusted $R^{2}$ & & & & & \\
\hline
\end{tabular}

Note. All values are $p<.001$. 
Testing the regression model, in the first, second, and third steps, oral reading fluency ability as measured by the first grade 2007 DIBELS ORF $(\beta=.134, p<.001)$, second grade 2008 DIBELS ORF $(\beta=.179, p<.001)$, and third grade 2009 DIBELS ORF $(\beta=.356, p<.001)$ contributed unique variance to the prediction of third grade reading comprehension achievement as measured by the 2009 FCAT Reading Achievement Level. A significant overall variance of $39.6 \%$ was realized when combining all oral reading fluency measures toward predicting reading comprehension achievement. While the first grade oral reading fluency ability measure explained an initial $29.7 \%$ of the variance, a $6.8 \%$ increase was realized by adding the second grade oral reading fluency ability measure to the regression equation, with an additional 3.2\% increase in variance being explained by adding the third grade oral reading fluency ability measurement.

To determine the collinearity between the variables of oral reading fluency ability in this model, the variance inflation factor (VIF) was examined. The degree of multicollinearity between variables is statistically quantified through VIF, which provides an index to estimate how much variance is inflated due to collinearity (Green, 1991). Multicollinearity is indicated through VIF values that exceed 10.0 and tolerance values less than 0.1 (Green, 1991). All three of the oral reading fluency ability variables examined in this model produced VIF values of 5.07 or less, well within the acceptable range of $<10.0$, and tolerance values that were all greater than 0.1 .

Demographic student data provided additional variables to further investigate the relationship between selected student demographics and achievement as measured by these two early reading assessments. All data were disaggregated by demographic 
subgroup membership for gender (i.e., male, female), race/ethnicity (i.e., Black, White, Hispanic, Other), and socioeconomic status (i.e., low, moderate) to determine if demographics impacted the relationship of oral reading fluency ability and reading comprehension achievement.

Hierarchical multiple regression analyses for testing $\mathbf{H}_{4}$. A hierarchical regression analysis was performed to test Hypothesis 4 that stated the relationship of early oral reading fluency ability and reading comprehension achievement would significantly vary by gender (i.e., male, female).

All data were disaggregated by the gender demographic subgroups of male and female students. Each of the predictor variables $(2007,2008,2009$ DIBELS ORF WCPM Scores) was sequentially entered into the regression equation one step at a time to determine which of these predictor variables adds statistically significant amounts of unique or independent variance over and above the male and female student gender subgroups toward predictability of the criterion variable (Field, 2009; Petrocelli, 2003).

The first predictor variable added to the multiple regression equation was the oral reading fluency data obtained at first grade (2007). Immediately following was the entry into the equation of the data obtained at second grade (2008), with the data obtained at third grade (2009) entered last. These analyses were conducted to establish how much the prediction is improved by these variables independently and combined for each of the male and female student gender subgroups (Field, 2009). Table 15 provides a summary of the hierarchical regression analysis between first, second, and third grade oral reading fluency ability $(2007,2008,2009)$ and third grade reading comprehension achievement (2009) specific to the male and female student gender subgroups. 
Table 15

Hierarchical Multiple Regression Analyses Predicting Third Grade Reading Comprehension Achievement From First, Second, and Third Grade Oral Reading Fluency Ability By Gender Subgroups

\begin{tabular}{|c|c|c|c|c|}
\hline \multirow[t]{3}{*}{ Predictor } & \multicolumn{4}{|c|}{ Gender } \\
\hline & \multicolumn{2}{|c|}{ Male } & \multicolumn{2}{|c|}{ Female } \\
\hline & $\Delta R^{2}$ & $\beta$ & $\Delta R^{2}$ & $\beta$ \\
\hline
\end{tabular}

Step 1

DIBELS ORF 2007

WCPM score

$.314 * * * \quad .144 * *$

$.262 * * *$

$.133^{* *}$

Step 2

DIBELS ORF 2008

WCPM score

$.069 * * * \quad .189 * *$

$.060 * * * \quad .147 *$

Step 3

DIBELS ORF 2009

WCPM score

Total adjusted $R^{2}$

$n$

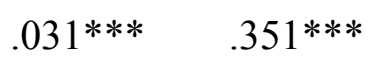

$.412 * * *$

853
$.032 * * *$

$.353^{* * *}$

$.352 * * *$

810

Note. ${ }^{*} p<.05 . * * p<.01 . * * * p<.001$.

Testing the regression model for male students, in the first, second, and third steps, oral reading fluency ability as measured by the first grade 2007 DIBELS ORF ( $\beta=$ $.144, p<.01)$, second grade 2008 DIBELS ORF $(\beta=.189, p<.01)$, and third grade 2009 DIBELS ORF $(\beta=.351, p<.001)$ contributed unique variance to the prediction of third grade reading comprehension achievement as measured by the 2009 FCAT Reading Achievement Level. Identical testing of the regression model for female students was next conducted in the same manner as for male students. For female students, oral reading fluency ability as measured by the first grade 2007 DIBELS ORF $(\beta=.133, p<$ 
$.01)$, second grade 2008 DIBELS ORF $(\beta=.147, p<.05)$, and third grade 2009 DIBELS ORF $(\beta=.353, p<.001)$ likewise contributed unique variance to the prediction of third grade reading comprehension achievement as measured by the 2009 FCAT Reading Achievement Level.

These findings suggest that third grade reading comprehension achievement as measured by the FCAT Reading Achievement Level can be predicted by oral reading fluency ability as measured subsequently in first, second, and third grades for both male and female students. Overall, the regression model, accounting for gender demographic subgroup membership, explained the variance in third grade reading comprehension achievement as $41.2 \%$ among male students and $35.2 \%$ among female students, producing a $6.0 \%$ difference between these two subgroups.

To determine the collinearity between the variables of oral reading fluency ability in this model based on gender (i.e., male, female), the variance inflation factor (VIF) was examined. Multicollinearity is indicated through VIF values that exceed 10.0 and tolerance values less than 0.1 (Green, 1991). All three of the oral reading fluency ability variables examined in this model for gender produced VIF values of 5.04 or less among male students and 4.84 or less among female students, well within the acceptable range of $<10.0$, and tolerance values that were all greater than 0.1 among both gender subgroups.

\section{Hierarchical multiple regression analyses for testing $\mathbf{H}_{5}$. A hierarchical} regression analysis was performed to test Hypothesis 5 that stated the relationship of early oral reading fluency ability and reading comprehension achievement would significantly vary by race/ethnicity (i.e., Black, White, Hispanic, Other). However, first race/ethnicity was entered in the first step, followed by 2007, 2008, 2009 DIBELS ORF 
WCPM Scores in respective, separate steps. Thus, there were four separate steps. The hierarchical regression results revealed that the race/ethnicity variable explained $1.9 \%$ of the variance in the dependent variable $(\beta=.076, p<.001), 2007$ score $(\beta=.141, p<$ $.001), 2008$ score $(\beta=.178, p<.001)$, and 2009 score $(\beta=.342, p<.001)$. The unique variance (adjusted $R^{2}$ ) explained by each step was as follows: race/ethnicity 1.9\%, 2007 oral reading fluency $29.1 \%, 2008$ oral reading fluency $6.3 \%$, and 2009 oral reading fluency $2.9 \%$ for a total $R^{2}$ of $40.2 \%(F(4,1658)=278.90, p<.001)$. Because the researcher detected a race/ethnicity main effect, separate regression analyses were run for each racial/ethnic group. Thus, the following information reported below amounts to simple effects versus the main effects reported above (Field, 2009).

All data were disaggregated by the racial/ethnic demographic subgroups of Black, White, Hispanic, and Other (i.e., Asian, Multiracial, Native American) student populations. Each of the predictor variables $(2007,2008,2009$ DIBELS ORF WCPM Scores) was sequentially entered into the regression equation one step at a time to determine which of these predictor variables adds statistically significant amounts of unique or independent variance over and above the Black, White, Hispanic, and Other racial/ethnic subgroups toward predictability of the criterion variable (Field, 2009; Petrocelli, 2003).

The first predictor variable added to the multiple regression equation was the oral reading fluency data obtained at first grade (2007). Immediately following was the entry into the equation of the data obtained at second grade (2008), with the data obtained at third grade (2009) entered last. These analyses were conducted to establish how much the prediction is improved by these variables independently and combined for each of the 
racial/ethnic subgroups (Field, 2009). Table 16 provides a summary of the hierarchical regression analysis between first, second, and third grade oral reading fluency ability (2007, 2008, 2009) and third grade reading comprehension achievement (2009) specific to the Black, White, Hispanic, and Other racial/ethnic subgroups.

Table 16

Hierarchical Multiple Regression Analyses Predicting Third Grade Reading Comprehension Achievement From First, Second, and Third Grade Oral Reading Fluency Ability By Racial/Ethnic Subgroups

\begin{tabular}{|c|c|c|c|c|c|c|c|c|}
\hline \multirow[t]{3}{*}{ Predictor } & \multicolumn{8}{|c|}{ Race/ethnicity } \\
\hline & \multicolumn{2}{|c|}{ Black } & \multicolumn{2}{|c|}{ White } & \multicolumn{2}{|c|}{ Hispanic } & \multicolumn{2}{|c|}{ Other $\wedge$} \\
\hline & $\Delta R^{2}$ & $\beta$ & $\Delta R^{2}$ & $\beta$ & $\Delta R^{2}$ & $\beta$ & $\Delta R^{2}$ & $\beta$ \\
\hline
\end{tabular}

Step 1

DIBELS ORF 2007

WCPM score $.283^{* * *} .175^{* *} \quad .308^{* * *} .555^{* * *} \quad .311^{* * *} .287^{* *} \quad .524 * * * .563 * *$

Step 2

DIBELS ORF 2008

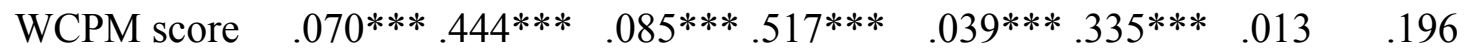

Step 3

DIBELS ORF 2009

WCPM score $\quad .029 * * * .345 * * * \quad .030 * \quad .330 * \quad .028 * * \quad .319 * * \quad .034 * \quad .383 *$

$\begin{array}{lllll}\text { Total adjusted } R^{2} & .379 * * * & .410 * & .370 * * & .550 *\end{array}$

$\begin{array}{lllll}n & 1206 & 134 & 256 & 67\end{array}$

Note. ${ }^{*} p<.05 .{ }^{* *} p<.01 .{ }^{* * *} p<.001 .{ }^{\wedge}$ Other includes Asian, Multiracial, and Native American populations.

Testing the regression model for all racial/ethnic subgroups of students, in the first, second, and third steps, oral reading fluency ability as measured by the first grade 2007 DIBELS ORF $($ Black $\beta=.175, p<.01$; White $\beta=.555, p<.001$; Hispanic $\beta=$ 
$.287, p<.01$; Other $\beta=.563, p<.001$ ), second grade 2008 DIBELS ORF (Black $\beta=$ $.444, p<.001$; White $\beta=.517, p<.001$; Hispanic $\beta=.335, p<.001$; Other $\beta=.196, p=$ .19 ), and third grade 2009 DIBELS ORF (Black $\beta=.345, p<.001$; White $\beta=.330, p<$ .05 ; Hispanic $\beta=.319, p<.01$; Other $\beta=.383, p<.05$ ) contributed unique variance to the prediction of third grade reading comprehension achievement as measured by the 2009 FCAT Reading Achievement Level.

These findings suggest that third grade reading comprehension achievement as measured by the FCAT Reading Achievement Level can be predicted by oral reading fluency ability as indicated in Table 16. Overall, the regression model, accounting for racial/ethnic demographic subgroup membership, explained the variance in third grade reading comprehension achievement as $37.9 \%$ among Black students, $41.0 \%$ among White students, 37.0\% among Hispanic students, and 55.0\% among Other (i.e., Asian, Multiracial, Native American) students producing a noteworthy difference in variance being explained of $14.0 \%$ to $18.0 \%$ between the Other subgroup and each of the Black, White, and Hispanic subgroups.

To determine the collinearity between the variables of oral reading fluency ability in this model based on race/ethnicity (i.e., Black, White, Hispanic, Other), the variance inflation factor (VIF) was examined. Multicollinearity is indicated through VIF values that exceed 10.0 and tolerance values less than 0.1 (Green, 1991). All three of the oral reading fluency ability variables examined in this model for race/ethnicity produced VIF values of 5.18 or less among Black students, 5.28 or less among White students, 4.38 among Hispanic students, and 4.71 or less among Other students (i.e., Asian, Multiracial, 
Native American), well within the acceptable range of $<10.0$, and tolerance values that were all greater than 0.1 among all four racial/ethnic subgroups.

Additional hierarchical multiple regression analyses by SES. An additional hierarchical regression analysis was performed to further explore the data by examining the relationship of early oral reading fluency ability and reading comprehension achievement by socioeconomic status (i.e., low, moderate).

Socioeconomic status is defined by eligibility for free or reduced price meals, established by qualification standards of the National School Lunch Program that schools use as eligibility guidelines (U.S. Department of Agriculture [USDA], 2011). Specific to this study, low socioeconomic status was attributed to any student who qualified for free or reduced price meals, while moderate socioeconomic status was attributed to any student who did not meet eligibility requirements for free or reduced price meals.

All data were disaggregated by the socioeconomic status demographic subgroups of low and moderate income. Each of the predictor variables (2007, 2008, 2009 DIBELS ORF WCPM Scores) was sequentially entered into the regression equation one step at a time to determine which of these predictor variables adds statistically significant amounts of unique or independent variance over and above the low and moderate socioeconomic status subgroups toward predictability of the criterion variable (2009 FCAT Reading Achievement Level; Field, 2009; Petrocelli, 2003).

The first predictor variable added to the multiple regression equation was the oral reading fluency data obtained at first grade (2007). Immediately following was the entry into the equation of the data obtained at second grade (2008), with the data obtained at third grade (2009) entered last. These analyses were conducted to establish how much the 
prediction is improved by these variables independently and combined for each of the low and moderate socioeconomic status subgroups (Field, 2009). Table 17 provides a summary of the hierarchical regression analysis between first, second, and third grade oral reading fluency ability $(2007,2008,2009)$ and third grade reading comprehension achievement (2009) specific to the low and moderate socioeconomic status subgroups.

Table 17

Hierarchical Multiple Regression Analyses Predicting Third Grade Reading Comprehension Achievement From First, Second, and Third Grade Oral Reading Fluency Ability By Socioeconomic Status Subgroups

\begin{tabular}{|c|c|c|c|c|}
\hline \multirow[t]{3}{*}{ Predictor } & \multicolumn{4}{|c|}{ Socioeconomic status } \\
\hline & \multicolumn{2}{|c|}{ Low } & \multicolumn{2}{|c|}{ Moderate } \\
\hline & $\Delta R^{2}$ & $\beta$ & $\Delta R^{2}$ & $\beta$ \\
\hline \multicolumn{5}{|l|}{ Step 1} \\
\hline \multicolumn{5}{|c|}{ DIBELS ORF 2007} \\
\hline WCPM score & $.289 * * *$ & $.187 * * *$ & $.288 * * *$ & $.536^{* * *}$ \\
\hline \multicolumn{5}{|l|}{ Step 2} \\
\hline \multicolumn{5}{|c|}{ DIBELS ORF 2008} \\
\hline WCPM score & $.066^{* * *}$ & $.435^{* * *}$ & $.077 * * *$ & $.457 * * *$ \\
\hline \multicolumn{5}{|l|}{ Step 3} \\
\hline \multicolumn{5}{|c|}{ DIBELS ORF 2009} \\
\hline WCPM score & $.032 * * *$ & $.358 * * *$ & $.041 * * *$ & $.392 * * *$ \\
\hline Total adjusted $R^{2}$ & $.386^{* * *}$ & & $.396^{* * *}$ & \\
\hline$n$ & 1473 & & 190 & \\
\hline
\end{tabular}

Note. ${ }^{*} p<.05 . * * p<.01 .{ }^{* * *} p<.001$.

Testing the regression model for low income students, in the first, second, and third steps, oral reading fluency ability as measured by the first grade 2007 DIBELS ORF $(\beta=.187, p<.001)$, second grade 2008 DIBELS ORF $(\beta=.435, p<.001)$, and third 
grade 2009 DIBELS ORF $(\beta=.358, p<.001)$ contributed unique variance to the prediction of third grade reading comprehension achievement as measured by the 2009 FCAT Reading Achievement Level. Similar testing of the regression model for moderate income students was next conducted in the same manner as for low income students. For moderate income students, oral reading fluency ability as measured by the first grade 2007 DIBELS ORF $(\beta=.536, p<.001)$, second grade 2008 DIBELS ORF $(\beta=.457, p<$ $.001)$, and third grade 2009 DIBELS ORF $(\beta=.392, p<.001)$ likewise contributed unique variance to the prediction of third grade reading comprehension achievement as measured by the 2009 FCAT Reading Achievement Level.

These findings suggest that third grade reading comprehension achievement as measured by the FCAT Reading Achievement Level can be predicted by oral reading fluency ability in first, second, and third grades for both low and moderate income students. Overall, the regression model, accounting for socioeconomic status demographic subgroup membership, explained the variance in third grade reading comprehension achievement as $38.6 \%$ among low income students and $39.6 \%$ among moderate income students, a slight difference of only $1.0 \%$. This indicates that the three oral reading fluency measures combined provide as a very similar predictor for both the low and moderate socioeconomic subgroups of students.

To determine the collinearity between the variables of oral reading fluency ability in this model based on socioeconomic status (i.e., low, moderate), the variance inflation factor (VIF) was examined. Multicollinearity is indicated through VIF values that exceed 10.0 and tolerance values less than 0.1 (Green, 1991). All three of the oral reading fluency ability variables examined in this model for socioeconomic status produced VIF 
values of 5.05 or less among students of low socioeconomic status and 4.62 or less among students of moderate socioeconomic status, well within the acceptable range of $<$ 10.0, and tolerance values that were all greater than 0.1 among both socioeconomic subgroups.

\section{Summary}

Results of this study support all hypothesized models of predicted reading comprehension achievement that were tested using correlational and hierarchical regression analyses. The models hypothesized that early oral reading fluency ability as measured in first, second, and third grades would be related to third grade reading comprehension achievement. The research evidence supported Hypotheses 1, 2, and 3 resulting in significant positive relations between each of the three oral reading fluency ability measures (in first grade [2007], second grade [2008], and third grade [2009]) and the reading comprehension achievement measure (in third grade [2009]). In addition, the research evidence supported Hypotheses 4 and 5 resulting in significant variances in reading comprehension achievement being explained by early oral reading fluency ability among each of the gender subgroups (i.e., male, female), racial/ethnic subgroups (i.e., Black, White, Hispanic, Other), and socioeconomic status subgroups (i.e., low, moderate). The results and implications of these findings for research, theory, and practice are presented in Chapter 5. 


\section{CHAPTER V}

\section{DISCUSSION}

The final chapter provides a summary of the study, an interpretation of the data analyses, and an explanation of the study limitations. Implications for theory, policy, and practice are presented. The chapter concludes with recommendations for future research.

\section{Summary of the Study}

Several earlier research studies have confirmed the predictive ability of oral reading fluency assessment measures toward achievement on standardized state reading comprehension assessments (Buck \& Torgesen, 2002; Hintze \& Silberglitt, 2005; Kloo, 2006; Riedel, 2007; Roehrig, Petscher, Nettles, Hudson, \& Torgesen, 2008; Uribe-Zarain, 2006). Some of this research targeted large populations of students attending higher achieving schools (Buck \& Torgesen, 2002; Hintze \& Silberglitt, 2005), while other research included smaller populations of students with more diverse demographic backgrounds attending both lower and higher achieving schools, that produced significant differences in findings when the data were disaggregated by racial and ethnic diversity (Kloo, 2006; Roehrig et al., 2008; Uribe-Zarain, 2006).

Little research however had previously examined the relationship between oral reading fluency development and achievement in reading comprehension for large populations of racially/ethnically and socioeconomically diverse students attending lower performing schools, and neither had this relationship been examined longitudinally. Although several of these studies provided significant evidence of correlation between the two early reading assessments, most had failed either to disaggregate the data 
according to student demographic subgroups or secure a large enough sample of students to adequately represent the diverse subgroups.

The scope of this current study focused on the effectiveness of early oral reading fluency progress-monitoring assessments for predicting reading comprehension achievement, when analyzed among a large sample of diverse students attending historically lower performing schools in South Florida. The findings of this study are vital toward adding to the literature about learners with varied demographic backgrounds, as it included large numbers of racial and ethnic minority students and students from lowincome families, for whom the available research has remained limited. The sample of 1,663 participants in this current study was comprised of $72.5 \%$ Black $(n=1,206), 15.4 \%$ Hispanic $(n=256), 8.1 \%$ White $(n=134)$, and $4.0 \%$ Other (a combined population of $n=$ 67 Asian, Multiracial, and Native American) students.

\section{Findings and Interpretation}

\section{Linear Regression Analyses}

The correlation of early oral reading fluency ability with third grade reading comprehension achievement for all 1,663 participants produced significant positive results in this study. When the data were analyzed through linear regressions, $37.2 \%$ of the variance of third grade reading comprehension achievement was accounted for by its linear relationship with third grade oral reading fluency ability, while $35.2 \%$ of the variance was accounted for by the linear relationship between third grade reading comprehension achievement and second grade oral reading fluency ability, and $29.7 \%$ of the variance was accounted for by the linear relationship between third grade reading comprehension achievement and first grade oral reading fluency ability. 
The correlation between third grade reading comprehension achievement and oral reading fluency ability was more powerful the closer together these two early reading assessments were administered. Third grade oral reading fluency ability demonstrated the closest association with third grade reading comprehension achievement $(r=.61)$, followed by oral reading fluency ability at second grade $(r=.59)$, and oral reading fluency ability at first grade $(r=.55)$.

Several research studies have explored the use of oral reading fluency assessments as predictors of performance on state-mandated, standardized tests of reading comprehension (Buck \& Torgesen, 2002; Kloo, 2006; Riedel, 2007; Roehrig, Petscher, Nettles, Hudson, \& Torgesen, 2008; Uribe-Zarain, 2006), and found there to be a high correlation of student achievement between these types of early reading assessments.

\section{Hierarchical Regression Analyses}

The assessment data in this study were also analyzed through hierarchical regressions to determine the predictive potential of first, second, and third grade oral reading fluency ability toward third grade reading comprehension achievement for all 1,663 participants. Each of the oral reading fluency measures taken at first, second, and third grade were sequentially entered (in this order) into the regression equation one step at a time to determine which of these measures added statistically significant amounts of unique or independent variance. A significant overall variance of $39.6 \%$ was realized when combining all oral reading fluency measures toward predicting reading comprehension achievement. While the first grade oral reading fluency ability measure explained an initial $29.7 \%$ of the variance, a $6.8 \%$ increase was realized by adding the 
second grade oral reading fluency ability measure to the regression equation, with an additional 3.2\% increase in variance being explained by adding the third grade oral reading fluency ability measurement.

First grade oral reading fluency ability explained the most variance in third grade reading comprehension achievement. Appreciably less variance was explained by the second grade and then even less by the third grade oral reading fluency ability measure scores. This is the same pattern for all the hierarchical regressions computed in this research; that is, the first step (first grade oral reading fluency ability) in the hierarchical regression explained the most variance, followed by the second step (second grade oral reading fluency ability), and finally the third step (third grade oral reading fluency ability).

This pattern of data entry, beginning with the first grade oral reading fluency measure entered in the first step, was chosen based on previous research that signified the importance of measuring early reading ability toward future reading success and identifying potential reading deficiencies to more effectively target differentiated intervention instruction as early as possible (Buck \& Torgesen, 2002; Hintze \& Silberglitt, 2005). The earlier intervention needs are identified, the greater likelihood the reading deficiencies can be remedied (Juel, 1988).

Riedel (2007) found the Oral Reading Fluency (ORF) subtest, when administered to first grade students, proved to be the best Dynamic Indicators of Basic Early Literacy Skills (DIBELS) subtest predictor, as well as the most strongly correlated for both the first grade and second grade reading comprehension measures. The first grade DIBELS ORF scores provided similar predictive power toward comprehension achievement in 
Grade 1 (79.5\%) as well as Grade 2 (71.8\%; Riedel, 2007). In a longitudinal study, Kloo (2006) collected DIBELS ORF data over three grade levels (Grades 1, 2, and 3) along with reading comprehension achievement data from the Pennsylvania System of School Assessment (PSSA) outcome measure administered at third grade. Upon analyzing the DIBELS ORF and PSSA data longitudinally for the same set of students, Kloo confirmed positive correlations and predictive ability between these assessment measures. In another longitudinal study, Hintze \& Silberglitt (2005) likewise found predictive validity of first, second, and third grade Curriculum Based Measurement (CBM) of oral reading fluency ability toward reading comprehension achievement as measured on the highstakes third grade Minnesota Comprehensive Assessment (MCA) was significant and strongly correlated at all grade levels.

Gender demographics. When the data were further disaggregated by student demographic membership of gender (i.e., male, female), slight differences occurred between the predictive power of oral reading fluency ability toward reading comprehension achievement across each of the demographic subgroups and oral reading fluency measures. An overall difference in variance of $6.0 \%$ was produced between male $(41.2 \%)$ and female (35.2\%) student subgroups when all three oral reading fluency ability measures were combined (first, second, and third grade), an indication that the three oral reading fluency measures combined provided as a slightly better predictor of reading comprehension achievement for male students than for female students. This is an area of research that warrants further exploration as despite the difference in variance between male and female students in this study this researcher was unable to locate previous studies that reported differences based on gender. 
For male students, first grade oral reading fluency explained the most variance in reading comprehension achievement (31.4\%), when compared to second grade oral reading fluency $(6.9 \%)$ and third grade oral reading fluency (3.1\%). For female students, first grade oral reading fluency likewise explained the most variance in reading comprehension achievement (26.2\%), when compared to the impact of the second grade oral reading fluency measure (6.0\%), and third grade oral reading fluency (3.2\%). Overall, first grade oral reading fluency explained the most unique variance in third grade reading comprehension achievement for both male and female students.

Race/ethnicity demographics. When the data were further disaggregated by student demographic membership of race/ethnicity (i.e., Black, White, Hispanic, Other), notable differences occurred between the predictive power of oral reading fluency ability toward reading comprehension achievement across each of the demographic subgroups and oral reading fluency measures. Some of the demographic subgroups realized more significant results than others for each of the oral reading fluency ability measures.

The overall explained variance between all three oral reading fluency ability measures combined (first, second, and third grades) among the racial/ethnic demographic subgroups of students was fairly consistent for the Black (37.9\%), White (41.0\%), and Hispanic (37.0\%) students, however, these three subgroups varied significantly from the Other subgroup (i.e., Asian, Multiracial, and Native American populations) of students (55.0\%). Among the remaining three subgroups, overall the White student population realized a slightly better predictive ability than did the Black or Hispanic student populations. 
First grade oral reading fluency ability was the best predictor of reading comprehension achievement with similar unique variances of $28.3 \%$ for the Black student subgroup, $30.8 \%$ for the White student subgroup, and $31.1 \%$ for the Hispanic student subgroup, and a powerful 52.4\% for the Other student subgroup (i.e., Asian, Multiracial, and Native American populations). In this current study, the Other subgroup of students represented only $4.0 \%$ of the sample participants (67 out of 1,663 students). Low representation of students in the Other subgroup warrants caution regarding the results. It is recommended that future research target a larger student population representing this subgroup to determine if similar results would be achieved.

A similar study conducted by Uribe-Zarain (2006) in Delaware determined differences in the relationship between performance measured on the DIBELS ORF assessment and their state-mandated reading comprehension achievement assessment the Delaware Student Testing Program (DSTP) when the data were disaggregated by student demographic subgroups of race/ethnicity and socioeconomic status. By disaggregating the data into these specific subgroups, the results of the correlation coefficients varied widely. Prior to the data disaggregation of the subgroups, Uribe-Zarain obtained a strong correlation between performance on these two assessments, but when the data were disaggregated for these subgroups the correlations proved far weaker for the African American students and students from low-income families.

Socioeconomic status demographics. When the data were further disaggregated by student demographic membership of socioeconomic status (i.e., low, moderate), changes occurred between the predictive power of oral reading fluency ability toward reading comprehension achievement across each of the demographic subgroups and oral 
reading fluency measures. Specific to this study, low socioeconomic status was attributed to any student who qualified for free or reduced price meals, while moderate socioeconomic status was attributed to any student who did not meet eligibility requirements for free or reduced price meals.

Consistent overall variances with only a $1.0 \%$ difference were produced between the low (38.6\%) and moderate (39.6\%) socioeconomic status subgroups of students when all three oral reading fluency ability measures were combined (first, second, and third grade). This indicates that the three oral reading fluency measures combined provide as a very similar predictor for both the low and moderate socioeconomic status subgroups of students.

For students of low socioeconomic status, first grade oral reading fluency explained the most variance in reading comprehension achievement $(28.9 \%)$, when compared to second grade oral reading fluency $(6.6 \%)$ and third grade oral reading fluency $(3.2 \%)$. For students of moderate socioeconomic status, first grade oral reading fluency likewise explained the most variance in reading comprehension achievement (28.8\%), when compared to the impact of the second grade oral reading fluency measure (7.7\%), and third grade oral reading fluency (4.1\%). For students of both low and moderate socioeconomic status, first grade oral reading fluency explained the most variance in third grade reading comprehension achievement, followed by second grade oral reading fluency, and third grade oral reading fluency.

Demographics. Male $(n=853)$ and female $(n=810)$ student subgroups were evenly distributed among the total sample of participants in this study; nonetheless, the socioeconomic status subgroups were not as evenly distributed. The number of low- 
income students in this sample outnumbered the moderate-income students by a ratio of almost 9:1. The racial/ethnic subgroups were not as evenly distributed either. The sample participants included a majority of Black students at a ratio of approximately 5:1 when compared to the Hispanic student subgroup, approximately 9:1 when compared to the White student subgroup, and approximately 20:1 when compared to the Other student subgroup (i.e., Asian, Multiracial, and Native American populations).

Although the resulting data were very similar among the gender subgroups for male and female students as well as the socioeconomic status subgroups of low and moderate income, larger discrepancies between the racial/ethnic subgroups were realized. Oral reading fluency ability provided as a much better predictor of achievement in reading comprehension for the Other student subgroup (i.e., Asian, Multiracial, and Native American populations) when compared to the Black, White, and Hispanic racial/ethnic subgroups, which produced similar results when compared to each other.

\section{Limitations of the Study}

Although the sample of this study was chosen from Reading First funded schools in which the early oral reading fluency data were abundant, obtaining participants from these schools does present a limitation. Reading First funded schools were typically located in lower socioeconomic areas of the district and contained large numbers of racial and ethnic minority students and low-income families. Because one of the demographic subgroups for which the data were disaggregated was based on race/ethnicity, the subgroups of the sample were significantly unequal, as the Black and Hispanic student population attending these targeted schools were far greater in number than the White and Other student populations. Although this presents a possible limitation of the current 
study, similar research studies have included student samples that significantly lacked racial/ethnic minority and low-income representation. This current study addressed that gap in the research, as the targeted schools serviced large populations of racial/ethnic minority students of low-socioeconomic status.

Reading comprehension is a sophisticated process that involves the reader employing his or her prior knowledge while interacting with the content of the text and the author's intended message (Harris \& Hodges, 1995; RAND Reading Study Group, 2002). Measuring achievement in reading comprehension involves a much more complicated process than simply reading passages and responding to multiple-choice performance tasks to answer select skill-related questions of comprehension. The FCATSSS Reading, designated in this study as the measurement tool for determining reading comprehension achievement is one way of measuring reading comprehension, but presents a possible limitation.

Although the FCAT-SSS Reading, a state-mandated high-stakes standardized test of reading comprehension, is used to satisfy the accountability measures within all school districts across the state of Florida, it does not provide a comprehensive measure of achievement in reading comprehension. It is acknowledged that this current study was limited to measuring student achievement in reading comprehension through the use of this one standardized traditional multiple-choice formatted testing measure, which was limited by the scope of the comprehension skills assessed.

\section{Implications and Recommendations}

Early oral reading fluency ability in this study, as measured on progressmonitoring assessments administered in 2007, 2008, and 2009, explained substantial 
variance in third grade reading comprehension achievement as measured on one highstakes test administered in 2009, with considerable implications for theory, policy, practice, and research. The results of this longitudinal study seem all that more essential considering the overall achievement gap in reading development across the nation continues to significantly widen, despite research supporting the relationship between oral reading fluency ability and reading comprehension achievement (FDOE, 2009; Gamse, Jacob, Horst, Boulay, \& Unlu, 2008; Kim \& Sunderman, 2005; Schott Foundation for Public Education [SFPE], 2010).

\section{Implications for Theory}

Results of this study support all hypothesized models of predicted reading comprehension achievement that were tested using correlational and hierarchical regression analyses. The models hypothesized that early oral reading fluency ability as measured in first, second, and third grades would be related to third grade reading comprehension achievement. The research evidence supported Hypotheses 1, 2, and 3 resulting in significant positive relations between each of the three oral reading fluency ability measures (in first grade [2007], second grade [2008], and third grade [2009]) and the reading comprehension achievement measure (in third grade [2009]). In addition, the research evidence supported Hypotheses 4 and 5 resulting in significant variances in reading comprehension achievement being explained by early oral reading fluency ability among each of the gender subgroups (i.e., male, female), racial/ethnic subgroups (i.e., Black, White, Hispanic, Other), and socioeconomic status subgroups (i.e., low, moderate). 
As guiding research for the federal legislation of the No Child Left Behind (NCLB) Act of 2001, the Report of the National Reading Panel: Teaching Children to Read (National Institute of Child Health and Human Development [NICHD], 2000) recognized reading fluency as an essential component of reading instruction. Long before the National Reading Panel Report (NICHD), Allington (1983) stressed the importance of reading fluency as a foundational skill necessary for effective literacy development, yet it failed to receive the emphasized attention until it was brought to the national forefront through policy reforms of the federal NCLB legislation (Rasinski, 2005).

With this renewed national interest in reading fluency development, standardized assessment of fluency became common practice toward measuring and promoting accountability for the early reading progress of young learners through the Reading First Initiative (Torgesen, 2003). In this study, the first, second, and third grade oral reading fluency measures of the Dynamic Indicators of Basic Early Literacy Skills (DIBELS) correlated to and provided significant predictive ability toward comprehension achievement as measured on the state-mandated third grade Florida Comprehensive Assessment Test of the Sunshine State Standards (FCAT-SSS) Reading. Solely analyzing this data provides support for the continued practice of using DIBELS ORF assessments to monitor student progress in first, second, and third grades as the data provides predictive power toward comprehension achievement on the FCAT-SSS Reading.

With the heightened awareness of the importance for monitoring student fluency progress and providing fluency instruction and practice opportunities to young learners, Allington (1983) along with Pikulski and Chard (2005) caution that comprehension of text must be emphasized. While a strong correlation exists between effective reading 
fluency and reading comprehension (Pikulski \& Chard, 2005), key findings of the research team that released the Reading First Impact Study: Final Report have raised significant concerns for schools that participated in the Reading First Initiative (Gamse, Jacob, Horst, Boulay, \& Unlu, 2008). Following years of funding through Reading First, Gamse et al. (2008) concluded that although the Reading First Initiative produced a positive and statistically significant impact on the amount of time spent instructing the five essential components of reading that included reading fluency in Grades 1 and 2, the initiative failed to produce a statistically significant impact on student achievement in reading comprehension test scores for Grades 1, 2, or 3 (Gamse et al., 2008). Despite the strong correlations and predictive ability provided between the DIBELS ORF and FCATSSS Reading measures, the fact that Gamse et al. (2008) found there to be no statistically significant impact on first, second, and third grade student achievement in reading comprehension is troubling.

Many researchers agree that if young learners are to develop appropriate reading fluency, their instruction, practice, and assessment of fluency must interactively and comprehensively integrate all three of its essential elements: reading rate, reading accuracy, and prosodic reading (Allington, 1983, 2001; Hudson, Lane, \& Pullen, 2005; Rasinski, 2004; Stahl, Heubach, \& Holcomb, 2005; Valencia et al., 2010). While reading rate and reading accuracy consist of the speed with which one reads the words correctly, prosodic reading incorporates the use of appropriate phrasing and language patterns, pitch and stress, intonation, expression and volume, smoothness, and pace during the oral reading process (Allington, 1983; Hudson et al., 2005; Rasinski, 2004). 
The early oral reading fluency measures of DIBELS used in this current study provide developmental data specific to the rate and accuracy of reading fluency, neglecting the prosodic reading element (Hasbrouck \& Tindal, 2006; Hudson et al., 2005). According to Hudson et al., the lack of attention provided to the development of prosodic skills can directly contribute to the creation of learners who are capable of reading quickly and accurately, yet exhibit poor comprehension of text.

When effectively applied to the oral reading of text, prosodic skills signify the reader's proper use of volume, phrasing, language patterns, smoothness, pace, and natural intonation, which then each contribute to activating the appropriate expression during reading (Allington, 1983; Hudson et al., 2005; Rasinski, 2004). Complex prosodic skills provide the reader support with making sense of the language and structure of text (Hudson et al., 2005), making it clear that a reciprocal relationship exists between reading prosody and reading comprehension (Allington, 1983, 2001; Hudson et al., 2005; Rasinski, 2004). The absence of data reflecting the development of reading prosody implies that the prosodic element is less significant to fluency development than reading rate and accuracy (Allington, 1983; Hudson et al., 2005; Rasinski, 2004).

Although becoming a fluent reader is critical to proficient and motivated reading, fluency assessments that isolate these two measured elements often lead educators to narrowly focus on supporting improvement in their students' rate and accuracy scores for which they are held accountable (Hasbrouck \& Tindal, 2006; Valencia et al., 2010). This practice further encourages educators to limit reading fluency instruction and practice experiences solely in these measured elements. Improper instruction and application that specifically targets rate and accuracy can result in children reading too quickly, focusing 
on reading the words fast with minimal attention to the content of the text for which they should be reading to understand (Stahl et al., 2005). Rasinski (2000) cautioned when reading is paced too quickly, the reader often experiences difficulty processing the content of the text, causing comprehension to be severely compromised.

Along with a heightened awareness of the importance for providing effective fluency instruction and practice opportunities to young learners, there is additional concern regarding how significant the relationship is between reading fluency development and the overall ability to read proficiently with a more rigorous and critical comprehension of text. In this current study, the FCAT-SSS Reading is the statemandated standardized assessment used to measure achievement in reading comprehension, but the skills and competencies measured on this test are restricted to a select set of eight reading benchmarks in a multiple-choice response format (FDOE, 2007).

As proficient readers comprehend, a much more complex process is executed (Allington, 2000; Durkin, 1993; Harris \& Hodges, 1995; RAND Reading Study Group, 2002), which is grander in scope than one can demonstrate by the limited benchmarks measured in multiple-choice format on a traditional standardized test of reading comprehension achievement such as the FCAT. While the current assessment practice involves locating and matching information found in texts, the full scope of comprehension involves a more complex process of simultaneously extracting and constructing meaning with an accurate understanding of the intended message through interaction and involvement with written or spoken language (Allington, 2000; Harris \& Hodges, 1995; RAND Reading Study Group, 2002). 
While the ultimate goal of reading is to understand and comprehend the meaning of text (Allington, 2001; Hudson et al., 2005; Snow, Burns, \& Griffin, 1998; Torgesen, 2002), what constitutes effective measurement of comprehension and progress monitoring of learners toward proficient reading development is not as clearly defined. Despite the research that currently exists in support of oral reading fluency ability toward predicting achievement in reading comprehension for which this current study adds to, the overall achievement gap in reading development across the nation continues to widen significantly (FDOE, 2009; Gamse et al., 2008; Kim \& Sunderman, 2005; Schott Foundation for Public Education [SFPE], 2010). If the Reading First Initiative, designed to target diverse students attending lower-performing schools, failed to produce a statistically significant impact on student achievement in reading comprehension (Gamse et al., 2008), despite the reliance of oral reading fluency progress monitoring assessments that correlate to and provide strong relationships with several state-mandated tests of reading comprehension achievement for diverse learners, then further investigation into this problem is warranted.

\section{Implications for Policy}

As first evidenced by Stanovich (1986) over 25 years ago, the Matthew effect phenomenon continues to pervade classrooms today with higher-achieving learners who tend to maintain their academic success, while struggling learners often remain on a path of academic failure. Unless struggling learners receive effective academic support, the achievement gap will continue to widen between these groups of learners, and in fact, according to Kim and Sunderman (2005), widening of the achievement gap seems to 
have persisted despite the efforts of No Child Left Behind (NCLB) and its primary goal of supporting our most struggling learners in low achieving schools.

Another aspect of the Matthew effect that warrants consideration, according to Stanovich (1986), is the importance for students to be surrounded by higher ability peers. When all members of the classroom are of lower ability, growth and development are much less likely to occur among members of the group. This has presented a problem for young learners who have attended Reading First funded schools. The Reading First Initiative originated to target students attending lower achieving schools, which tend to be located in communities where low-income, minority families reside. Schools located in these lower socioeconomic areas of this South Florida school district tend to service student populations who enter school with limited foundational development in literacy, therefore large numbers of minority students from low-income families have been placed most at risk for failure of this initiative.

The recently released 2010 Schott 50 State Report on Black Males in Public Education (Schott Foundation for Public Education [SFPE], 2010) has evidenced continuation of the widening achievement gap, and despite the intention of the Reading First Initiative minimal progress was made in an effort to reverse this trend (Gamse, Jacob, Horst, Boulay, \& Unlu, 2008; Kim \& Sunderman, 2005). The achievement gap continues to plague all levels through high school. Examining the disparity of the Black male student population, the Schott Report (SFPE, 2010) reveals the rapidly decreasing rate at which Black male students are graduating from high school on a national scale, consistently decreasing by far greater numbers than any other racial or gender subgroup population. 
The conclusion reached in the Schott Report is that "the American educational system is systematically failing Black males" (SFPE, 2010, p. 37). This trend must be reversed in every state throughout the nation, and schools held accountable for providing equal and effective educational opportunities that address the needs of all students, including diverse populations, "to ensure educational outcomes are not identifiable by race or gender" (SFPE, 2010, p. 2).

While it has been well documented that Black male students are of greatest risk for academic failure (SFPE, 2010), what occurs in the classroom impacts their progress. For far too long, curriculum and instruction has failed to address the needs of all students (Baker \& Digiovanni, 2005), with too many states and districts reluctant to modify their curriculum and instruction and reflect more engaging and equitable practices to support the diverse needs of every learner (SFPE, 2010). The focus should not solely be placed on students mastering a specified curriculum, but more inclusively on how we can effectively facilitate all students with mastering a curriculum they find engaging and recognize as relevant to their lives (Baker \& Digiovanni, 2005).

All too often, classroom practice fails to provide learners a connection between their life experiences and education; therefore, infusing one's culture into curriculum through relevant and engaging experiences is essential for teachers to become effective facilitators capable of addressing the diverse needs of all learners (Baker \& Digiovanni, 2005; Brown-Jeffy \& Cooper, 2011). This requires teachers to fully understand a variety of cultural perspectives essential to integrating experiences into teaching and learning practices designed to be more reflective of the cultural diversity that represents all learners in the classroom (Baker \& Digiovanni, 2005; Brown-Jeffy \& Cooper, 2011). 
In addition to a modified curriculum and instructional practice, a closer look at the progress monitoring of reading achievement among diverse student populations is warranted to support the selection of assessment tools that will consistently, accurately, and effectively measure growth in reading achievement across all gender, racial/ethnic, and socioeconomic populations. The more thoroughly we examine teaching and learning for all essential foundational components of reading instruction (oral language, phonemic awareness, phonics, fluency, vocabulary, and comprehension) among all student populations, the more effective educators will be at addressing the differentiated needs of all learners (Wolf, 2007). Instruction and application of these foundational skills must occur through a variety of integrated reading, writing, listening, speaking, and language experiences rather than through isolated instruction of these prerequisite components (International Reading Association Common Core State Standards Committee [IRACCSSC], 2012).

Despite the efforts of the current federal No Child Left Behind (NCLB) legislation, which originated to assist the most struggling learners (Olson \& Viadero, 2002), there does not appear to be widespread success with closing the achievement gap (Kim \& Sunderman, 2005; SFPE, 2010). Although the intent of the federal NCLB legislation was to provide significant support to lower performing schools, which occurred through the Reading First Initiative, according to school grading records, significant progress was not achieved at these targeted schools across the state (FDOE, 2009). The time has come to seriously reevaluate the efforts of NCLB and all associated educational practices that have been put in place to meet these legislative requirements and identify alternative actions that will best support struggling learners so that ultimately 
the elimination of, and more realistically the reduction in, the achievement gap can be realized.

While a strong correlation between early oral reading fluency ability and reading comprehension achievement among a large diverse group of primary students in first through third grades was evidenced through the current research study, some levels of disparity between racial/ethnic subgroups of students continue to rise dramatically resulting in an ever-widening achievement gap. With these incongruent results, this research study suggests a need to further explore the assessment tools being used to measure foundational reading skills in the early grades and how these tools directly impact the complexity of comprehension development that leads to increased proficiency in reading.

Five years overdue, the federal public education legislation, NCLB Act of 2001, was slated for reauthorization in early 2007 (U.S. Department of Education [USDOE], 2008). The original intent of the NCLB legislation was to significantly increase reading achievement among learners attending public schools across the nation, by instituting strict policy standards for reading education (NICHD, 2000). A substantial increase in support provided to lower performing schools was included in the legislation through the federal Reading First Initiative (Torgesen, 2003).

Despite the efforts that have been instituted toward this end, the progress has fallen far short of its goal (Altshuler \& Schmautz, 2006), as closing the achievement gap between academically and socioeconomically advantaged and disadvantaged learners has not been realized (Kim \& Sunderman, 2005; SFPE, 2010). Although reauthorization of NCLB will require thorough investigations into present practice and how to adjust policy 
to significantly increase learners' progress in reading achievement, each component of the policy will require scrutiny for its effectiveness at realizing this goal.

\section{Implications for Practice}

A strong educational plan in reading includes reciprocity between curriculum, assessment, and instruction (Ransom, Santa, Williams, \& Farstrup, 1999). As Cobb (2003) pointed out, "the relationship of curriculum, assessment, and instruction must be integrated and reciprocal", as all are "critical components of effective teaching and learning" processes (p. 386). Each component is integral to a young learner's academic development.

While the reciprocity of curriculum, assessment, and instruction is critical, exactly what defines these components will change as new research guides policy revisions and our nation faces new challenges to provide the most effective public education. No Child Left Behind (NCLB), the current federal legislation that has prevailed throughout the last decade appears to be losing the momentum it once endured. More legislative changes have begun. The most recent urgency in public education is to drastically move from state-specific standards and accountability measures that present disparity across states to a more consistent set of common standards and assessments (Reeves et al., 2011).

The new Common Core State Standards (CCSS) were released in 2010 by the National Governors Association (NGA) Center for Best Practices and the Council of Chief State School Officers (CCSSO - National Governors Association Center for Best

Practices, Council of Chief State School Officers [NGACBP, CCSSO], 2010; Reeves, et al., 2011). The state-led development of the standards occurred in a decade-long process 
of collaboration between a variety of stakeholders that included content experts, state education departments, teachers, school administrators, and parents.

These rigorous standards provide new promise for all students nationally as they are research and evidence based, internationally benchmarked, and aligned with college and career expectations necessary for meeting success in our 21 st century globally competitive society (NGACBP, CCSSO, 2010). With the introduction of the CCSS that currently 45 states and Washington, D.C. have adopted, changes to assessment will follow (NGACBP, CCSSO, 2010). The state of Florida, having adopted the Common Core State Standards in July of 2010, is serving on the Governing Board and as Fiscal agent of the consortium to develop the new Partnership for Assessment of Readiness for College and Careers (PARCC) due to begin its administration in the fall of 2014 (Partnership for Assessment of Readiness for College and Careers [PARCC], 2012).

The PARCC, designed for administration throughout the school year, is being aligned to formative instructional practice that will include the integration of literacy components in reading, writing, listening, speaking, and language (PARCC, 2012). This is opposed to the design of most current state tests that serve as high-stakes accountability measures based primarily on a minimal set of broad reading benchmarks presented in a multiple-choice response format administered once a year as a summative assessment, providing little to no guidance for informing daily instructional practice throughout the school year.

While little has been done to significantly decrease the achievement gap in reading development across the nation (FDOE, 2009; Gamse, Jacob, Horst, Boulay, \& Unlu, 2008; Kim \& Sunderman, 2005; Schott Foundation for Public Education [SFPE], 
2010), new promise prevails with the implementation of the CCSS and PARCC assessments. For many of the past education initiatives as far back as $A$ Nation at Risk (National Commission on Excellence in Education [NCEE], 1983) concern has been raised about curriculum that has fallen far short of rigorous. This necessity is apparent with the increasing literacy demands placed upon reading and understanding more complex texts that are evident in college, careers, and life experiences across the last several decades (NGACBP, CCSSO, 2010), while at the same time the texts used in K-12 public education have dramatically declined in sophistication (Chall, Conrad, \& Harris, 1977; Hayes, Wolfer, \& Wolf, 1996). This has presented a lack of support provided to students in developing their independence to proficiently read and understand more rigorous, complex texts that make it necessary to achieve success in our present 21 st century globally competitive society (NGACBP, CCSSO, 2010).

Implementation of these new highly rigorous standards represent outcomes that are qualitatively different from past standards and provide promise in better preparing students for success (International Reading Association Common Core State Standards Committee [IRACCSSC], 2012), but simply adding more rigorous standards to current traditional instructional practices will not suffice. Rigor without relevance is not possible according to Daggett (2009), and unless educators develop relationships with their students to better understand what interests them and plan teaching and learning practices that capitalize on their differentiated interests then relevance will not be possible. When students are interested in and find relevance to their instruction, they will be more engaged and motivated to learn even with increased rigor (Daggett, 2009). 
While a large number of children continue to experience difficulty acquiring proficiency in reading, most often these lower achieving numbers are overrepresented by children of racial/ethnic minority groups in low-income families (Allington, 2000; SFPE, 2010). Providing all learners scaffolded instructional support through motivation, proficient models of expected academic behaviors, and close instructional guidance until students are capable of performing independently is critical for all students to achieve success in accomplishing these new standards (IRACCSSC, 2012; Wood, Bruner, \& Ross, 1976).

The common core standards and assessments may provide promise of an improved educational plan, but the progress of our most academically and socioeconomically disadvantaged children will require increased support and close monitoring. Effective instructional scaffolding must be provided based on every student's uniquely individual and differentiated needs to halt academic failure by promoting success that will serve to reduce and eventually eliminate the current gap in achievement that exists between advantaged and disadvantaged students.

\section{Recommendations for Future Research}

Based on the results of this study, further research is warranted and the recommendations are multidimensional.

While oral reading fluency measures may continue to be administered as early progress monitoring tools, it is recommended that a replication of this study be conducted to further explore their correlation to and predictive ability toward reading comprehension achievement specific to the demographic subgroups of gender (i.e., male, female) and race/ethnicity (i.e., Black, White, Hispanic, Other). The Other subgroup for 
which any racial/ethnic population fits beyond the Black, White, and Hispanic subgroups will be necessary to explore depending on the specific student population that is targeted. In this South Florida school district, due to the significant differences in variance resulting for the Other subgroup further examination of correlations and predictive ability between oral reading fluency and reading comprehension achievement measures within the Asian, Multiracial, and Native American populations is recommended.

Although the DIBELS oral reading fluency ability measures correlate to the reading comprehension achievement of FCAT-SSS Reading in this study, it is recommended that further exploration of relationships between oral reading fluency assessment measures (that include prosodic reading ability data in addition to reading rate and reading accuracy data) and reading comprehension achievement be examined. Additionally, it is recommended that a broader, more complex measurement of reading comprehension achievement be used for determining the predictive power between oral reading fluency ability and reading comprehension achievement.

Despite the type of progress monitoring that has been conducted in the past and to what degree the progress monitoring has provided correlation to achievement in reading comprehension, with the implementation of the common core state standards more comprehensive progress monitoring measures will be warranted. While implementing this new set of common core standards will require a drastic change in educational practice, if children of racial/ethnic minorities (i.e., Black and Hispanic) and from lowincome families received better curriculum, instruction, and assessment perhaps replicating this study would provide a different set of results. It is therefore recommended that further research be conducted following full implementation of the common core 
state standards into instructional practice and ongoing assessment to better reflect achievement in more complex comprehension development.

Future research will need to focus on progress monitoring measures that provide greater accuracy in predicting later reading achievement as it relates directly to the understanding and comprehension of more complex and rigorous text meaning through the integration of reading, writing, listening, speaking, and language development (NGACBP, CCSSO, 2010). With full implementation of the CCSS and PARCC assessments instituted in the fall of 2014, now is the time to consider research that focuses on developing progress-monitoring tools to assist readers with proficiently meeting these higher standards of reading comprehension achievement.

Finally, and most importantly, it is recommended that all future research suggested above explore the diverse needs of all learners to more effectively provide equitable teaching and learning experiences no matter what their current level of achievement, where they attend school, or what their demographic background. Cultural relevance requires educators to understand the uniquely diverse backgrounds of students and recognize the importance of capitalizing on individual relevance to provide effective foundations for developing engaging learner experiences that are highly motivating. Given the results of this current research study and the achievement gap that continues to widen between academically and socioeconomically advantaged and disadvantaged populations the future success of all children depends on a more thorough understanding of how better curriculum, instruction, and assessment impact their ability and desire to learn. 


\section{Conclusion}

One of the major instructional shifts of the common core state standards calls for developing proficient readers who are capable of reading and comprehending more rigorous, complex texts that graduating high school students can expect in college and careers (NGACBP, CCSSO, 2010). As such, isolated skill intervention instruction currently being provided to struggling readers must be redesigned and implemented through an integrated literacy format. All students, including struggling readers, need ample opportunity to apply skills learned while reading text that increases in difficulty, and to more critically comprehend and demonstrate understanding for what is read through a variety of oral and written expressions.

While the drastic change in educational practice providing for the implementation of common standards and assessment is promising, new research will be warranted to ensure the drastic changes serve all students equitably as intended. Relevance for learning must be made apparent through engaging teaching and learning experiences that provide the foundation for motivating and developing eager self-initiated learners. Increased student achievement must be made possible for and realized by all learners, not just exclusively for the more academically and socioeconomically advantaged, regardless of gender, racial/ethnic background, or socioeconomic status. A focus on the optimal achievement among all students with the ultimate goal of eliminating the achievement gap is a priority we must make for ensuring equitable educational opportunities, increased levels of achievement, and proficient literacy development for all. 


\section{References}

Allington, R. L. (1983). Fluency: The neglected reading goal. The Reading Teacher, $36,556-561$.

Allington, R. L. (2000). Effects of reading policy on classroom instruction and student achievement (Report No. CELA-RR-13011). Albany, NY: National Research Center on English Learning and Achievement. (ERIC Document Reproduction Service No. ED450354)

Allington, R. L. (2001). What really matters for struggling readers: Designing researchbased programs. New York, NY: Addison Wesley Longman.

Allington, R. L. (2003). High-stakes testing does not improve the teaching or learning of reading. New England Reading Association Journal, 39(1), 31-37.

Altshuler, S. J., \& Schmautz, T. (2006). No Hispanic student left behind: The consequences of "high stakes" testing. Children and Schools, 28, 5-14.

American Federation of Teachers (AFT) of Washington, D.C. (n.d.). Retrieved June 4, 2006, from http://www.aft.org/pubs-reports/downloads/teachers/iraunionwork.pdf

Baker, P. B. \& Digiovanni, L. W. (2005, July). Narratives on culturally relevant pedagogy: Personal responses to the standardized curriculum. Current Issues in Education, 8(22). Retrieved from http://cie.ed.asu.edu/volume8/number22/index.html

Brown-Jeffy, S. \& Cooper, J. E. (2011). Toward a conceptual framework of culturally relevant pedagogy: An overview of the conceptual and theoretical literature. Teacher Education Quarterly, 38(1), 65-84.

Buck, J., \& Torgesen, J. (2002). The relationship between performance on a measure of oral reading fluency and performance on the Florida Comprehensive Assessment Test (Report No. 1). Tallahassee: Florida Center for Reading Research.

Chall, J. S., Conrad, S., \& Harris, S. (1977). An analysis of textbooks in relation to declining SAT scores. Princeton, NJ: College Entrance Examination Board.

Cobb, C. (2003). Effective instruction begins with purposeful assessments. The Reading Teacher, 57, 386-388.

Daggett, W. R. (Fall 2009). Relevance, rigor, and relationships: Bill Daggett's three R's for American schools. Educator, 4-9. 
Deno, S. L. (1985). Curriculum-Based Measurement: The emerging alternative. Exceptional Children, 52, 219-232.

Durkin, D. (1993). Teaching them to read (6th ed.). Boston, MA: Allyn and Bacon.

Field, A. P. (2009). Discovering statistics using SPSS: And sex and drugs and rock ' $n$ ' roll (3rd ed.). London: Sage.

Florida Center for Reading Research (FCRR). (2009a). FCRR assessment programs. Retrieved from http://fcrr.org/assessmentScreeningProgress Monitoring.htm

Florida Center for Reading Research (FCRR). (2009b). Progress monitoring and reporting network. Retrieved from http://www.fcrr.org/pmrn/ index.htm

Florida Department of Education (FDOE). (2005). FCAT handbook - A resource for educators. Retrieved from http://fcat.fldoe.org/handbk/fcathandbook.asp

Florida Department of Education (FDOE). (2007). Assessment and accountability briefing book. Retrieved from http://fcat.fldoe.org/fcatpub3.asp

Florida Department of Education (FDOE). (2008a). 2008 FCAT SSS reading, mathematics, and science. Retrieved from http://fcat.fldoe.org/mediapacket/2008/ default.asp

Florida Department of Education (FDOE). (2008b). 2008-09 Florida school indicators report. Retrieved from http://www.fldoe.org/eias/eiaspubs/0809fsir.asp

Florida Department of Education (FDOE). (2008c). Keys to FCAT 2009, grades 3-5. Retrieved from http://fcat.fldoe.org/fcatkeys.asp

Florida Department of Education (FDOE). (2009). FCAT state, district, and school reports. Retrieved from http://fcat.fldoe.org/results/default.asp

Florida Department of State (FDOS). (2010). State library and archives of Florida: Florida administrative weekly and Florida administrative code. Retrieved from https://www.flrules.org/gateway/ruleNo.asp?ID=6A-6.054

Florida Department of State (FDOS). (2011). Florida administrative weekly and Florida administrative code. Retrieved from https://www.flrules.org/gateway/ruleNo.asp?id=6A-6.053

Fuchs, L. S., \& Fuchs, D. (1999). Monitoring student progress toward the development of reading competence: A review of three forms of classroom-based assessment. School Psychology Review, 28, 659-671. 
Gamse, B. C., Jacob, R. T., Horst, M., Boulay, B., \& Unlu, F. (2008). Reading First impact study: Final report (NCEE 2009-4038). Washington, DC: National Center for Education Evaluation and Regional Assistance, Institute of Education Sciences, U.S. Department of Education.

Gay, L. R., \& Airasian, P. (2000). Educational research: Competencies for analysis and application (6th ed.). Upper Saddle River, NJ: Prentice-Hall.

Good, R. H., \& Jefferson, G. (1998). Contemporary perspectives on Curriculum-Based Measurement validity. In M. R. Shinn (Ed.), Advanced applications of Curriculum-Based Measurement (pp. 61-88). New York, NY: Guilford.

Good, R. H., \& Kaminski, R. A. (Eds.). (2005). Dynamic Indicators of Basic Early Literacy Skills (6th ed.). Eugene, OR: Institute for Development of Educational Achievement.

Gordinier, C. L., \& Foster, K. (2004). What stick is driving the Reading First hoop? Childhood Education, 81, 94.

Green, S. B. (1991). How many subjects does it take to do a regression analysis? Multivariate Behavioral Research, 26, 449-510.

Green, S. B., \& Salkind, N. J. (2003). Using SPSS for Windows and Macintosh: Analyzing and understanding data (3rd ed.). Upper Saddle River, NJ: Prentice Hall.

Harris, T. L., \& Hodges, R. E. (Eds.). (1995). The literacy dictionary: The vocabulary of reading and writing. Newark, DE: International Reading Association.

Hasbrouck, J., \& Tindal, G. A. (2006). Oral reading fluency norms: A valuable assessment tool for reading teachers. The Reading Teacher, 59, 636-644.

Hayes, D. P., Wolfer, L. T., \& Wolfe, M. F. (1996). Sourcebook simplification and its relation to the decline in SAT-Verbal scores. American Educational Research Journal, 33, 489-508.

Hinkle, D. E., Wiersma, W., \& Jurs, S. G. (2003). Applied statistics for the behavioral sciences (5th ed.). Boston, MA: Houghton Mifflin.

Hintze, J. M., \& Silberglitt, B. (2005). A longitudinal examination of the diagnostic accuracy and predictive validity of R-CBM and high-stakes testing. School Psychology Review, 34, 372-386.

Hudson, R. F., Lane, H. B., \& Pullen, P. C. (2005). Reading fluency assessment and instruction: What, why, and how? The Reading Teacher, 58, 702-714. 
International Reading Association Common Core State Standards (CCSS) Committee. (2012). Literacy implementation guidance for the ELA Common Core State Standards [White paper]. Retrieved from http://www.reading.org/Libraries/association-documents/ira_ccss_guidelines.pdf

Johnson, B. (2001). Toward a new classification of nonexperimental quantitative research. Educational Researcher, 30(2), 3-13.

Johnson, D. (1999). Balanced reading instruction: Review of literature. North Central Regional Educational Laboratory (NCREL). Retrieved from http://www.ncrel/ org/sdrs/timely/briiss.htm

Juel, C. (1988). Learning to read and write: A longitudinal study of 54 children from first through fourth grades. Journal of Educational Psychology, 80, 437-447.

Kim, J. S., \& Sunderman, G. L. (2005). Measuring academic proficiency under the No Child Left Behind Act: Implications for educational equity. Educational Researcher, 34(8), 3-13.

Kloo, A. M. (2006). The decision-making utility and predictive power of DIBELS for students' reading achievement in Pennsylvania's Reading First Schools. Dissertation Abstracts International: Section A. Humanities \& Social Sciences, 68(1), 129.

Kohn, A., \& Henkin, R. (2002). Poor teaching for poor kids. Language Arts, 79, 251255.

LD Online. (2008). Glossary. Retrieved from http://www.ldonline.org/glossary

Manzo, K. K. (2002). Some educators see reading rules as too restrictive. Education Week, 21(23), 1 \& 23-24.

Manzo, K. K. (2005). National clout of DIBELS test draws scrutiny. Education Week, 25(5), 1-2.

Marshall, J. D., Sears, J. T., \& Schubert, W. H. (2000). Turning points in curriculum: A contemporary American memoir. Upper Saddle River, NJ: Prentice-Hall.

National Center for Education Statistics (NCES). (2010). 2008-09 Common core of data: Public school district data. Retrieved from http://nces.ed.gov/ccd/districtsearch/ district_detail.asp?Search=1\&InstName=broward\&Zip=33301\&County=broward $\&$ DistrictType $=1 \&$ DistrictType $=2 \&$ DistrictType $=3 \&$ DistrictType $=4 \&$ DistrictTyp $\mathrm{e}=5 \&$ DistrictType $=6 \&$ DistrictType $=7 \&$ NumOfStudentsRange $=$ more $\&$ NumOfSc hoolsRange $=$ more $\& I D 2=1200180 \&$ details $=$ 
National Commission on Excellence in Education (NCEE). (1983). A nation at risk: The imperative for educational reform. Washington, DC: National Commission on Excellence in Education.

National Governors Association Center for Best Practices, Council of Chief State School Officers (NGACBP, CCSSO). (2010). Common core state standards for English language arts and literacy in history/social studies, science, and technical subjects. Washington, DC: National Governors Association for Best Practices, Council of Chief State School Officers.

National Institute of Child Health and Human Development (NICHD). (2000). Report of the National Reading Panel. Teaching children to read: An evidence-based assessment of the scientific research literature on reading and its implications for reading instruction (NIH Publication No. 00-4769). Washington, DC: Government Printing Office.

Olson, L., \& Viadero, D. (2002). Law mandates scientific base for research. Education Week, 21(20), 1 \& 14-15.

Partnership for Assessment of Readiness for College and Careers (PARCC). (2012). About PARCC. Retrieved from http://www.parcconline.org/governance

Perfetti, C. (2007). Reading ability: Lexical quality to comprehension. Scientific Studies of Reading, 11, 357-383.

Petrocelli, J. V. (2003). Hierarchical multiple regression in counseling research: Common problems and possible remedies. Measurement and Evaluation in Counseling and Development, 36, 9-22.

Pikulski, J. J., \& Chard, D. J. (2005). Fluency: Bridge between decoding and reading comprehension. The Reading Teacher, 58, 510-519.

Pressley, M. (2002). Effective beginning reading instruction. Journal of Literacy Research, 34, 165-188.

Proximity One. (2010a). 2008-09 school district ranking. Retrieved from http://www. proximityone.com/sddmi.htm

Proximity One. (2010b). Largest 100 U.S. school districts. Retrieved from http://www. proximityone.com/lgsd.htm

RAND Reading Study Group. (2002). Reading for understanding: Toward a research and development program in reading comprehension. Santa Monica, CA: RAND Education. 
Ransom, K. A., Santa, C. M., Williams, C. K., \& Farstrup, A. E. (1999). High-stakes assessments in reading: A position statement of the International Reading Association. Journal of Adolescent \& Adult Literacy, 43, 305-312.

Rasinski, T. V. (2000). Speed does matter in reading. The Reading Teacher, 54, 146-151.

Rasinski, T. V. (2004). Creating fluent readers. Educational Leadership, 61(6), 46-51.

Rasinski, T. V. (2005). The role of the teacher in effective fluency instruction. New England Reading Association Journal, 41(1), 9-13.

Reutzel, D. R., \& Mitchell, J. (2005). High-stakes accountability themed issue: How did we get here from there? The Reading Teacher, 58, 606-608.

Reeves, D. B., Wiggs, M. D., Lassiter, C. J., Piercy, T. D., Ventura, S., \& Bell, B. (2011). Navigating implementation of the common core state standards. Englewood, CO: Lead + Learn Press.

Riedel, B. W. (2007). The relation between DIBELS, reading comprehension, and vocabulary in urban first-grade students. Reading Research Quarterly, 42, 546-562.

Robelen, E. W. (2002). ESEA to boost federal role in education. Education Week, 21(16), $1,28-29 \& 31$.

Roehrig, A. D., Petscher, Y., Nettles, S. M., Hudson, R. F., \& Torgesen, J. K. (2008). Accuracy of the DIBELS oral reading fluency measure for predicting third grade reading comprehension outcomes. Journal of School Psychology, 46, 343-366.

Schott Foundation for Public Education (SFPE). (2010). Yes we can: The 2010 Schott 50 state report on black males in public education. Retrieved from http://www.black boysreport.org/

Schubert, W. H. (1986). Curriculum: Perspective, paradigm, and possibility. Upper Saddle River, NJ: Prentice-Hall.

Snow, C. E., Burns, M. S., \& Griffin, P. (Eds.). (1998). Preventing reading difficulties in young children. Washington, DC: National Academy Press.

Soper, D. S. (2004). A priori sample size calculator for multiple regression. Retrieved March 12, 2009 from Daniel Soper web site: http://www.danielsoper.com/ statcalc/calc01.aspx 
Stahl, S. A., Heubach, K. M., \& Holcomb, A. (2005). Fluency-oriented reading instruction. Journal of Literacy Research, 37, 25-60.

Stanovich, K. E. (1986). Matthew effects in reading: Some consequences of individual differences in the acquisition of literacy. Reading Research Quarterly, 21, 360-407.

Teach in Florida. (2010). Florida's south east region. Retrieved from http://www. teachinflorida.com/Recruitment/TourtheSunshineState/SouthEastRegion/tabid/ 183/Default.aspx

Tindal, G. A., Marston, D., \& Deno, S. L. (1983). The reliability of direct and repeated measurement (Report No. 109). Minneapolis, MN: University of Minnesota Institute for Research on Learning Disabilities.

Tomlinson, C. A. (2000). Differentiation of instruction in the elementary grades (Report No. EDO-PS-00-7). Champaign, IL: Clearinghouse on Elementary and Early Childhood Education. (ERIC Document Reproduction Service No. ED-99-CO0020).

Torgesen, J. K. (2002). The prevention of reading difficulties. Journal of School Psychology, 40, 7-26.

Torgesen, J. K. (2003). Florida's Reading First assessment plan: An explanation and guide. Retrieved from Florida Center for Reading Research (FCRR) website: http://www.fcrr.org

Torgesen, J. K. (2006). A comprehensive K-3 reading assessment plan: Guidance for school leaders. Portsmouth, NH: RMC Research Corporation, Center on Instruction.

U.S. Department of Agriculture (USDA). (2011). Food and nutrition service: Income eligibility guidelines. Retrieved from http://www.fns.usda.gov/cnd/Governance/notices/iegs/IEGs.htm

U.S. Department of Education (USDOE). (2008). No Child Left Behind reauthorization. Retrieved from http://www.ed.gov/nclb/overview/intro/reauth/index.html

University of Oregon Center on Teaching and Learning. (2009). DIBELS data system. Retrieved from https://dibels.uoregon.edu/samples/index.php

Uribe-Zarain, X. (2006). Relationship between student performance on DIBELS oral reading fluency and third grade reading DSTP (Report No. T06.013.01). Newark: University of Delaware, Education Research and Development Center. 
Valencia, S. W., \& Buly, M. R. (2004). Behind test scores: What struggling readers really need. The Reading Teacher, 57, 520-531.

Valencia, S. W., Smith, A. T., Reece, A. M., Li, M., Wixson, K. K., \& Newman, H. (2010). Oral reading fluency assessment: Issues of construct, criterion, and consequential validity. Reading Research Quarterly, 45, 270-291.

Venable, J. W. (2006). The national reading curriculum's oobleck. Phi Delta Kappan, $87,693-695$.

Wolf, M. (2007). Proust and the squid: The story and science of the reading brain. New York, NY: HarperCollins.

Wood, D., Bruner, J. S., \& Ross, G. (1976). The role of tutoring in problem solving. Journal of Child Psychology and Psychiatry and Allied Disciplines, 17, 89100. 
VITA

TERI L. ACQUAVITA

July 19, 1957 Born, West Palm Beach, Florida

1975-1976 Bank Teller

Citizens Bank

West Palm Beach, Florida

1976-1978 Head Teller

First Forest Hill Bank

West Palm Beach, Florida

1978-1979 Motor Bank Supervisor

Texas Commerce Bank

Houston, Texas

$1979-1981$

Training Supervisor

Avis Rent A Car

Houston, Texas

1985

A. A., General Studies

Broward Community College

Davie, Florida

1990

B. A., Elementary Education

Florida Atlantic University

Boca Raton, Florida

1990-1999

Elementary School Teacher

Broward County Public Schools

Fort Lauderdale, Florida

1996

M. A., Elementary and Primary Education

Florida Atlantic University

Boca Raton, Florida

1999-2002

Reading Resource Specialist

Broward County Public Schools

Fort Lauderdale, Florida

2002

M. S., Reading Education

Florida International University

Miami, Florida 
2002-Present Curriculum Supervisor, Literacy K-12

Literacy Department, Instruction and Interventions Division

Broward County Public Schools

Fort Lauderdale, Florida

2011

Ed. S., Curriculum and Instruction, Reading Education

Florida International University

Miami, Florida

2012

Doctoral Candidate, Curriculum and Instruction, Reading Education Florida International University

Miami, Florida

\section{PRESENTATIONS}

Acquavita, T. \& Yocum, L. (2004). Improving Reading Achievement: The Struggling Reader Plan. Presented at the Council of the Great City Schools (CGCS) 48th Annual Fall Conference, Las Vegas, Nevada.

Acquavita, T., Coyle, T., Goldberg, E., \& Wilen, D. (2003). The Struggling Reader Plan: Collaboration with General Education, ESE, ESOL. Presented at the International Dyslexia Association (IDA) 54th Annual Conference, San Diego, California.

Acquavita, T., Goldberg, E., \& Yocum, L. (2003). The Struggling Reader Plan and the Collaborative Development Process. Presented at the Florida Department of Education Administrator's Management Meeting (AMM), Orlando, Florida. 